University of San Diego

Digital USD

Dissertations

Theses and Dissertations

1997-05-01

\title{
The Perspectives of the Woman/Nurse/Executive Working in the Managed Care Environment of Southern California
}

Cheryl Lynn Brandi DNSc, MS, MSN, RN

University of San Diego

Follow this and additional works at: https://digital.sandiego.edu/dissertations

Part of the Nursing Commons

\section{Digital USD Citation}

Brandi, Cheryl Lynn DNSc, MS, MSN, RN, "The Perspectives of the Woman/Nurse/Executive Working in the Managed Care Environment of Southern California" (1997). Dissertations. 259.

https://digital.sandiego.edu/dissertations/259

This Dissertation: Open Access is brought to you for free and open access by the Theses and Dissertations at Digital USD. It has been accepted for inclusion in Dissertations by an authorized administrator of Digital USD. For more information, please contact digital@sandiego.edu. 
THE PERSPECTIVES OF THE WOMAN/NURSE/EXECUTIVE

WORKING IN THE MANAGED CARE ENVIRONMENT

OF SOUTHERN CALIFORNIA

by

Cheryl Lynn Brandi, MS, MSN, RN

A dissertation presented to the

FACULTY OF THE PHILIP Y. HAHN SCHOOL OF NURSING

UNIVERSITY OF SAN DIEGO

In partial fulfillment of the

requirements for the degree

DOCTOR OF NURSING SCIENCE

May 1997

Dissertation Committee

Janet Harrison, EdD, RN, Chair

Diane Hatton, DNSc, RN

Dorothy Kleffel, DNSc, RN 


\begin{abstract}
The Perspectives of the Woman/Nurse/Executive

Working in the Managed Care Environment of Southern California

The purpose of this study was to explore the perspectives of the
\end{abstract}

woman/nurse/executive working in the managed care environment of Southern Califormia.

This research was extremely timely because (a) Southern California leads the nation in managed care market penetration, (b) changes in health care financing have resulted in a prolific expansion of nurse executive responsibilities, and (c) nurse executive experiences regarding increased responsibilities have not been researched. Role expansion impacts both male and female nurse executives, but female nurse executives must confront the dilemma of functioning in administrative domains which have been largely dominated by men. Knowledge about their experiences is vital to the future of the nursing profession and to the health care delivery system.

This study blended feminist ideology with grounded theory. Seventeen woman/nurse/executive participants from mostly hospital settings were interviewed. Using primarily the dimensional analysis approach to grounded theory, the metaphor of a managed care battlefield became the study context. A typology of participants was discovered, consisting of four consecutive groups: (a) the Unsung Heroines, (b) the Engineers, (c) the Team Leaders, and (d) the Champions. Participants of each group made different ethical decisions about their most important responsibilities and leadership actions, resulting in a different professional identity, or battlefield position, for each group. The typology represented a continuum, ranging from the Unsung Heroines, who exhibited 
the strongest nursing identity and the least degree of organizational influence, to the Champions, who exhibited the weakest nursing identity but the greatest degree of organizational influence.

The most important implications from this study involve nursing education, nursing research, and healthcare policy. Nursing education needs to be revamped to adequately prepare nurses for the expanding nurse executive roles. Additional research which explores the personal and professional value shifts involved in shaping these new roles is necessary. Finally, nurses must value feminist perspectives and become more involved in making healthcare policies which protect the essence of professional nursing practice. 
May, 1997 Cheryl Lynn Brandi

c ALL RIGHTS RESERVED

Reproduced with permission of the copyright owner. Further reproduction prohibited without permission. 


\section{DEDICATION}

I dedicate this dissertation to my husband, Jim. Without his love, unwavering support, and numerous sacrifices, my completion of this dissertation and attainment of a doctoral degree would not have been possible. 


\section{ACKNOWLEDGEMENTS}

I wish to publicly express my deepest appreciation to a number of people who made completion of this dissertation a reality:

First, I would like to acknowledge my study participants. I owe these women a big debt of gratitude for their generous contribution of precious time, as well as for their openness and honesty during their interviews.

Next, I would like to acknowledge my committee members who gave so freely of their time in helping me with this study. Dr. Jan Harrison, my chairperson, has truly been a tremendous support and inspiration to me for the past several years. Her encouragement and mentorship were essential for fostering my creativity while keeping me on track. I am very grateful for the superb advice and guidance of Dr. Diane Hatton and Dr. Dorothy Kleffel throughout every step of this project. Thank you all for your commitment to my professional growth and to this study.

I would also like to thank my husband's family for the years of encouragement and support in all my scholarly and professional endeavors. Betty and Gus, you have been like my own parents with your concern, your understanding, and your prayers.

Special thanks go to Kathy, for facilitating the awakening of my own feminist consciousness, and to friends Duffy and Eileen for all their help and encouragement during my doctoral studies.

Finally, I am perhaps most grateful to my late father. Thanks, Dad, for steering me toward a professional nursing career and for always believing in me. 


\section{TABLE OF CONTENTS}

$\begin{array}{ccc}20 & \text { Page }\end{array}$

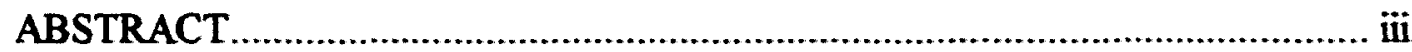

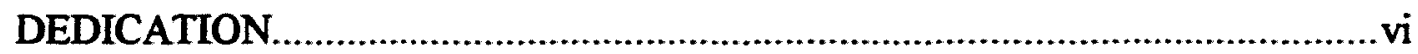

ACKNOWLEDGEMENTS ........................................................................

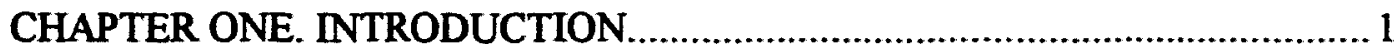

The Research Problem............................................................................ 1

Theoretical Perspective .................................................................6

Researcher's Perspective................................................................. 9

Significance of the Study............................................................ 12

CHAPTER TWO. REVIEW OF THE LITERATURE ............................... 14

The Context of Health Care Delivery.................................................. 14

The Woman/Nurse/Leader Dilemma......................................... 18

Review of Relevant Research..............................................................2 20

Women's Development Studies................................................20

Women's Leadership Studies.....................................................21

The Bridge Between Feminist Ideology

and Nursing Administration........................................... 23

Gender and Nursing Leadership Studies..................................... 23

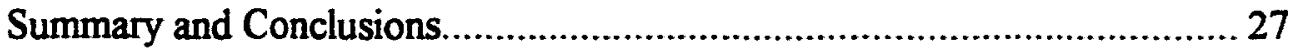

CHAPTER THREE. METHODOLOGY

Methodological and Epistemological

Considerations in Research Design ......................................................3 30

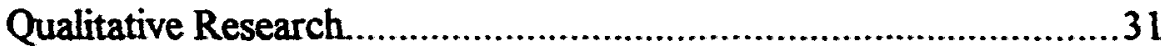

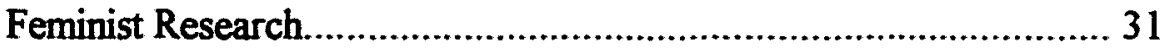

Grounded Theory....................................................................... 33

Grounded Theory Methodology and Feminist Research.................. 37

Adequacy of Inquiry............................................................ 39

Reflexivity.............................................................. 40

Rapport, Honesty, and Mutuality.................................. 41

Coherence............................................................... 41

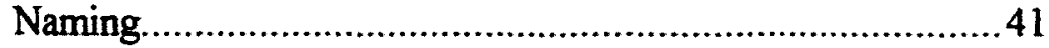

viii 


\section{TABLE OF CONTENTS (Continued)}

Summary of Methodological and Epistemological

Considerations.

Research Specifications and Process.................................................... 42

Criteria and Process for Participant Selection................................ 42

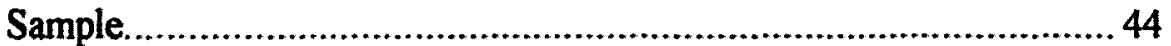

Gaining Entree and Ethical Considerations................................... 47

Data Collection and Analysis..................................................... 49

Data Collection........................................................... 49

Data Analysis......................................................... 53

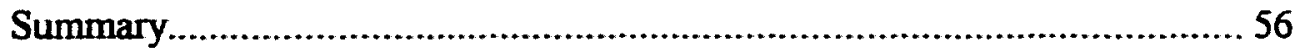

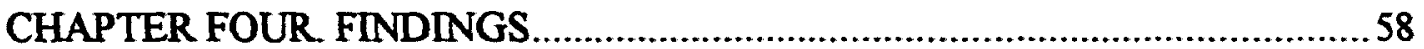

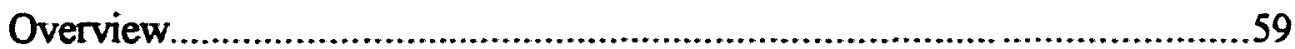

The Perspective of Economics: A Man's

Game in a Man's World ............................................................. 61

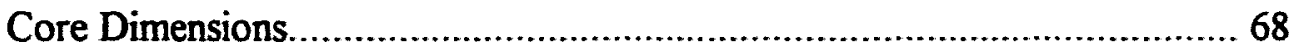

The Managed Care Battlefield........................................................ 69

Calls to Action............................................................................. 75

Corporate Bottom Line...................................................76

The Players................................................................. 77

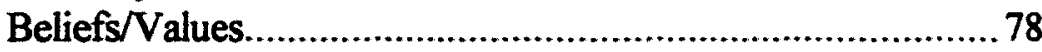

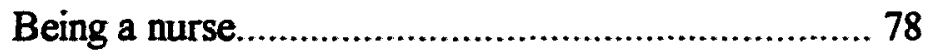

Caring for the patient.......................................... 81

Having a balanced life....................................... 82

Defining the Mission.................................................................86

Battlefield Position/Professional Identity: The Heroines..................93

A Typology of Heroines on the Managed Care Battlefield........................95

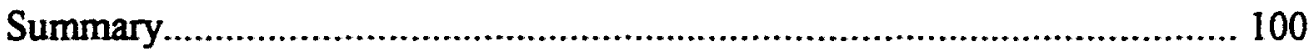




\section{CHAPTER FIVE. AWAKENING AND CHAOS:}

THE UNSUNG HEROINES AND THE ENGINEERS............................... 102

The Unsung Heroines.

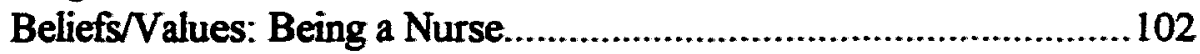

Beliefs/Values: Caring for the Patient............................................. 104

Beliefs/Values: Having a Balanced Life.............................................104

Corporate Bottom Line................................................................. 105

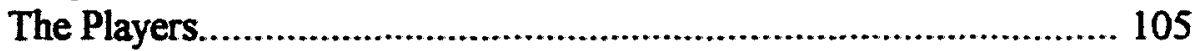

Defining the Mission: Moving Nursing Out of the

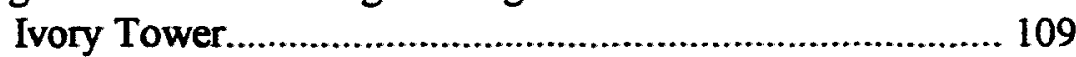

Battlefield Position/Professional Identity: The Unsung Heroines...... 110

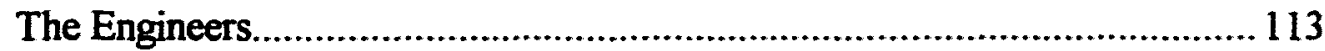

Corporate Bottom Line

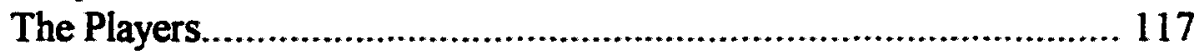

Beliefs/Values: Being a Nurse..................................................... 120

Beliefs/Values: Caring for the Patient.......................................... 124

Beliefs/Values: Having a Balanced Life...........................................124

Defining the Mission: Finding Middle Ground.............................. 126

Battlefield Position/Professional Identity: The Engineers.................131

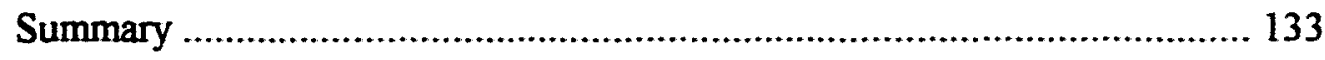

CHAPTER SIX. RESOLUTION:

THE TEAM LEADERS AND THE CHAMPIONS.................................. 135

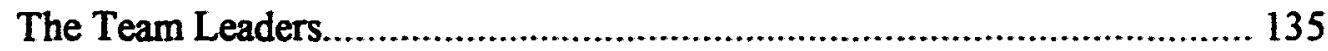

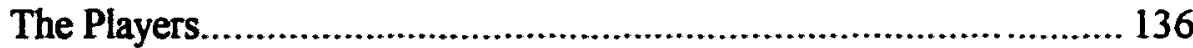

Beliefs/Values: Being a Nurse .................................................... 142

Beliefs/Values: Caring for the Patient.............................................. 143

Beliefs/Values: Having a Balanced Life...........................................145

Corporate Bottom Line.............................................................. 147

Defining the Mission: Building, Caring for and

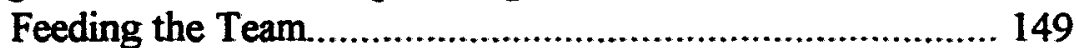

Battlefield Position/Professional Identity: The Team Leaders............ 156

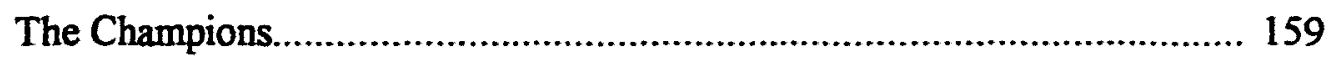

Corporate Bottom Line ............................................................ 160

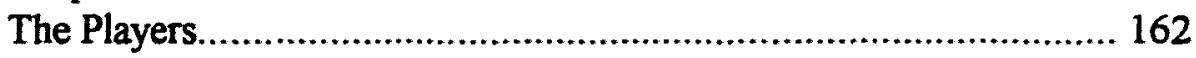

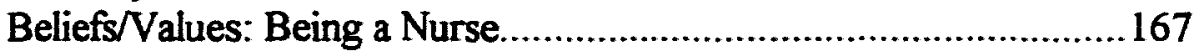




\section{TABLE OF CONTENTS (Continued)}

Beliefs/Values: Caring for the Patient........................................ 172

Beliefs/Values: Having a Balanced Life......................................... 173

Defining the Mission: Growing the Business................................... 176

Battlefield Position/Professional Identity: The Champions.................184

Summary

CHAPTER SEVEN. CONCLUSIONS AND IMPLICATIONS ............................... 189

Summary: A Story of Heroines on the Managed Care Battlefield...................189

Study Critique

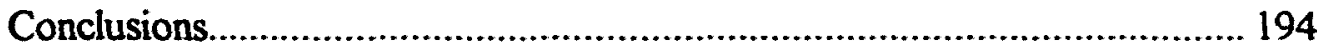

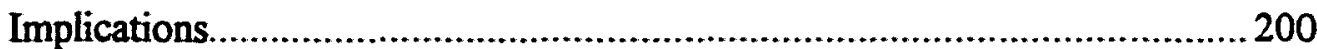

Nursing Administration and Leadership..........................................200

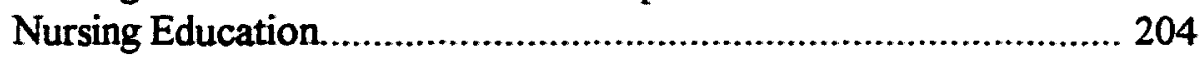

Nursing and Health Care Research.............................................. 207

The Macro-Organizational Perspective................................................ 213

Final Thoughts

REFERENCES

APPENDICES

APPENDIX A. HUMAN SUBJECTS APPROVAL ………………........... 233

APPENDIX B. INITLAL RECRUTTMENT LETTER ………………...... 238

APPENDIX C. CONSENT FORM ……………………..................... 241

APPENDIX D. REVISED RECRUTTMENT LETTER …........................ 243

APPENDIX E. INTERVIEW GUIDE ............................................... 247

APPENDIX F. RESEARCHER REFLECTION NOTE GUIDE................ 249

\section{FIGURES}

Figure 1. The relationships among study perspective and core dimensions in the form of an explanatory matrix.

Figure 2. The typology of heroines based upon the dimensions of defining the mission and battlefield position/professional identity, and the typology continuum 


\section{CHAPTER ONE}

\section{INTRODUCTION}

The purpose of this study was to explore the perspectives of the woman/nurse/executive working in the managed care environment of Southern California. This research was extremely timely because (a) Southern California leads the nation in the managed care market penetration, (b) changes in health care financing have resulted in a prolific expansion of nurse executive responsibilities, and (c) nurse executive experiences regarding increased responsibilities have not been researched. By combining feminist ideology with grounded theory, the intent of the study was to generate a substantive theory grounded in the responses of female nurse executives employed in rapidly changing Health Services Organizations. The research centered on the following question: What are the perspectives of the woman/nurse/executive working in the managed care environment of Southern California?

This introductory chapter will first (a) elaborate upon the research problem, then (b) provide the theoretical perspectives relevant to the problem and method of inquiry, (c) share the researcher's perspective in the evolution of the problem, and (d) conclude with the significance of this study.

The Research Problem

The rapid and radical changes occurring in the health care delivery systems of the United States are being driven by economics. With a national health care budget that has 
grown at two to two-and-a-half times the rate of inflation, United States health care costs have become out-of-control (Lamm, 1994/1995). As of 1997, the U.S. Congress has failed to pass a comprehensive health reform bill, but the economic crisis has caused various states to take the initiative in moving health care financing in a procompetitive direction, using market mechanisms to control costs (Parmet, 1993). Powerful interest groups have also adopted a managed competition strategy to ensure their survival and accommodate members' interests (Buerhaus, 1994b). The question in health care is no longer what role competition will play, but rather how to make it work (Buerhaus, 1994a).

The transformation of health care financing has bred serious concerns.

Not-for-profit Health Services Organizations (HSOs) have feared losing sight of caring and humanitarian motives in favor of financial considerations and economic survival as they compete for market share and position along with for-profit HSOs (Rakich, Longest, \& Darr, 1992). MacPherson, in 1987, warned that those who would profit most as health care became increasingly corporatized would be the executives and directors of large health care corporations and health insurance firms, politicians and political appointees, directors of large foundations, and the directors of multinational pharmaceutical companies. Achterberg (1990) asserted that changes in health care delivery were only adding layers of male authority in the patriarchal context of health care.

Perhaps one of the most difficult roles in this chaotic and constantly changing health care environment is that of the nurse executive, especially, the Chief Nurse Executive (CNE), or Chief Nurse Officer (CNO). The emphasis in this current health care environment favors organizational economics over goals of building the nursing discipline 
(Fagin, 1996), and nursing administrators are increasingly required to either align themselves in support of organizational fiscal objectives or resign (Edwards \& Horn, 1995).

While there is no scientific evidence to establish a satisfactory turnover rate among Chief Nurse Officers (CNOs) at the present time, the attrition rates have been considered high (Kippenbrock, 1995). A descriptive study by Kippenbrock (1995) revealed the most frequent duration of CNO employment to be between one and three years. Kippenbrock's (1995) study examined responses of Chief Nurse Officers (CNOs) who had recently left their positions and those of the Chief Executive Officers (CEOs) for whom they had worked. Out of the $68 \mathrm{CNO}$ respondents in this study, conditions for leaving were voluntary resignation ( $45 \%$ ), retirement $(22 \%)$, termination (15\%), promotion (13\%), lateral transfers within the system (10\%), and better job offers (10\%). The three major reasons for departure given by $\mathrm{CNO}$ s were lack of power, conflict with the $\mathrm{CEO}$, and inadequate nursing staff. Of particular interest were the CEO responses regarding the effect of the CNO departures on overall hospital operations. Of the 47 CEO respondents, $43 \%$ answered "not much;" 38\%, "positive;" and only $17 \%$ answered "negative" (Kippenbrock, 1995). These perceptions were surprising in view of Kippenbrock's (1995) introductory statement in reporting his study which mentioned the vital leadership role the CNO plays in an organization.

A noteworthy statistic in Kippenbrock's (1995) study which he did not discuss in summarizing his findings is that of gender. The CNO group was $93 \%$ female compared to the CEO group of $72 \%$ male. The CNO gender composition of his study is consistent with 
the finding of a $91 \%$ female nurse executive community according to a recent study by the American Organization of Nurse Executives (Nursing Economics data bank, 1996). In Kippenbrock's study, the issues of power and conflict raised by the predominantly female CNO group, and the perceptions of the predominantly male CEO group regarding the limited impacts of CNO departures, stimulate questions about the role that gender might play in CNO attrition.

Without argument, the complex challenges confronting nurse executives impact both the men and women of this community based upon the fact alone that the nursing profession is overwhelmingly female. The nurse executive, regardless of gender, functions in a world where caring for the sick historically became associated with women's work (Bradley, 1989), in a culture which values men's work over women's work (Cummings, 1995). However, there are two reasons why gender issues may affect the female nurse executive more acutely. Stivers (1991) pointed out that the woman/nurse/administrator faces a complex task of self-definition in confronting the dilemma of functioning as a woman and a nurse in a world where organizational and political leadership are defined in masculine terms. While men in leadership positions may feel some degree of dissonance between their personal styles and leadership expectations, they are never criticized for being successful leaders. A successful woman leader is considered one who appears to align primarily with the traditionally masculine business objectives of the organization. The cost to her for playing by men's rules is dissonance between her sense of self as a woman and caregiver, and her sense of self as a leader. The cost to her for openly demonstrating 
womanly values and styles is to be viewed as ineffective or inappropriate. In either case, she risks criticism (Stivers, 1991).

There is another way that gender may be disadvantageous to women in nursing service leadership positions. A qualitative study by Williams (1995) revealed the potential of bias toward male nurses in nursing administration. One of Williams' findings, based upon her interviews of 32 male nurses during the time frame of 1985 to 1991 , was that participants were either motivated from the beginning of their nursing careers or pressured during their careers to seek out nursing specialties considered more socially acceptable and more "masculine" such as nursing administration. Ironically, these positions pay better compared to others in nursing. She concluded that cultural and social stereotypes about masculinity may actually channel male nurses toward the more prestigious and higher-paying jobs within the nursing profession such as nursing administration. Her conclusion may have some substance, considering that as nursing service leadership takes on a more business orientation, the concentration of men in nurse executive roles is increasing, from five percent in 1990 to the present nine percent Nursing Economics data bank, 1996). The issue in this case is not about numbers of male or female nurses in any nursing specialty. The point here is that male nurses may face an entirely different set of issues related to gender and leadership compared to female nurses, and there is a subtle hint that androcentric biases either from within or outside the nursing profession may be creating preferential hiring and promotion practices more favorable to men than women in such fields as nursing administration. 
In addition to Williams' (1995) study, only two other nursing studies were found which examined the influence of gender on leadership as part of the research design (Borman, 1993; Redmond, 1995). Yet, the nursing administration literature contains clues that issues related to gender could somehow influence promotion and attrition. As the health care environment moves increasingly toward a business orientation, the care versus cost-control dilemmas and the resultant experiences of personal dissonance might be expected to intensify for the female nurse executive. The ultimate cost of these personal dilemmas to her own organization, the nursing executive community, or the entire nursing profession are unknown and are especially important as nurse executives assume expanded roles. Additionally, there is an important and unexplored aspect regarding female nursing leadership. One finding in Borman's (1993) study of female nursing leadership revealed that female nurse executives may lead in nontraditional ways which could actually be advantageous to their organizations. In summary, despite the overwhelmingly female composition of the nurse executive community, the voice of the woman/nurse/executive is noticeably absent but greatly needed.

\section{Theoretical Perspective}

The theoretical perspective selected for this study was feminist philosophy which set the stage for feminist inquiry. Feminist philosophy was chosen for this study consistent with Bem's (1993) assertion that our world view is based upon inequalities between men and women. Bem derived an enculturated-lens theory of individual gender formation which is based upon the culturally-constructed meanings of gender evident throughout the history of Western civilization. The lenses of gender are embedded in our cultural 
discourses, social institutions and individual psyches; they comprise our social reality. The lenses of gender reproduce male power by prescribing different and unequal life situations for men and women, and through an enculturation process where boys and girls internalize the lenses and form identities consistent with them (Bem, 1993). Therefore, one "hypothesis" of this study was that the lenses of gender were perpetuating male power in the form of the business paradigm to some extent at the expense of the care and responsibility paradigm associated with women and nurses in the present social reality of health care systems.

Feminism offers a lens of analysis by which to find dimensions of situations that would be otherwise lost. It should not be one's only lens, but without it, certain phenomena can not be understood in a world where most of our beliefs about organizational and political leadership are culturally masculine (Stivers, 1991). Feminist philosophy revolves around the premise that gender injustices, of which the oppression of women is most fundamental, span across all known periods of history and human experience (Cole, 1993). The value of feminist discourse is to find the submerged voices of marginalized women (Ferguson, 1984). Since nurses are predominantly women, the linkages between the oppression of women and of nurses are close (Chinn \& Wheeler, 1985). Of further importance to the conception of this study was Ashley's (1980) reminder that being a woman antecedes being a nurse.

There is a firm connection between feminist ideology and nursing administration theory. Miller $(1988,1991)$, as part of a foundational inquiry to delineate the relationship of feminism to nursing, synthesized three feminist ideological themes of advocacy, 
consciousness-raising, and empowerment, which she claimed are central to nursing administration practice roles. Therefore, using a feminist framework to analyze, critique, and study nursing administration seemed logical and necessary.

A conceptual link between feminism and transformational leadership, that type of visionary leadership which positively changes organizations, was made by Barker and Young (1994). The concept of transformational leadership is a hopeful one for nursing leadership. A transformational leader has a vision, communicates the vision, and knows the direction by which to accomplish the vision. Values between leaders and followers are congruent, and these values transcend the agenda and loyalties of the leader (Dunham \& Klafehn, 1990). Transformational leadership contains a moral dimension in that it brings out the best in both the leader and follower. It embraces the ideal of an organizational structure built on a web of relationships as opposed to a hierarchy, and it encompasses the notions of care, moral responsibility, and empowerment The characteristics of the transformational leader parallel those attributes of the female constructed knower, the most integrated level of women's epistemological development revealed in the classic feminist research by Belenky, Clinchy, Goldberger and Tarule (1986) according to Barker and Young (1994). However, they conclude that enacting transformational leadership in hierarchical, patriarchal healthcare organizations is extremely difficult. To enable transformational leadership to flourish, scholarly inquiry from a feminist perspective is highly justifiable in that feminist research is committed to analyzing the conditions of women's lives (MacPherson, 1983), and seeks to find answers for women (Hall \& Stevens, 1991). 


\section{Researcher's Perspective}

Consideration of the researcher's perspective is critically important in feminist inquiry. Using one's own experience as a starting point is acceptable. Personal experience helps define research questions, leads to sources of data, builds trust, and enables the partial testing of findings (Reinharz, 1992). In cases where there is a connection between the researcher's experience and research project, Reinharz (1992) supported a statement about the researcher's position and experience at the beginning of the report. The caveat to this type of subjectivity is that the history, motives, assumptions, interests, and interpretations of the researcher must be explicitly scrutinized throughout the study (Hall \& Stevens, 1991).

Therefore, I must share my perspective and admit my biases, since my interest in doing this study grew out of personal experience. Approximately 17 of my 22 years in nursing were in nursing administration positions at a wide variety of military installations. I have served in middle management roles as a head nurse, as a house supervisor on evening and night shifts, in permanent patient care coordinator roles, as a department head for various inpatient and ambulatory nursing services, and as an assistant director for nursing services. I have served on many interdisciplinary committees, and in several positions have also assumed responsibility for continuous quality improvement for both nursing and ambulatory services. On numerous occasions, I have served as interim director for nursing services. My nursing experience has been entirely in bureaucratic federal government settings. Other than several clinical experiences as a graduate nursing student and while 
collecting data for my master's thesis, I have never served as a registered nurse in the private, civilian sector.

Three realms of personal experiences stimulated my research inquiry in terms of both content and methodology. These include, my observations about working for my exclusively-female nursing bosses while enacting middle management and nursing supervisory responsibilities, my more-limited experiences in beginning nurse executive roles, and the acknowledgment of my own feminist consciousness. I must add that not all of these occurred in a particularly linear fashion.

My years of working for many female nursing supervisors stimulated my curiosity about certain aspects of women's leadership. First, I became intrigued with observing the variety of ways my female leaders interacted with male and non-nurse supervisors in light of their successes or failures in achieving their objectives. Second, under the direction of some female nursing supervisors, my professional and career development was enhanced, while under others I felt terribly defeated and constrained. In both cases, I think that organizational socialization and work environment had great impacts upon the behaviors of my leaders, and in reflecting on these behavioral extremes, suspected that there was an influential bigger picture of which I was not aware.

My beginning experiences functioning at the nurse executive level were rewarding but stressful. I learned the difficulty one faces in balancing nursing and organizational demands, especially when the role of nursing is not clear or valued. When perceived as the leader of "those girls," effecting positive change for nurses was extremely frustrating. 
Finally, the raising of my own feminist consciousness played a large role in framing my concerns and determining the methodology for this study. It enabled me to look at some of my more frustrating leadership experiences, recognizing that some of the dilemmas I had experienced were not only ethical, but basically had more to do with the issue of gender. I recognized that my failure to be heard on many occasions when advocating nursing concerns stemmed from subtle (and sometimes, not-so-subtle) forms of gender discrimination by male supervisors. I also learned to open my eyes to include the context of every situation, and not to blame women for those situations in which they conformed to patriarchal thinking. In fact, I learned to admire many of them for the courage they displayed under extreme constraints. I also learned the value of caring, connection, and networks of relationships in leadership roles, an instinctive part of my own practice, recognizing that the greatest asset of any organization is its people. In consideration of my own feminist philosophy and personal experiences, I believed feminist inquiry would enable maximum fulfillment of my objective of synthesizing the collective voice of the woman/nurse/executive into a scientific form.

The corporate system of health care delivery was one about which I knew little at the beginning of this study. However, I believe that as nurses, we need to be cautious about new systems and bureaucracies, particularly when we have had little involvement in their inception. I am neutral about the advantages and disadvantages of managed care in health care, but I am more skeptical about managed competition in an environment where market mechanisms are the driving forces behind the health care transformation, yet how these mechanisms will be made socially accountable has yet to be defined. Health care 
reform is inevitable, but we do have a responsibility to monitor any system for symptoms of injustice and oppression. Feminist scholarship provides one way of conducting this ongoing critique and dialogue.

\section{Significance of the Study}

The study has significance for several disciplines in that feminist scholarship has a particular openness to being transdisciplinary (Reinharz, 1992). For nursing, it will add to the theory of nursing administration which is lacking (Miller, 1988). It will help in designing and redesigning nursing administration education programs to meet the challenges of the rapidly changing health care environment (Fagin, 1996). The environment of this study, the Southern California region, is particularly important in this regard. To date, San Diego and Los Angeles are among four areas in the nation most advanced in the market evolution of health care delivery. San Diego and Los Angeles have been categorized at stage four in a five stage process which begins with an unstructured environment and ends with markets of integrated systems which manage specific patient populations ("Executive chartbook: how markets evolve," 1995). The lessons learned from Southern California will benefit nurse executives in other parts of the country as their markets evolve.

The study is also intended to enlighten members of other health care disciplines about the value that nurses bring to the transforming environment of health care delivery as well as to critique the changes in delivery systems. The study is considered important in adding to the body of knowledge under the category of Women's Studies, as well as building or adding to organization and leadership theories. Nursing, as the most 
female-dominated profession in the United States (Williams, 1995), presents rich opportunities for gender and feminist scholarship, yet nurses themselves overlook these opportunities. For example, one of the first nursing studies about the sexual harassment of nurses appeared as recently as 1994 (Libbus \& Bowman).

Finally, the nursing profession needs to hear and recognize the contributions being made by the woman/nurse/executive, as well as to share her concerns, as part of defining what service nursing brings to institutional settings in a rapidly changing environment. Presently, there is no script to guide nurse executives as they take on new and unfamiliar roles. Hopefully, this study will stimulate a wave of nursing research about this important group of health care professionals and add to a body of knowledge which has not kept pace with the times. This study affords an opportunity for the collective voice of nursing leadership in Health Services Organizations to be heard and recognized in the interest of effecting positive change for the future of health care delivery at organizational and societal levels. 


\section{CHAPTER TWO}

\section{REVIEW OF THE LITERATURE}

The intention of a grounded theory study is to explain phenomena as the theoretical framework evolves during the study. However, knowledge of philosophic literature and existing theories helps determine how data will be approached and interpreted (Strauss \& Corbin, 1990). With these purposes in mind, the literature review for this study is in two sections. The first section examines the (a) health care setting and the woman/nurse/leader dilemma within that context to show the value of a feminist approach for the study. In the next section, research relevant to the formulation of question and methodology is explored. This section breaks into subsections which include:

(a) women's development studies, (b) women's leadership studies, (c) the bridge between feminist ideology and nursing administration, and (d) gender and nursing leadership studies. The chapter closes with a summary of the literature review and conclusions.

The Context of Health Care Delivery

Contemporary healthcare delivery systems are organizational bureaucracies. The years of bureaucratization in health care are considered to have begun in the 1930 s, when the scientific principles of Frederick Taylor gained popularity in hospitals. Under this type of management system, detailed rules and standards with an emphasis upon tasks dictated how work was to be done. Hospitals were supposed to function like factories, with the head nurses functioning like factory supervisors (Klakovich, 1994). Nursing work was 
organized according to tradition as well as the new management trends. Routine activities were arranged according to schedules, tasks defined in meticulous detail, and training programs organized according to the orderly procedures and tasks. Not until the 1970s, when a shift would occur in the focus of management science from productivity to human relations, would there even be a perception of the nursing administrator as more of a leader than a bureaucrat (Hegyvary, 1983).

According to Ferguson (1984), a bureaucracy is both a structure and a process with main objectives of control and conformity. As a structure, the arrangement of roles and assignment of tasks is fairly fixed and static. As a process, it consists of a temporal ordering of human action. Bureaucracies are political arenas, ruled by a few elite, in which struggles for power, status, personal values, and possibly survival are common among members. They are established in order to meet the needs of certain forms of technology and science and simultaneously maintain social control. Their membership is composed of individuals with perceived expertise in relevant areas. Bureaucracies exist in both public and private sectors of society. An example of a public bureaucracy is the Pentagon, corporations are examples of private bureaucracies, and universities exemplify a combination of public and private bureaucracies. As authoritarian forms of organization, with hierarchical chains of command, bureaucracies institutionalize modes of male domination and encourage patterns of oppression which continue the myth that women's traits equate with powerlessness (Ferguson, 1984).

The male-domination, female-subordination model in organizational bureaucracies occurs as a result of four analytically distinct processes (Acker, 1992). The first set of 
processes involves the production of gender divisions, such as the gender patterning of jobs. Gender and sexuality contribute significantly to the reproduction of hierarchies. The next set of processes involves the creation of symbols, forms of consciousness, and images which support and sustain the gender divisions. The third set of processes is the interactions between individuals which encourage subordination and domination and enable the formation of alliances and exclusions among the organizational members. The fourth set of processes involves the internal mental work of people as they consciously construct their understanding of the gendered structures and opportunities, and create the appropriate gendered persona while hiding the unacceptable aspects of their lives (Acker, 1992).

The predominantly female occupation of nursing in health care organizations is even more susceptible to the processes which contribute to organizational gendering because of an organizational theory concept known as sex role spillover. Sex role spillover means that being a man or a woman has implications for the occupation which are not inherent in the actual job (Gutek \& Cohen, 1992). The gender role assumes precedence over the work role.

There are several reasons for sex role spillover. First, the most salient and immediately-noticed characteristic is that of gender. Second, the process of learning gender roles starts earlier in life that does the process of learning work roles. Third, men and women are more comfortable in interacting with members of the opposite gender in ways consistent with their gender role, even when this behavior conflicts with more appropriate work-role behaviors (Gutek \& Cohen, 1992). 
Sex role spillover is exacerbated when occupational members are mostly of one gender (Gutek \& Cohen, 1992). Nursing is one of those occupations with its $97 \%$ female composition. In nursing, women represent the majority gender. Sex roll spillover contributes to problems for the majority gender when certain jobs are stereotyped according to the traits of the majority gender, and the minority gender holds all the dominant positions (Gutek \& Cohen, 1992). In a society where women are devalued, nursing is devalued (Gutek \& Cohen, 1992; Lynaugh \& Fagin, 1988). Sex role spillover has another dimension when the majority gender holds most of the dominant positions, and members of the minority gender attempt to function in these positions (Gutek \& Cohen, 1992). Female nurses moving into health care administrative positions traditionally held mostly by men may therefore anticipate encountering difficulties related to gender.

The bureaucratic environment of health care delivery is currently shifting in terms of structure and form. Health care in the United States originally developed into an array of fragmented systems (Lamm, 1994/1995), or bureaucracies, each with its individualized and unchallenged reimbursement schemes, in a dichotomous societal context which has considered economics to be independent of physician-patient relationships (Moss, 1996). Ashley (1976) thoroughly described the oppressive hospital environment for nurses resulting from the dominant, masculine authoritarianism of physicians and hospital administrators in these various systems. The fragmented systems of health care delivery are currently surrendering control of health care to large corporations because of a theory that market competition between corporations will reduce health care costs (Enthoven, 1993). The privatization of health care in the form of corporatization is evolving with little 
direct government control (MacLeod, 1995). As the embodiment of wealth and power in American society, and subject to a limited degree of governmental regulation, the corporation has been challenged for its emphasis upon private gain with few public responsibilities (Bellah, Madsen, Sullivan, Swidler \& Tipton, 1992). Corporations enable the concentration of great degrees of political power, not easily accounted for by democratic processes (Bellah, 1992). Both MacPherson (1987) and Achterberg (1991) predicted additional patriarchal layers for nurses consisting of insurers, corporate managers, politicians, and large pharmaceutical companies in the reforming health care systems. Additional patriarchal layers could leverage power imbalances in a way that enhances the subordination of nurses who work in corporate settings.

\section{The Woman/Nurse/Leader Dilemma}

MacPherson (1989) made an interesting point when she stated that nursing has steadily been developing the ethic of caring as the health care system has been moving toward competition. Stivers (1991) claimed that superimposed upon the tensions that nurses experience resulting from their need to balance their female caring values against the male dominance of the practice setting, is a complex task of self-definition for nurses in administrative positions who also have to deal with performing as a woman leader in a man's world. The nursing objective is predominantly the facilitation of care and caring. The organizational objectives are minimizing costs, efficient resource utilization, protection of organizational prerogatives, advancing organizational goals, and optimizing the organization's control over its environment, concerns which have been traditionally masculine. The importance of including feminist perspectives on nursing and caring in 
graduate nursing administration curriculums has only been recently addressed (Miller, 1991; Nyberg, 1993; Stivers, 1991) as part of consciousness-raising for the tough challenges which will confront these nurses as administrators and executives.

Women in organizations live simultaneously in two different worlds, a political concept termed marginality (Greenleaf, 1980; Mason, Backer, \& Georges, 1991). In feminist ideology, the marginality of women means being part of a subordinate group, functioning as an active member within the domain of the dominant male group, without the ability to fully contribute to that group. The result is that women live two lives, a public life in the dominant world and a private and submerged life rich with its own language, standards, morals, and behaviors (Ferguson, 1984; Miller, 1988). Miller (1986) asserted that authenticity for women, that is "being oneself" (p. 98), is incompatible with subordination. Therefore, Miller would say that only by leading in a way congruent with self-identity would women experience a psychological state of authenticity.

The dilemma for women in bureaucracies is really about a struggle between conformity and resistance, with resignation the cost of the former and disintegration the cost of the latter (Ferguson, 1984). Since most of our beliefs about organizational and political leadership are culturally masculine, women in leadership positions are continually exposed to the tensions between expectations about leaders and expectations about women. They face a difficult choice between displaying the more desirable masculine characteristics and behaviors and conforming to organizational standards, or exhibiting unconventional styles of leadership. The cost of the first choice may be a personal experience of dissonance between their sense of themselves as women and as leaders. The 
cost of projecting an unconventional leadership image congruent with self-definition may be a perception by others as incapable of the leadership role (Stivers, 1991).

Nurses in leadership positions in Health Services Organizations have tended to align with male models of management (Young \& Hayne, 1988), probably because a female leader who advocates from a woman-centered perspective is considered an aberrancy who has a reduced chance of success (Stivers, 1991). Aligning with the patriarchy by top organizational nursing leaders is consistent with the behaviors of members of oppressed groups, and historically enhanced the oppression of nurses lower in the organizational hierarchy, leading to a negative stereotype of nursing administrators by the practicing nursing community (Roberts, 1983). The nursing leadership dilemma has therefore augmented dissension and conflict between members of the same discipline, helping to fragment nurses as a collective group.

\section{Review of Relevant Research}

The research aims of this study were derived after a review of certain major categories of gender research. These include: (a) women's development studies, (b) women's leadership studies, (c) a study which links nursing administration and feminism, and (d) nursing leadership studies which address the issue of gender. Key studies from each category which influenced the development of this study will be discussed.

\section{Women's Development Studies}

The private and submerged world of women's experience has recently begun to be explored, revealing that women develop and experience life differently than men. The studies of Gilligan (1982) and Belenky, Clinchy, Goldberger, and Tarule (1986) are 
consistent with a category of research derived by Padgett (1993), entitled radical feminist situation research, because they emphasize experiences unique to women while stressing a need for social change through the revaluing of those experiences. The studies have had a strong impact upon reshaping theories about moral and epistemological development for a variety of disciplines. Gilligan's (1982) important research on women's moral development demonstrated that for her 144 female participants, moral reasoning was based upon an ethic of care and responsibility in which interpersonal relationships played a predominant part. The study by Belenky et al. (1986) showed dimensions in the epistemological growth of the 135 participants which were different from the results of previous studies of men. Both of these studies used open-ended interview techniques to meet the objective of linking feminist and mainstream interview research. The mainstream research in each case was that of Kohlberg (Gilligan, 1982), and Kohlberg and Perry (Belenky et al., 1986); research which had either ignored or failed to incorporate the viewpoints of women (Reinharz, 1992). These two classical studies set the stage for more recent studies about women's leadership.

\section{Women's Leadership Studies}

Two leadership studies which point out how women's leadership deviates from traditional thoughts about leadership are those of Astin and Leland (1991) and Helgeson (1990). Astin and Leland (1991) used open-ended interview techniques as well as secondary sources such as speeches and autobiographical accounts to collect data on a sample of 77 women who had played prominent positional roles in American society during the period of time between the 1950s and the 1980s. Dissatisfied with 
conventional views of leadership which they believed inadequate to explain women's behavior, the intent of their study was to document the leadership of women involved in the modern women's movement, and to find out why the participants were so determined in their quest for social justice. They were seeking to reframe the way we think about leadership in order to prepare for the future. Different from traditional thinking, the participants in their study viewed leadership as nonhierarchical, facilitating, and based upon personal values. The three major elements that emerged which participants considered significant to their leadership accomplishments were collective action, passionate commitment, and consistent performance. Collective action was a process in which people were motivated to change by working through people. Passionate commitment formed out of a sharp awareness of societal injustices based upon personal experiences and values learned from their ancestors. Consistent performance implied acceptance of challenges and complexity, with reliance upon self-awareness and interpersonal and communication skills (Astin \& Leland, 1991).

Helgeson (1990) took a different approach in studying her four participants. Her ethnographic approach required making meticulous diary observations and interviewing participants in their work setting. Her study was initiated as a response to Mintzberg's study of men in management, considered as the basis for contemporary management theories. She found for all participants that relationships, connection, and sharing of information were especially important, and her participants saw themselves influencing their organizations from a central position surrounded by networks of people rather than from the top of a hierarchy (Helgeson, 1990). In essence, the women's development 
studies and leadership studies showed congruent pattems and themes which revolve around caring, connection, and relationship-orientation.

\section{The Bridge Between Feminist Ideology and Nursing Administration}

The value of a feminist ideology in the domain of nursing administration was underscored by Miller (1988), whose dissertation research resulted in a conceptual model which links feminist and nursing administration theory. Originally intending to study the phenomenon of leadership as experienced by nurse executives using a variety of methodologies, she changed her plans after a review of the literature revealed very little information about gender and the leadership role, while the nursing literature endorsed a feminist perspective for nursing. She then became committed to scholarly work which would combine feminist ideology and nursing administration in the form of a foundational inquiry. She conducted a comprehensive review of over 200 literary references on feminism and nursing, and by using content analysis, she synthesized a model which connects eight central themes common to nursing and feminism with three primary roles of nursing administrators. The themes of (a) marginality, (b) invisibility, (c) leadership versus constituency, (d) diverse representations, (e) feminist consciousness, (f) personal as political, (g) paradoxical goals, and (h) theory building process are particularly relevant to the nurse administrator in her advocacy, consciousness-raising and empowerment roles according to Miller.

\section{Gender and Nursing Leadership Studies}

Nursing studies which examine the influence of gender on leadership are scarce, despite the fact that nursing is the most female-dominated profession in the United States 
(Williams, 1995), and that nurses function under layers of male authority (Achterberg, 1990). Only one study was found which focuses on male nurses (Williams, 1995), and only two which focus exclusively on female nurse executives (Borman, 1993; Redmond 1995). A grounded theory study done by Irurita (1994) does not focus on gender, but considers the patriarchal context of health care in a chaotic and changing health care environment. The few studies which have been done reveal that nursing is truly at an elementary stage in examining how gender, leadership and nursing are connected.

Borman (1993) conducted a trait comparison study of gender and nursing leadership. Using a quantitative design, she compared leadership traits between men and women in different organizational leadership positions. Using three standardized instruments, she surveyed 127 male chief executive officers (CEOs), 127 female CEOs, 232 female chief nurse executives (CNEs), and 117 male CNEs on self reports of (a) intellectual stimulation leadership, (b) contingent reward leadership, (c) value of organizational goals, (d) importance of organizational stakeholders, (e) executive characteristics, (f) connection and caring, and (g) executive skills. Important for this discussion was her finding that women in either the CNE or CEO position rated themselves significantly higher than did men in either role on the characteristics of flexibility and connection to others, and on the values of connection and caring. She concluded this finding suggests that women are not necessarily homogenized through organizational socialization as they move into top hospital positions, and that the values and characteristics associated with women's leadership may be advantageous to health care organizations (Borman, 1993). 
From a feminist viewpoint, there are several drawbacks to Borman's (1993) study. First, she used a traditional quantitative design for the study, consistent with a logical positivist view of science attributable to men. This methodology has been criticized for failing to account for large areas of women's experiences (MacPherson, 1983; Reinharz, 1992). Second, Borman (1993) used a gender-centered approach by looking almost exclusively at traits. While her findings did suggest that women in health care organizational leadership positions possess the internal resources to handle the changes in health care delivery, and that their values and characteristics which have been traditionally construed to be liabilities may actually be assets, the study did not address the organizational environments of the participants, or any of the barriers the women faced in achieving their organizational status. Furthermore, it implied organizational success in traditional, masculine terms. Borman's (1993) definition of success means "fitting in", and would be criticized by many feminists for failing to remember feminist concerns about organizational power as a corrupting influence (Padgett, 1993). Adams (1993) posed a cautionary note by pointing out that men dominate top hospital positions and make the hiring, firing, and promotion decisions about upper management positions. Borman's (1993) respondents were therefore successful in a situation largely dependent upon and defined by male thinking.

More inclusive of the entire experience of women in leadership positions was a qualitative study done by Redmond (1995). Redmond (1995) focused upon the development of nurse executives by taping life history interviews on a sample of ten female CNEs. She used ethnographic techniques to extract themes in order to construct a 
profile of her participants. She synthesized four major taxonomies which were (a) Significant Other, (b) Becoming A Nurse Executive, (c) Being a Nurse Executive, and (d) Executive Leadership. Thematic analysis identified themes of (a) power, (b) transformational leadership, (c) cyclic mentorship, (d) macro-organizational perspective, and (e) competition and achievement (Redmond, 1995). The macro-organizational perspective has particular relevance for understanding the nursing leadership dilemma in the service sector. Participants in Redmond's (1995) study agreed that their loyalties were divided between nursing and the corporate world, but that their commitment to patient care transcended that division. This finding alone invites more intensive analysis of the organizational contexts of the participants of her study.

Irurita (1994) conducted a study of nursing leaders in Australia which considered the societal and organizational contexts as well as individual experiences of informants. She used a grounded theory approach on a sample of 32 nurses in top-level positions in a wide array of health care organizations over a period of four years. Using semi-structured interviews, she arrived at three major values which influenced the nurses' leadership. These included their (a) personal values, (b) commitment, and (c) optimism. The participants relied on their values about clients, staff, and profession/organization in conjunction with commitment and optimism in a context of retardation (repression) and turbulence, and some of them used a process of leadership she called "optimizing." The retardation context was one of paternalism and medical dominance. Optimizing leadership had three realms of (a) surviving, (b) investing, and (c) transforming. Failure to optimize resulted in "floundering" (Irurita, 1994). Either optimizing or floundering could help explain how 
nurses who are predominantly women and leaders deal with their leadership dilemmas against the backdrop of their organizations. Irurita (1994) concluded that the leadership potential of her participants was not adequately developed or used in their health care system, and that the conditions which contribute to effective leadership need further study.

The Western Australian health care environment of Irurita's (1994) study was one of tremendous change, but different from the current United States environment. For example, nursing education in Australia at the time of the study was moving from hospitals into university settings, similar to what occurred for nursing education in the U.S. 30 to 40 years ago. Irurita's findings evoked questions about what is happening to nurse executives, especially female nurse executives, in other turbulent health care environments such as those of the United States. This type of study has enormous relevance for building theories about how women function in oppressive circumstances.

\section{Summary and Conclusions}

A review of the literature and relevant research revealed that there is little knowledge about gender as it influences the experiences of nurse executives, yet according to a recent survey, the composition of this group is $91 \%$ female Nursing Economics, 1996). This fact makes the nurse executive group susceptible to the issues associated with occupations characterized by sex role spillover (Gutek and Cohen, 1992), described earlier. Based upon the works of a variety of different writers from a variety of different perspectives including feminism (Ferguson, 1984; MacPherson, 1987, 1989), organizational theory (Acker, 1992; Gutek \& Cohen, 1992), public administration (Stivers, 1991), sociology and religion (Bellah, 1992), and nursing (MacPherson, 1987), 
one can further conclude that the corporation itself must be carefully scrutinized regarding its impact upon oppressed groups, especially women, as well as for its responsibility to society-at-large.

I believe that an assessment of the impact of changing health care systems upon the nursing leadership community is essential at a time in which American healthcare delivery systems are moving rapidly toward almost total corporatization. MacPherson (1987) criticized nursing for tending to focus upon health policies which enhance the power of the profession rather than examining structural problems which have impeded collectivism, cooperation, and equality. Greenleaf (1988) stated that nursing needs a macro level of analysis which would look at contexts and implications for the behaviors of nurses.

The behavioral implications have particular importance in light of the recent study about chief nursing officer (CNO) turnover by Kippenbrock (1996), already described in the introductory chapter. Significant findings were (a) $93 \%$ of the $68 \mathrm{CNO}$ respondents were women; (b) vacating their positions did not seem to have much impact on their former organizations in the eyes of the 47 CEO respondents who were $72 \%$ male; and (c) lack of power, conflicts with chief executive officers, and inadequate nursing staff were cited by CNOs as the three greatest reasons for leaving their organizations (Kippenbrock, 1996). Miller's (1988) foundational inquiry connecting nursing administration and feminism described empowerment as a major component of the nursing leadership role. The findings about power and interpersonal conflict in Kippenbrock's (1996) study suggested that more deeply-rooted issues involving gender may be contributing to the nurse executive turnover problem. 
The nursing studies by Miller (1988), Borman (1993), Irurita (1994) and Redmond (1995) showed that only recently have connections been made among gender, nursing administration, and nursing leadership. Yet, as early as 1974, after describing a nursing leadership crisis, Leininger called for research which would examine the effects of different organizational structures upon nursing leadership. One of her specific suggestions was to see what happens to female administrators in a patriarchal social system. Borman (1993) questioned why women in business have been challenging their "glass ceiling" for over 20 years, while nursing has been silent about gender and leadership research. Ayman (1993) asserted that research on people, particularly women, who regularly experience a multitude of conflicting cues in daily lives is scarce and merits further attention (Ayman, 1993). Female nurses in service leadership positions with their daily exposure to numerous conflicting societal and cultural cues qualify as one of these groups deserving of further research.

The scarcity of research regarding women in leadership positions, the subtle messages of androcentric biases against women in healthcare leadership positions, as well as the suggestion that women's ways of leading may actually be advantageous, point out that research about the woman/nurse/executive is timely and urgently needed in shaping the nurse executive role of the future. Furthermore, these factors underscore the need, from an epistemological standpoint, to ensure that the voice of the woman/nurse/leader is included in the development of the nursing discipline. Grounded theory research combined with feminist ideology was felt to be one way of meeting that need. 


\section{CHAPTER THREE \\ METHODOLOGY}

The purpose of this study was to explore the perspectives of the woman/nurse/executive working in the managed care environment of Southern California. The intent of the study was to generate a substantive theory grounded in the responses of female nurse executives employed in rapidly changing Health Services Organizations. The research centered on the following question: What are the perspectives of the woman/nurse/executive working in the managed care environment of Southern California? This study was feminist research using grounded theory methods.

This chapter is divided into two major sections. The first section is on methodological and epistemological considerations for this type of research design. This section covers: (a) qualitative research, (b) feminist research, (c) grounded theory, (d) grounded theory methodology and feminist research, and (e) adequacy of inquiry, and (f) a brief summary. The second section on research procedures delineates the specific plan I used in carrying out this research and includes (a) criteria and process for participant selection, (b) sample, (c) gaining entree and ethical considerations, and (d) data collection and analysis. A summary concludes this chapter.

Methodological and Epistemological Considerations in Research Design

In this section, I will explain the rationale and special considerations necessary for combining a feminist perspective with grounded theory methodology. This section will 
discuss: (a) qualitative research, (b) feminist research, (c) grounded theory, (d) grounded theory methodology and feminist research, (e) adequacy of inquiry, and concludes with a brief summary.

\section{Qualitative Research}

My reason for selecting a qualitative methodology in conducting this study was influenced by Bell and Nkomo (1992), who criticized the two usual approaches for studying women in management, which have tended to be exclusively either gender-centered or organization-structure approaches. The gender-centered approach focuses on women's deficiencies and hides the organizational meaning of gender. The organization-structure approach represents women as powerless victims, and ignores the dynamics between individual and system. Therefore, I believed that only by using a qualitative design could the gap between women's experiences and organizational contexts be bridged.

\section{Feminist Research}

Chinn (1991) stated that silence is a feminist issue and a nursing issue. In light of my finding that the voice of the woman/nurse/executive was notably absent in nursing theorizing, feminist scholarship seemed a logical choice for this project. In feminist research, the researcher is guided by feminist consciousness in being sensitized to the important concerns of women, and in searching for institutional discrimination against women (Duffy \& Hedin, 1988). Feminist research specifically concerns values, focuses upon research questions relevant to women, aims at analyzing the condition of women's lives, is grounded in experiences which are closely related to societal change, and helps 
liberate participants by making research findings available to them (Webb, 1993).

Feminist research serves equally important purposes of contributing to the welfare of women and contributing to a body of knowledge. In addition to constructing an abstract empirical analysis of gender and building grand theory, feminist research aims at improving gender relations and society (Reinharz, 1992).

This study, guided by my feminist consciousness, focused upon the woman/nurse/executive, with a deliberate intention of illuminating her values and the conditions of her life in a culturally and organizationally masculine world. The study deliberately screened for evidence of institutional biases against the women participants in the hope that exposure would stimulate change. A major intent of this study was to fill the void in the body of nursing leadership knowledge and literature about the woman/nurse/executive working in changing Health Services Organizations, and to publicize the concerns of female nurse executives as a beginning step toward raising societal consciousness.

Feminist research involves two dimensions, the world of feminist scholarship and the world of a particular discipline, academy, or funder. Feminism is the perspective guiding feminist research, and methodology is supplied by a discipline. The feminist researcher stands at the intersection, believing that the tension between the two dimensions will benefit the research (Reinharz, 1992). Multiple methods may be used (Reinharz, 1992), but methodologies in and of themselves are not feminist or nonfeminist. The intent and employment of the method define how it is appropriate for feminist 
research (Duffy \& Hedin, 1988). What made this study feminist research is that it conscientiously combined feminist ideology with grounded theory.

\section{Grounded Theory}

The overall strategy selected for this study was grounded theory. The methods of analysis were: (a) dimensional analysis as defined by Schatzman (1991), supplemented with (b) constant comparative analysis methods of grounded theory as described by Glaser and Strauss (1967). Organizational analysis as defined by Morgan (1986) was a useful adjunct to the other methods of analysis.

Grounded theory is similar to other qualitative methods because it requires that interpretations include the perspectives and the voices of the people being studied. However, grounded theory takes a position that the research should not only give voice to the person or group being investigated, but that the researcher assumes responsibility for interpreting the data; data in the form of observations, writings, or verbalizations. The uniqueness of grounded theory is the way interpretations about the data are formed and intended. Grounded theory procedures are designed to develop various levels of theory (Strauss \& Corbin, 1994).

Grounded theory research is used to study organizations, groups, and individuals (Strauss \& Corbin, 1990). Therefore, grounded theory seemed a particularly appropriate strategy for this study which was concerned with how female nurse leaders made sense of their organizational lives, with special attention to the interplay of interaction, process and social change in interpreting their behaviors. 
The most publicized approach to grounded theory was originally developed by two sociologists. Barney Glaser and Anselm Strauss have been credited with the discovery and development of grounded theory (Strauss \& Corbin, 1990). Glaser and Strauss fostered its development in the 1960s during a field observation study, and it was shaped by two streams of philosophical and social thought in its conception (Strauss, 1987). The background and education of Strauss, who came from the University of Chicago, contributed to the theory development in several particular ways (Strauss \& Corbin, 1990). The works of the American Pragmatists, which included John Dewey, George H. Mead, and Charles Pierce, influenced the emphases upon action and problem solving as part of method. The tradition in Chicago Sociology at the University of Chicago from the 1920 s to the mid 1950 s influenced the use of field observations and intensive interviews as techniques for data collection as well as the focus upon "grasping the actors' viewpoints for understanding interaction, process, and social change" (Strauss, 1987, p. 6).

Glaser contributed to the development of grounded theory in another way. He was educated at Columbia University and influenced by Paul Lazarsfeld, who is respected as an innovator of quantitative research methods. Glaser particularly stressed the need for a carefully planned, formulated, and systematic set of research procedures to be used during the research process as part of generating theory (Strauss \& Corbin, 1990).

Schatzman's dimensional analysis approach to the grounding of data is generally congruent with the basic ideas and practices of grounded theory as developed by Glaser and Strauss, but it is an alternative approach in that it has a unique set of epistemological assumptions, procedures, and logic (Schatzman, 1991). Schatzman's approach recognizes 
that people are naturally inclined toward the use of normative cognitive processes in interpreting and understanding problematic experiences or phenomena (Kools, McCarthy, Durham, \& Robrecht, 1996; Schatzman, 1991).

Schatzman (1991) was critical of grounded theory methods which overemphasized methodology and which were not attached to a substantive paradigm. In response to the complexity associated with the analytic procedures of grounded theory as it had come to be understood (Kools et al., 1996), and finding, in practice, that the safety net of methodology or intuition tended to divert the researcher from forming theory directly out of the data (Schatzman, 1991), Schatzman embedded his process of dimensional analysis in the philosophical foundation of symbolic interactionism (Kools et al., 1996). Schatzman (1991) defined dimensionality "as a property and variety of human thinking that turns language towards the interrogative and analytic processes in the face of cognitive problems with phenomena" (p. 309). Dimensionality as a scientific endeavor becomes necessary according to Schatzman (1991), when sufficient understanding is unattainable through recognition and recall.

Dimensional analysis was chosen because it provides a greater degree of freedom in extracting meaning from data compared to the approaches endorsed by Glaser and Strauss (1967) and Strauss and Corbin (1990). It enables the researcher to explore a variety of conceptual possibilities (Kools et al., 1996). It differs from the approach developed by Glaser and Strauss (1967) in that it does not try to explain a basic social process in arriving at a theory. Dimensional analysis involves observing interactions in situations and trying to discover the meanings of those interactions (Kools et al., 1996; 
Schatzman, 1991). It involves the construction, or novel reconstruction, of many components of a multifaceted social phenomenon (Kools et al., 1996). By not being locked into trying to study and analyze one particular social process, I believed that dimensional analysis was the most useful way to truly give voice to study participants by trying to understand and interpret how they made meaning for themselves in a rather chaotic and dynamic environment.

Organizational analysis as described by Morgan (1986) was felt to be a useful adjunct to the grounded theory strategy. Morgan (1986) stated that our ideas about organizations are really taken-for-granted metaphors. By using different metaphors to illuminate the complex and paradoxical character of organizational life, we acquire greater insights about the meaning of that life for the individuals in organizations (Morgan, 1986). Therefore I believed that organizational analysis would help strengthen the analyses and interpretations about how participants made sense of their environments in the development of theory.

The voices of women in public service have been absent in theories involving a number of different disciplines. As one example, Astin and Leland (1991) conducted their study on women's leadership in response to criticisms about earlier studies on gender and leadership for their narrow focus upon either differences between traits and leadership styles of men and women, or on stereotyped expectations of women regarding leadership ability. They stated that these strategies have led to questions about whether traditional frameworks in leadership research are adequate to explain women's leadership behavior (Astin \& Leland, 1991). While this study was not designed to specifically study leadership, 
the lack of a women's perspective in leadership studies underscored the lack of a women's viewpoint in understanding a wide array of phenomena regarding women in public life.

Therefore, I took a practical stance regarding this study. I felt that development of theory which could be extended and tested through future research would best meet the needs of the nursing leadership community and the nursing discipline, but it had to be woman-centered. The action orientation of feminist research (Duffy \& Hedin, 1988) fits well with the dynamic nature of grounded theory. Feminist research is geared toward the emancipation of women, and the building of theory that will contribute to social change make the two traditions of knowledge discovery especially compatible (Wuest, 1995).

The overall aim of this study was to develop substantive theory grounded in the responses of the woman/nurse/executive about her perspectives on working in a managed care environment. Two types of theories are possible in grounded theory studies. Substantive theory helps to explain an empirical area of sociological inquiry (Glaser \& Strauss, 1967). Examples include patient care and professional education. Formal theory is geared toward a conceptual area of sociological inquiry, such as formal organization, stigma, and power (Glaser \& Strauss, 1967). This study was aimed at developing a substantive theory to explain behaviors of female nurse executives in a specific arena of health care, rather than trying to synthesize a broader theory to explain the behaviors of a multitude of women in leadership positions.

\section{Grounded Theory Methodology and Feminist Research}

Grounded theory methodology seemed very compatible with feminist ideology for this study. Grounded theory methodology is open to contemporary intellectual trends and 
movements such as feminism in building knowledge in that it has a built-in flexibility to changing times and circumstances. The key in blending grounded theory and new intellectual trends is to ensure that the analytic procedures of grounded theory are not changed (Strauss \& Corbin, 1994).

Wuest (1995) enthusiastically supported the combining of a feminist viewpoint with grounded theory, calling it feminist grounded theory. Epistemologically, both schools of thought fit together well according to her. First, grounded theory methods support the feminist belief that research participants are subject matter experts regarding their experiences, and that data based upon their experiences are valid. Second, the grounded theory aim of discovering social process within social structure which involves deeply grounding personal and practical experiences, closes the distinctions between the personal and political, and theory versus practice; distinctions which are considered artificial in feminist thinking (Wuest, 1995). While the dimensional analysis approach of this study was not concerned with extracting a basic social process, it was very much involved with understanding the meanings of interactions occurring within social structures, and therefore supportive of Wuest's second premise that both research traditions merge the personal and political. Finally, both methods accept researcher bias. Wuest (1995) cited Strauss and Corbin's (1994) assertion that grounded theorists are biased by accepting responsibility for their interpretations. In feminist research, researcher bias influences research questions as well as analysis (Wuest, 1995).

There was a major issue which had to be considered in combining feminist research with grounded theory methodology. This issue concerned the potential for imposition of 
the feminist ideology on the grounded theory analysis (Wuest, 1995). In feminist research, the personal values of the researcher may influence every stage of the research, including problem selection, making research decisions during the study, and interpreting findings. Because feminist research permits such a degree of bias, this type of research requires a continual self-critique and analysis by the researcher in identifying and clarifying personal values for the readers. Subjectivity may not be used at the expense of scientific rigor (Webb, 1983), and the researcher must remain faithful to the techniques of grounded theory (Strauss \& Corbin, 1994).

\section{Adequacy of Inquiry}

The way to ensure rigor in this study, while protecting both research traditions of feminist science and grounded theory, was through an overall standard known as adequacy of inquiry. In feminist science, compartmentalized notions about reliability and validity are inappropriate. A more encompassing standard known as adequacy is used to ensure rigor. Adequacy of inquiry looks at research process as well as outcomes, searching for evidence of cogency, grounding, justifiability, relevance, and meaning (Hall \& Stevens, 1991). Ten elements to be considered in ensuring adequacy are suggested by Hall and Stevens (1991). While all are important in evaluating feminist research, I will discuss the ones which I selected, based upon their appropriateness for both feminist and grounded theory research. I will refer to all of them as standards. These include (a) reflexivity, (b) rapport, honesty and mutuality (c) coherence, and (d) naming (Hall \& Stevens, 1991). 


\section{Reflexivity}

The researcher-participant relationship is an extremely important part of feminist research, the "tool" by which data are collected, and therefore the relationship must be continually assessed. The concept of reflexivity in feminist research means that the researcher-participant relationship is checked throughout the study for mutual influences which affect the nature of responses of both participant and researcher. Since feminist research allows bias, reflexivity permits the existence of conflicting realities by requiring a continual self-dialogue by the researcher to note similarities and differences between researcher and participant (Hall \& Stevens, 1991).

The standard of reflexivity as it pertains to feminist research is highly congruent with the standard of theoretical sensitivity as described by Strauss and Corbin (1990). In grounded theory research, theoretical sensitivity involves all aspects of the research process, and means that the researcher has insight, is able to interpret data meaningfully, understands the data, and can separate the pertinent from the inessential in developing a grounded, conceptually dense, and well integrated theory (Strauss \& Corbin, 1990). For this study, I extended the concept of reflexivity to include theoretical sensitivity. Therefore, in addition to the assessment of the researcher-participant relationship, I believed that ongoing assessments of my insights and subjectivity throughout the data collection and analysis processes were necessary in order to ensure scientific rigor in this study. 
Rapport, Honesty, and Mutuality

Closely related to reflexivity are the interrelated standards of rapport, honesty and mutuality, which are essential in feminist research to ensure sufficient depth and scope of data collection and analysis. Rapport involves trust and openness in the researcher-participant relationship. Honesty means that participants believe there is no trickery or hidden motives regarding the study, and mutuality means that egalitarian cooperation exists between researcher and participants so that participants speak freely (Hall \& Stevens, 1991).

\section{Coherence}

Coherence is a standard which gauges the unity of the research account as it is derived from all the data. Research conclusions are coherent if they are consistent with raw data, and faithful to the participants' sentiments, stories, and behaviors conveyed in their narratives. Data analysis and interpretations must make logical sense in light of a broader understanding of the economic, social, and political contexts (Hall \& Stevens, 1991).

Naming

Naming enables the active voices of women participants to be heard, using terms which directly represent women's experiences (Hall \& Stevens, 1991). This standard of naming is actually a specific coding technique in grounded theory research. One way of finding category names during the open coding process is to seek out "in vivo" codes, or words or phrases actually used or coined by participants (Strauss \& Corbin, 1990). 


\section{Summary of Methodological and Epistemological Considerations}

In summary, the objective of this study, was to develop an inductively derived theory grounded in the realities of the woman/nurse/executive working in the health care environment of Southern California, while remaining allegiant to feminist ideology. By using the key process of dimensional analysis, a substantive structure, or matrix could be synthesized, which would serve as the foundation for explanation of a complex social phenomenon (Schatzman, 1991). Combining grounded theory with a feminist ideology as a research strategy has been supported and endorsed in the literature. The caveat is that both research traditions must be respected. Special attention to an overall standard known as adequacy of inquiry provided the answer for ensuring scientific rigor in this study which combined two research traditions.

\section{Research Specifications and Process}

In this section, I will describe the specific criteria for this research and the procedures for carrying it out. The following discussion includes: (a) criteria and process for participant selection, (b) sample, (c) gaining entree and ethical considerations, and (d) data collection and analysis. Discussions on adequacy of inquiry are woven throughout this section.

\section{Criteria and Process for Participant Selection}

The term, woman/nurse/executive, for this study meant a female senior-level nurse manager at the top of the nursing hierarchy in a Health Service Organization (HSO). Eligible participants had to be directly responsible to more senior-level executives outside of the nursing service arena, such as CEOs (chief executive officers) or COOs (chief 
operations officers), and had to retain responsibility for nursing service among their other responsibilities. Eligible participants therefore had to be serving in line versus staff positions of authority in their organizations. In some organizations, fingering the top nurse executive triggered confusion, and was clarified by asking for the name of the person who had designated oversight responsibility for nursing care in compliance with Joint Commission on Accreditation of Healthcare Organizations and the State of California Title 22 criteria. Since this study was specifically aimed at exploring the perspectives of female nurse executives who might be most impacted by working in a managed care environment, participants were recruited from private and public profit and not-for-profit organizations, but government organizations such as the Veteran's Administration or military were excluded from consideration.

The sole investigator for this study, I recruited female nurse executives working in Health Services Organizations (HSOs) in San Diego, Orange, and Los Angeles Counties in a number of ways. A list of nurse executives was obtained from 1995 The Directory of Health Care Professionals (HCIA Inc., 1994) and the list was compared with the ONE-Califomia 1996-97 Resource Directory (ONE-California), as well as with local telephone directories. In most cases, I found that I had to actually telephone various facilities to get the most current names of top nurse executives. I also used my personal contacts in the Southern California area to find names of potential participants, as well as snowball sampling techniques, which consisted of participants recommending other potential participants. Additionally, I recruited participants during a ONE-California 
(Organization of Nurse Executives-California) regional meeting, and by advertising the study in a ONE-C newsletter.

\section{Sample}

The convenience sample for this study consisted of 17 participants in both profit and not-for-profit HSOs in San Diego, Orange, and Los Angeles Counties. Since grounded theory procedures are aimed at identifying, developing, and relating concepts, the intent of sampling was to find the significance of concepts by noting either their repeated presence or obvious absence in order to ensure conceptual adequacy of the theory synthesized from the data (Strauss \& Corbin, 1990). Therefore, in accordance with the recommendations of Strauss and Corbin (1990), sampling continued in this study until the key dimensions emerged from the data, and there was sufficient data to support each of the dimensions. Sampling during the data analysis process helped assure theoretical sensitivity in the development of a grounded, conceptually dense, and well-integrated theory (Strauss \& Corbin, 1990)

Study participants worked in a variety of health care delivery systems in San Diego, Orange, and Los Angeles Counties. Systems included (a) an HMO; (b) a for-profit corporation; (c) several private, not-for-profit corporations; (d) a state-sponsored academic medical center; and (e) a private academic medical center. Sixteen of the participants worked in adult acute care, hospital settings, and two of these worked in pediatric hospital settings. One participant was responsible for a home health practice of a particular corporation as an out-sourced management consultant. 
Eight participants formed into four pairs because they worked for the same health system, but in different organizational entities. There were two participants from the same HMO; two from the same for-profit corporation; and two pairs of participants from two private, not-for-profit health care corporations.

Official titles varied among participants. Titles included: Assistant Administrator; Associate Administrator, Director, Patient Care Services; Vice President, Patient Care Services; Chief Administrative Officer; and Senior Vice President, Clinical Services. No participant held the official title of Director of Nursing Services, Chief Nursing Officer, or Chief Nursing Executive. All participants had responsibilities which included personnel in addition to nursing personnel, and the majority had some type of additional project management responsibilities. Some participants had direct responsibility for non-clinical operations such as physician contracts. A number had social work, food and nutrition, utilization review and quality assurance responsibilities. One participant was responsible for the hospital pharmacy.

There was a wide range of education for participants, with the highest degree earned extending from baccalaureate to doctorate. However, 14 participants had master's degrees as their highest degrees. One participant held a Doctor of Nursing Science degree, and one participant was midway through completion of a Ph.D. Two participants held baccalaureate nursing degrees as their highest levels of education, and both were currently involved in graduate degree programs. Attained master's degrees were largely in nursing, and included a nursing administration focus as well as a clinical specialist focus. One participant held an MBA. 
Participants described a variety of nursing experiences. All started their careers in clinical practice. Clinical nursing experiences predominantly consisted of medical/surgical, maternal/child, and intensive care/trauma nursing. All participants began their careers in acute care settings, and the majority had stayed in acute care settings. A few had diverse experiences including quality assurance, ambulatory care nursing, and school health nursing, but these participants eventually returned to the hospital setting. Length of time in nursing administration varied, but participants had all been involved in nursing management roles for at least 10 years. Most participants did not anticipate becoming a nurse administrator during the early years of their nursing careers.

Length of time in their current organizations also varied among participants. Several had been hired within the last five years, and a number had been with their present organizations from 15 to 20 years. This latter group had worked in a variety of organizational positions prior to assuming their current positions.

There were several other demographic factors of interest. The average age of participants was estimated to be mid-to-late 40 s. The majority of participants were not California natives, and a surprising number had begun their careers in the Midwest or Rocky Mountain areas. There were only two participants who did not mention current spouses or boyfriends in their lives. The other 15 participants spontaneously talked about husbands, boyfriends, and children.

In summary, all participants except one worked in acute care settings, and their background experiences were largely in similar settings. The average age of participants was estimated to be mid-to-late $40 \mathrm{~s}$, and the majority of participants mentioned 
boyfriends, spouses, and families. Lengths of tenure in organizations showed wide variability, but all had served for at least 10 years in nursing management roles. Most participants were prepared at the masters' degree level, and most masters' degrees were in nursing. All participants had responsibilities for more that the oversight of nursing care and services.

\section{Gaining Entree and Ethical Considerations}

After receiving permission from the University of San Diego Committee on the Protection of Human Subjects (Appendix A), I sent out a number of recruitment letters (Appendix B) and copies of the consent form (Appendix C) to explain the study, and after approximately two weeks, I began to follow up with a telephone call as originally planned. Potential participants were assured that participation in this study was entirely voluntary and that complete confidentiality was guaranteed.

Early in the recruitment process, I realized that gaining entree was more difficult than I originally anticipated for this group of participants. First, these women had such incredible workloads and demanding schedules, that personally contacting potential participants was not possible. Second, I became concerned about the ethics involved in trying to gain access to them through their secretaries. Therefore, I designed a letter, with an enclosure and a self-addressed envelope that participants could return to me if they were interested in study participation (Appendix D). Approximately 40 recruitment letters were sent during the time of data collection, and about 20 were returned to me with a response. The return time on the majority of the 20 letters was four to six weeks. 
This changed recruiting approach worked out well for several reasons. First, it provided a better way to protect participant confidentiality. It served as a direct means for communicating only with potential participants. Furthermore, by eliminating the need for initial telephone contact, nurse executives were protected from having to explain reasons to me for not participating. Second, this letter empowered potential participants by allowing them to determine the best time, place, and way to schedule the interview. Considerations of equity and the empowerment of participants in decision-making are consistent with feminist praxis (Duffy \& Hedin, 1988). This revised way of protecting confidentiality and of empowering potential participants supported the standards of rapport, honesty, and mutuality (Hall \& Stevens, 1991) in the researcher-participant relationship.

All participants except one had me contact their secretaries to schedule interview appointments at their facilities, but initial interview appointments usually had to be changed to accommodate the participants' constantly changing schedules. However, no participant withdrew from the study despite scheduling changes and heavy workloads.

In summary, gaining entree was difficult, and required sending a letter, waiting for at least one month, and scheduling and rescheduling appointments. Special attention was paid to the standards of rapport, honesty, and mutuality (Hall \& Stevens, 1991) during participant recruitment. No participant withdrew from the study after consenting to participate. 


\section{Data Collection and Analysis}

In a study which combines a feminist perspective with grounded theory strategy, the processes of data collection, data analysis, and evaluation of rigor are all inextricably linked throughout the study, and are not discrete, linear phases. These processes are aiternated during a period of time. However, for the sake of discussion, data collection, and analysis will be presented separately.

\section{Data Collection}

Data collection for this study occurred in several ways. Data collection began with participant interviews. Interviews were conducted beginning in July 1996, and ending mid-November 1996. All participants gave informed consent (Appendix C) prior to the interviews. Ten interviews were done in the field at the participants' places of employment, so these interviews were supplemented with field observations. The other seven interviews were conducted by telephone. One interview began in the field, and was completed by telephone from the participant's home. Of the seven interviews done entirely by telephone, six participants were interviewed at their work sites, and one was done entirely from the participant's home.

All interviews were tape-recorded and the time range for interviews was from 45 minutes to 1 hour and 15 minutes. The average interview was 50 minutes in length. Interview lengths depended largely upon the amount of time the participant could spare. Participants were all informed of the possibility that I would need to contact them for clarification of interview data. 
In support of the standards of rapport, mutuality, and honesty in the researcher-participant relationship (Hall \& Stevens, 1991), I paid special attention to confidentiality and privacy during all interviews. Actual interviews involved only myself and the participant, and they took place in private locations behind closed doors. Tape-recording equipment was only taken out for use in these private areas. Telephone interviews were conducted in private and from my home.

Interviews were conducted in a semi-structured format. The initial interview guide which was used is shown in Appendix E. The semi-structured interview guide was a starting point for this study and changed over the course of the study, which is common in grounded theory methodology (Schatzman \& Strauss, 1973). For example, during one of the initial interviews, a participant brought up the idea that nursing had been viewed as a "favored child" in her organization, so future participants' ideas about how they as nurses were perceived in their organizations were solicited. As another example, early in the interview process, several participants spontaneously brought up the importance of a balanced personal and professional life, so that theme was intentionally pursued throughout the study. I deleted the question asking participants to describe an average work day after several interviews, as I found the responses lacking in desired depth and a less-than-economical use of interview time.

There were several additional steps I took regarding the interview procedures in order to enhance rapport, honesty, and mutuality (Hall \& Stevens, 1991) in my relationships with participants, and to maximize the depth of the data obtained. One way was by dressing for interviews in a way that matched the attire of participants. Another 
way was by sharing personal information about myself at the onset of the interview. I learned early in the data collection process that reassuring participants by sharing my plans and motives regarding this research was essential in a competitive environment where job tenure of some participants was uncertain. As a result, participants willingly shared a surprising amount of personal information about their lives, and unhesitatingly provided me with names of possible future participants.

Recording field notes and notes about the interviews was done in a planned fashion using techniques described by Schatzman and Strauss (1973), and through use of an additional guide I developed which I called a "reflection note guide" (Appendix F). This guide helped me meet the standard of reflexivity (Hall \& Stevens, 1991) as I defined it for this study. It stimulated self-dialogue about my subjectivity regarding my relationships with participants, and helped expose my biases regarding the interview process, content, and analysis. The guide was adapted from feminist research guidelines suggested by Christman (1988), Duffy and Hedin (1988), and grounded theory guidelines endorsed by Strauss and Corbin (1990). After each participant interview, using the guide, I privately audiotaped my own impressions, observations, thoughts, and feelings about the interaction.

I was the only person who listened to interview tapes, and I personally transcribed all 17 interviews in this study. All interview data were coded in a way which was untraceable to participants, and all identifying information was camouflaged in the transcripts. 
Rapport, honesty, and mutuality (Hall \& Stevens, 1991) in my relationships with participants were enhanced by involving participants in the study process. Approximately four to seven weeks after the interview, each participant was sent a copy of the interview transcript with a self-addressed retum envelope. In the accompanying letter, participants were encouraged to freely modify the interview texts, and provide supplemental information. Several participants telephoned me with questions about their texts, and after personally reassuring them of confidentiality, I modified future letters I sent with transcripts to stress the aspect of confidentiality. Transcripts were sent to participants with the outer envelopes marked "confidential."

In the packages containing the interview transcripts, I also included another question to assist in data collection and analysis. I asked each participant to describe her relationship with her organization. In keeping with feminist ideology, I also asked for responses in any fashion, which included artwork, poetry, etc. Of 17 transcript packages sent to participants for review, I received 15 back. Of these 15 , eight participants responded in some form to the additional question. Only two participants drew pictures. The others provided brief comments.

One final contact was made with all participants. At the conclusion of the study, all participants were provided with a condensed copy of the results, and a letter thanking them for their participation.

Data were also collected during this study in one additional way. I collected news clippings and articles in local magazines pertaining especially to the San Diego County health care scene during the period of July through December 1996. This data became 
helpful in understanding participants' descriptions of their organizations, as well as for providing a sense of the overall climate regarding health care delivery during this time period.

In summary, data were collected in several ways during the entire time period of July 1996 through February 1997 . The primary source of data for this study was from semi-structured interviews with participants, 10 of which were field interviews and seven were telephone interviews. Field notes, archival data, a researcher reflection note guide, and participants' reviews of their transcripts supplemented interview data. The standards of reflexivity, rapport, honesty, and mutuality (Hall \& Stevens, 1991) were assessed throughout the data collection process.

\section{Data Analysis}

Data analysis consisted primarily of the techniques of dimensional analysis as developed by Schatzman (1991) and elaborated by Kools et al. (1996), and was ongoing during data collection. Data analysis was aided by processes of organizational analysis (Morgan, 1986) and constant comparative analysis (Glaser and Strauss, 1967).

Beginning with the question, "What 'all' is involved here?" (p. 310), early analysis began with the coding of data as a means of identifying participant experiences (Schatzman, 1991). These early coding procedures involved the naming of data bits, as described by Kools et al. (1996). Data about structures, processes, contexts, or conditions, were all considered as possible codes (Schatzman, 1991).

Out of line-by-line analysis of participant narratives, memoranda, and field notes, a major recurring theme of relationships regarding participant experiences began to 
consistently be found. Relationships formed into codes such as relationships with self, relationships with nursing, relationships with nursing staff, relationships with organization and environment, relationships with other professionals, relationships with physicians, and relationships with bosses, to name a few.

Data bits (Kools et al., 1996) also consisted of "in vivo" codes from participants, such as that of "unsung heroines" in describing nurse executives. By focusing heavily on "in vivo" codes, I demonstrated support for the standard of naming (Hall \& Stevens, 1991).

By continually asking, "What 'all' is involved here?" (Schatzman, 1991, p. 310), core dimensions became apparent. Some data bits merged with others, and clusters of data bits with similar properties began to form, and could be placed under certain "headings" as described by Schatzman (1991).

At this point in the analysis, an organizational analysis was done as described by Morgan (1986) in order to get a sense of the participants' overall environment. Data bits and preliminary codes were used for this analysis, and the health care delivery environment was considered as a singular concept of "organization." Morgan (1986) defined eight metaphors of organizations, including such metaphors as organizations as machines, organizations as organisms, organizations as cultures, etc. The disadvantage in using this technique was that it artificially forced the collective participant data into an examination using each of these metaphorical lenses. The advantage was, it enabled an understanding of what some of the most salient dimensions were for the overall analysis in light of feminist ideology. 
Returning to more inductive procedures of dimensional analysis, a story was beginning to emerge, but to ensure that it truly represented what participants were actually saying, I again reviewed all participant transcripts, searching specifically for "in vivo" codes which would demonstrate most faithfully the participants' perspectives. In this way, I purposefully sought to ensure the unity of the research account as it was being derived from the data, which helped meet the standard of coherence (Hall \& Stevens, 1991).

Comparing "in vivo" codes with salient dimensions resulted in a process of differentiation, where data for consideration were limited, and analysis was more focused (Kools et al., 1996). While different dimensions were being "auditioned" to serve as overall study perspective, a process of finding the dimension which best explained all other dimensions (Schatzman, 1991), I was also finding vast differences in certain properties of certain dimensions. These properties had a certain "measurement" value (Schatzman, 1991), so that comparisons could be made between various groups of participants. Essentially, as data were being reconstructed into an explanatory matrix (Schatzman, 1991), a typology of participants in terms of the dimensions of actions/interactions and consequences emerged.

I then used the techniques of constant comparative analysis as defined by Glaser and Strauss (1967) to get a grasp of the magnitudes of certain concepts or dimensions. My reflection note guide played an important role during this stage of data analysis, and helped me to meet the standard of reflexivity (Hall \& Stevens, 1991) in my relationship with the data. Analyzing my own biases regarding certain participant responses was 
important during constant comparative analysis, enabling me to keep an open mind and to be especially gender-sensitive in comparing and analyzing certain findings.

Constant comparative analysis was then used in comparing study findings with findings from a review of the literature, but literature which was feminist. In conducting feminist research, Hall and Stevens (1991) and Duffy and Hedin (1988) cautioned against comparing data against standards which reflect the norms of men's experiences in the use of the literature. By deliberately seeking out only feminist literature in interpreting findings, I maintained allegiance to feminist ideology.

In summary, the primary method of data analysis in this study was dimensional analysis, supplemented with organizational analysis, and constant comparative analysis. Through the techniques of dimensional analysis, an explanatory matrix was formed. Organizational analysis was useful for discovering the most salient dimensions from the data, and constant comparative analysis helped in synthesizing a typology of participants from the data. The standards of reflexivity, coherence, and naming (Hall \& Stevens, 1991) were assessed during data analysis to ensure scientific rigor in this study.

\section{Summary}

In this chapter on methodology, I have discussed my rationale for selecting and blending the two traditions of knowledge discovery, grounded theory and feminist research, and have shown how I operationalized these traditions while respecting them. In the first section, I discussed the methodological and epistemological considerations which guided my research design. In the second section on research procedures, I elaborated upon how the design was implemented. This study consisted of a sample of 17 female 
nurse executives from both profit and not-for-profit HSOs in San Diego, Orange, and Los Angeles Counties. Data collection was primarily by means of tape-recorded semi-structured interviews. Data were analyzed using primarily the method of dimensional analysis, supplemented by organizational analysis, and constant comparative analysis. Scientific rigor, or adequacy of inquiry, was achieved through special attention to the standards of (a) reflexivity; (b) rapport, honesty, and mutuality; (c) coherence, and (c) naming throughout the data collection and analysis processes.

In the next three chapters, I describe the findings which emerged. The findings are intertwined with a review of the feminist literature. In Chapter Four, I describe the study perspective and core dimensions which were discovered, how these integrated into an explanatory matrix, and the typology which was synthesized. In Chapter Five, I describe two participant classifications: (a) the Unsung Heroines and (b) the Engineers. In Chapter Six, I discuss two classifications: (a) the Team Leaders, and (b) the Champions. 


\section{CHAPTER FOUR}

\section{FINDINGS}

The purpose of this study was to generate a substantive theory grounded in the responses of the woman/nurse/executive working in the managed care environment of Southern California. The research centered on the following question: What are the perspectives of the woman/nurse/executive working in the managed care environment of Southern California? This study was a combination of feminist and grounded theory research.

The next three chapters will concentrate on presenting the findings. This chapter will describe the core dimensions which emerged from the data, discuss how these dimensions integrated into a framework, and introduce the typology of participants which emerged. The next two chapters will focus exclusively on descriptions of the four classifications of participants which comprise the typology. All chapters will incorporate a review of the literature to help explain the findings using the lens of gender.

This chapter is divided into four sections. In the first section, an (a) overview of findings is provided. The second section discusses (b) gender bias in economic theorizing. The third section describes the (c) dimensions which emerged, and how they integrated into a foundational framework. This section breaks into: (a) managed care battlefield, (b) calls to action, (c) defining the mission, and (d) battlefield position/professional identity. The subsection on calls to action breaks into subsections which include dimensions of 
(a) corporate bottom line, (b) the players, and (c) beliefs/values. Beliefs/values breaks down further into the subdimensions of (a) being a nurse, (b) caring for the patient, and (c) having a balanced life. The fourth section introduces the typology which was discovered. A summary concludes this chapter.

\section{Overview}

The overall perspective which emerged from the data in this study, or that dimension which best serves to explain all the other dimensions (Schatzman, 1991), was health care economics. These data portrayed a story about how the changing climate of health care economics, by influencing organizational life, helped shape the professional identities of the 17 participants of this study. Economics can be linked in some way to every other dimension of the study.

The perspective of health care economics set the stage for the context of this study, which was the highly managed care environment of Southern California. The context included Los Angeles, Orange, and San Diego Counties. Based upon composite data from all interviews, as well as data obtained from local newspaper and magazine articles, a picture of the context as a battlefield became clear. In this study, the participants became heroines on the managed care battlefield.

From these data, the positions the participants envisioned themselves assuming on this battlefield, in essence their professional identities, were attained through processes of defining their professional responsibilities, and consequently, their most important leadership actions. Defining what they perceived to be their most important responsibilities 
as health care professionals was influenced by three salient dimensions, or conditions. These include: (a) corporate bottom line, (b) the players, and (c) beliefs/values. The condition of beliefs/values includes the subdimensions of (a) being a murse, (b) caring for the patient, and (c) having a balanced life. The interplay among the three conditions and subdimensions was very important in understanding how the participants shaped their perceptions of their responsibilities, determined their leadership actions, arrived at definitions of themselves as health care professionals in top institutional leadership positions, and experienced those roles. For these participants, the three conditions served as calls to action, as well as foci of their leadership actions. In keeping with the battlefield metaphor, the process of defining responsibilities and leadership actions was analogous to defining their mission on the battlefield.

Defining the mission consequently resulted in perceptions of a professional identity for the participants, which in many cases was very different from their initial career expectations when entering the nursing profession. Professional identities helped explain how the participants interpreted their positions on the managed care battlefield. Data from this study also revealed how well participants were able to maintain a certain identity or position. I called this dimension, "battlefield position/professional identity."

What became apparent to me more than halfway through the data collection process was that somehow, there were major differences in the essences of the interview texts among various participants. Certain participants perceived their calls to action (conditions) and defined their missions (interactions/actions) in ways which were uniquely different from each other, leading to major differences in professional identities or 
battlefield positions (consequences) among participants. This crucial discovery led to the overall finding that participants could be grouped into a classification of four different categories, resulting in a typology of four unique professional identities among the 17 participants. These four categories are: (a) the Unsung Heroines, (b) the Engineers, (c) the Team Leaders, and (d) the Champions. Figure 1 shows the synthesis of dimensions into an explanatory matrix.

The Perspective of Economics: A Man's Game in a Man's World

The storyline of this research begins with health care economics, since economics in some way triggered or impacted every dimension of the framework which was synthesized from the data. Since this was feminist research, feminist ideology served to provide the logic behind the findings. Finding how a feminist perspective merged with an economics perspective was not difficult. The managed care environment of Southern California at the time of this study was largely the result of an economic theory which contained biases against women.

The procompetitive direction in health care throughout the United States occurred as a result of the popular and poorly understood concept of managed competition (Wells, 1993). While there are other theories of managed competition, the model of managed competition as conceived by Alain Enthoven, an economist, had considerable political influence. Enthoven's ideas about managed competition were first publicly introduced during the Clinton presidential campaign, and endorsed as a strategy for health care reform by Senator Paul Tsongas (Buerhaus, 1994a) as part of his campaign for president 


\section{Figure Caption}

Figure 1. The relationships among study perspective and core dimensions in the form of an explanatory matrix. 


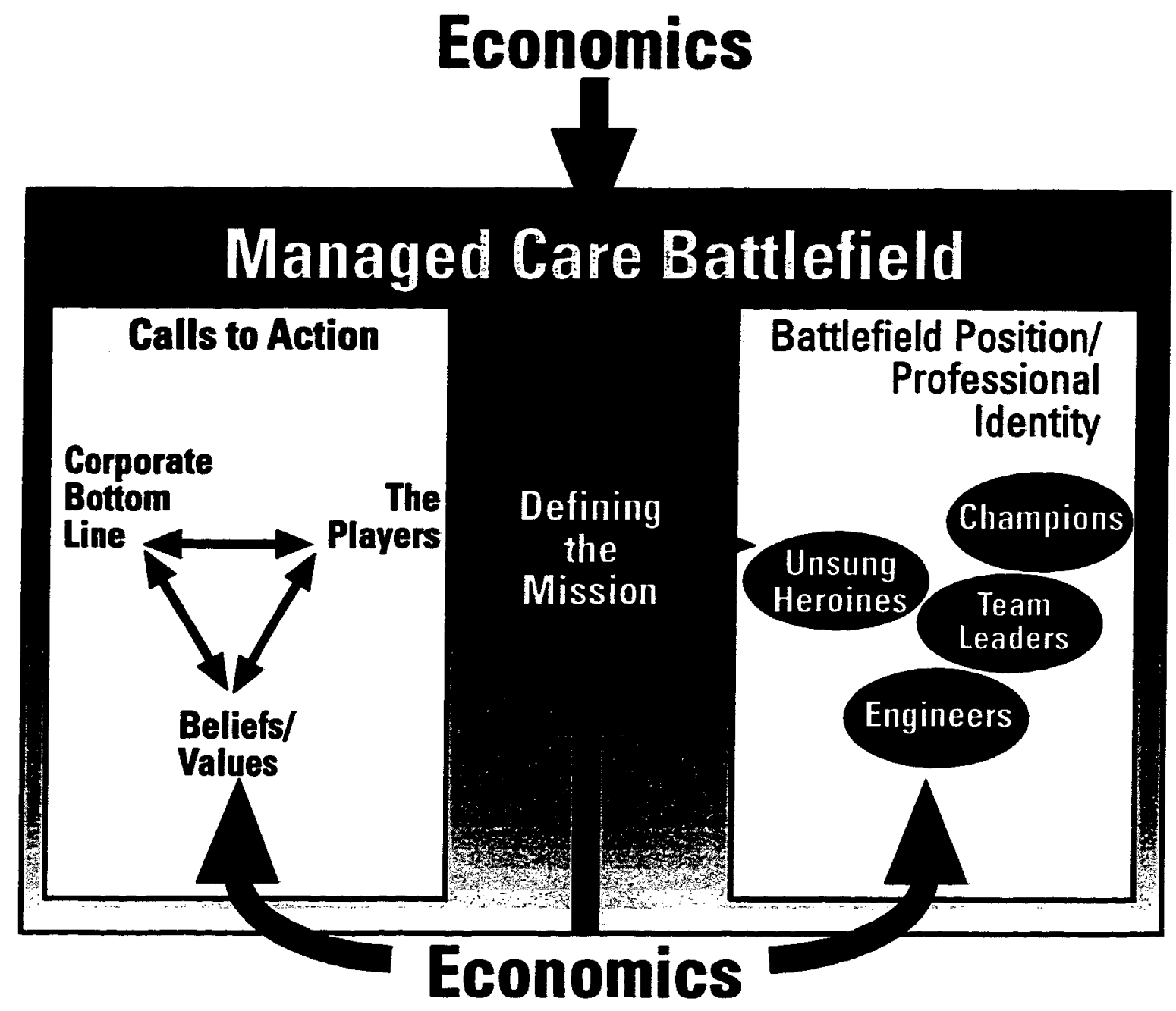


(Enthoven, 1993). The Managed Competition Act of 1992 under the Clinton administration was based upon this model (Enthoven, 1993).

Enthoven (1993) defined managed competition as a purchasing strategy, aimed at getting the most value for the money. It was created with an objective of providing economic control over a system out-of-control due to the cost-increasing incentives of fee-for-service payment plans in combination with the cost-ignorant demands of insured patients. It was designed to be enacted at the level of integrated financing and delivery plans rather than at the level of the individual provider, with an intention of dividing providers into competing economic units. These units would have to rely upon market forces to motivate providers to develop efficient delivery systems. Managed competition was really price competition, where the prices consisted of the annual premiums for comprehensive health services versus fees for individual health care services (Enthoven, 1993). Overall price controls would occur because firms would have to keep production costs low in order to price health care products attractively, while at the same time the products would also have to represent value to the consumers (Buerhaus, 1994a).

Managed competition, as defined by Enthoven (1993), was derived from a mainstream tradition of economics. Enthoven (1993) described managed competition as an integrated framework which combines observation and analysis with rational principles of microeconomics. Microeconomics involves studying and analyzing data about individual units of consumption rather than aggregates of units, and it focuses upon the allocation of resources among competing units (Greenwald et al., 1983). Arising out of a perspective of classical consumer economics (Buerhaus, 1994a), the concept of managed 
competition was based upon an idea of perfect competition, and a theory of supply and demand for individual markets (Skousen, 1991).

While the strengths of the mainstream model of economics are many, including durability, powerful predictive ability in a variety of situations common in industrialized societies, usefulness in solving public policy questions, and ability to translate to mathematical forms, it fails to account for the economic realities faced by women (Blank, 1993). Therefore, mainstream economics has been challenged in the literature by proponents endorsing inclusion of feminist perspectives in economics (Ferber \& Nelson, 1993; Folbre, 1994), and by those who believe that dominant approaches to economic analyses do not consider the subordination of women (Peterson, 1994). The inclusion of more diverse sets of models in economics is only in the beginning stages (Blank, 1993).

Traditional, mainstream economic science has come under criticism for embracing the Cartesian model of objectivity and dualistic thinking, in which humans are considered separate from their world, and divisions exist between rationality and embodiment. This model has been the prevalent and biased view of traditional science which has been criticized by feminists of many disciplines (England, 1993; Nelson, 1993), because the Cartesian ideal identifies science with masculinity, detachment and domination, and associates femininity with nature, submission, and subjectivity. The superior masculine approach to science is one of abstraction, detachment, generalization, and without emotion, in contrast with the inferior concrete, particular, passionate and embodied realities of the lives of women (Nelson, 1993). 
Waller (1994) argued that out of these dualistic constructions of reality, the economy and the household formed into separate spheres in economic thought. The economy became part of the public sphere and the household became the private sphere, where the public sphere came to be associated with men's activities and the private sphere with women's activities. This compartmentalization of social spheres enabled the development of universalized prescriptive social interpretations where higher status is conferred upon rational, masculine, economic pursuits, as compared to emotional, feminine and familial activities (Waller, 1994).

The predominance of male thinking in economics was explained in another way by Strassmann (1993). According to her, mainstream economics has come to be identified as an approach rather than as an empirical domain. Most empirical disciplines, such as the biological and physical sciences, are explained by domain rather than approach (Strassmann, 1993). Strassmann argued that by centering on approach rather than domain, the explanations that the discipline can provide are limited. The issues of value, power, and social construction can therefore be conveniently ignored in economic theorizing, making way for the primacy of the androcentric core ideas of self-interested individualism and contractual exchange to continue in an unchallenged fashion.

To further demonstrate the limitations of economic theorizing, and the emphasis upon a Cartesian ideal of objectivity and reductionism, Nelson (1993) asserted the most commonly-accepted definition of economics has been narrowed to essentially mean mathematical models of individual choices. The tradition of mathematical analysis was borrowed from eighteenth century physics. Phenomena which can not be explained by 
mathematical models have been eliminated from consideration by prominent mainstream economic theorists. The economic approach to a problem means examining the problem in terms of choices made by autonomous rational agents, choices which center on the material well-being on the agent and ignore other sources of human satisfaction (Nelson, 1993).

The narrow and exclusionary perspectives which promote the logical, masculine superiority of self-interested individualism and contractual exchange in economic science have continued unchecked for several reasons according to Strassmann (1993) and Ferber and Nelson (1993), and have not been entirely accidental (Strassmann, 1993). First, men have historically dominated the field and women are statistically strongly underrepresented (Nelson, 1993). The selection and socialization processes in economics have screened out those who are unable to do "proper economics" (Strassmann, 1993, p. 55). Discrimination, lack of women mentors, and structures of employment which emphasize professional achievement during the childbearing years have been cited as causes for the low numbers of women. Second, women have not been involved as economic researchers or as the subjects of economic study. Third, women's' experiences have been inadequately explained, especially regarding their rising participation in the labor force, and in terms of their role in the home and family environment (Ferber \& Nelson, 1993). Economic theories regard the family as an individual agent under the direction of a presumably altruistic male head-of-household, without consideration for imbalances of power among family members. The family has been conveniently compressed into a unit of analysis as an individual (Strassmann, 1993), and consequently individual family members escaped 
attention in economic theorizing (Ferber \& Nelson, 1993). Therefore, Strassmann (1993) argued that the construction of economic knowledge is not complete, and that economic science has not been developed based upon a "marketplace of ideas" (p. 56). Economic theorizing has been guided by certain mythical assumptions which ignore issues of value, power, and social construction, and which have greatly influenced and helped misguide public policy decisions (Strassmann, 1993).

The theory of market competition in a managed care environment was built upon economic assumptions which are biased against women, and the voice of women in economic theorizing has been noticeably absent. Additionally, the voice of nursing in the managed competition revolution has been absent. Therefore, most the findings in this study can be somehow attributed to the socioeconomic barriers of working in a male-dominated culture, where money is associated with male power, and where there is devaluation of women in the workforce. The study participants, as women and nurses assuming nontraditional roles; roles in which some of them had a significant connection to the corporate bottom line, were bound to experience conflicts related to power and control.

\section{Core Dimensions}

In this section, I will describe each dimension which became essential in shaping the storyline of this research about how woman/nurse/executive participants defined their missions and perceived their positions on the managed care battlefield of Southern Califormia. The dimensions will be discussed in the following sequence: context, conditions, actions/interactions, and consequences. Therefore, this section will discuss the 
following dimensions and the relationships among them: (a) managed care battlefield, (b) calls to action, (c) defining the mission, and (d) battlefield position/professional identity, and conclude with a (e) summary of core dimensions. The section on calls to action breaks into subsections which include dimensions of (a) corporate bottom line, (b) the players, and (c) beliefs/values. Participant beliefs/values breaks down further into the subdimensions of (a) being a nurse, (b) caring for the patient, and (c) having a balanced life.

\section{The Managed Care Battlefield}

Most of the participant interviews conveyed a sense of how the managed care evolution was impacting participants' organizations, and consequently the professional lives of the participants. One participant particularly reinforced the idea of the managed care environment as context, when at the end of the interview, in response to my question about whether she wanted to share anything else relevant to the topic of the study, she stated, "...I definitely think it's the managed care that's putting the pressure on the environment, creating the things that led to your other questions." Another participant talked about the work that she had done "in the Southern California and the managed care petri dish." Participant opinions about the impact of managed care ranged from a viewpoint that managed care has resulted in "a very positive force," to the more negative perception, "Managed care has certainly done a number on operations for us as well as for other facilities."

The key pressure, or driving force, in the managed care environment was understood by many participants to be market competition. One participant predicted: 
"One will continuously see 'reorgs', and whether you call it down-sizing, right-sizing, terminating employees, whatever you want to call it, the goal is to compete in a very competitive managed care market." One participant, in describing her organization, stated that it was located in a particular city, "in a very competitive market with a rapidly changing payor mix and patient mix."

The dynamic nature of the context, with organizations and systems in competition for market share was evident in the stories the participants told about their organizations. The organizational environments were characterized as "very aggressive environments" by one participant, at a point in the history of health care where times were "extremely turbulent" according to another participant. An article by Fikes (1996), which addressed the San Diego health care environment, supported the stories from the San Diego participants. He stated that San Diego's hospitals, doctors, and health insurance plans have reacted to the health care economic revolution by frantically seeking partners and alliances to increase market share and cut costs. However, interviews with participants from Orange and Los Angeles Counties demonstrated that the turbulence was just as pervasive in many of their organizations. Words such as "affiliation," "amalgamation," "merger," "partnership," and "joint venture" leapt out from many of the interview texts as participants described how their organizations were responding to the managed competition environment. One participant's comment summarized the dynamic nature of this context: "...change is the only thing that's constant."

Scattered throughout all of the interview texts were "in vivo" codes having to do with war and games. While the battlefield image was much stronger in the data from some 
participants compared to others, it came up often, in many ways, with a large number of participants, leading me to believe that the best descriptor for the context of this story was a battlefield.

The way several of the participants described their jobs alluded to the context of a battlefield. The words of one particular participant, who served in a position which placed her at the junction between the environment and the organization, strongly supported the image of a battlefield. In describing how she viewed her job, she stated, "We really are working, just sort of day-by-day--what are the issues, what are our priorities, what's the hill we're going to die on today?" Later in the interview, she stated,

I think about work and the challenges as sort of the battle, and I think, as issues come forward, I ask myself,...I want to win the war, so is this battle worth a win or a loss and how much effort and energy do I put into this? Is this the hill I want to die on today?

Another participant stated: "It's a dirty job, but somebody's got to do it. Someone has got to be a leader right now," borrowing her phrase from an American Western movie about a hero. Still another participant asserted: "And I just think that CNOs [chief nursing officers] are generally, unsung heroines, or heroes." A fourth participant, in talking about her experiences in her position stated that, "Feedback is the breakfast of champions." These participants seemed to have envisioned themselves as warriors, positioned on a battlefield.

The battlefield metaphor, which was shaped out of the combined narratives of participants, portrayed a context of a patriarchy. The term, "patriarchy," has been used in 
many ways by various feminist factions, but the most basic meaning is "'what men do that subordinates or exploits women"' (Lorber, 1994, p. 3). A battlefield is a patriarchal term. It supports Lorber's (1994) generic definition of "patriarchy" as a simultaneous ideology, process, and structure of women's subordination (Lorber, 1994).

The historical connection between war and patriarchal societies was made quite explicit by Eisler (1987). Eisler (1987) made a compelling case for understanding Western civilization as one which began in an environment of warfare and destruction. It marked the beginnings of societies of male domination; societies characterized by war, competition, and chaos. The emerging Western civilization was a direct contrast to an earlier, peaceful Cretan civilization, where partnerships between men and women were behavioral norms. The role of technology, during the time of the Cretan civilization, was to sustain and enhance the quality of life, but this emphasis on production was changed during the beginnings of Western civilization to one of destruction. During this time period, the icon of the goddess was replaced by the warrior god, and the acquisition of material wealth became equated with an ability to develop more effective technologies of destruction (Eisler, 1987). Furthermore, the acquisition of wealth became associated with power and strength, leading to hierarchical societal arrangements, with a "strongman elite at the top" (Eisler, 1987, p. 50).

Awareness of the patriarchal environment was expressed by a number of participants. Comments about patriarchy were made in reference to a variety of geographical regions involved in this study. One participant gave her opinion of the external environment: "And this is a very patriarchal, conservative-and you really have to 
get into the community and really be a business person in the community to really see it, but it's a very male, white male dominated culture here..." For that reason, she stated that in her health care system, at the corporate level, "there will never be a woman administrator." Another participant shared, "I think in this organization there is a bureaucratic male structure that exists...in the central office..." A third participant, in giving her opinions about the preparation necessary for the nurse of the future, commented, "...those nurses in those positions need to...really be able to speak on an equal basis with every other person that's sitting around the table, and very frequently it is gentlemen..." A participant from an entirely different metropolitan area stated, "I think that the one negative that, in the culture of this hospital I've not particularly enjoyed, is there is a very strong male culture." The context of the patriarchal battlefield set the tone for the internal organizational cultures of patriarchy in the data from many participants.

Furthermore, the power of the "strongman elite" (Eisler, 1987, p. 50) in the health care wars was clearly suggested by a number of participants. The strongman elite consisted primarily of "corporate gurus," bosses, and physicians, and regardless of how participants envisioned themselves in the context of these economic wars, all of their lives were somehow influenced by the strongman elite. The patriarchal metaphor of the battlefield in this story communicates an unfortunate message. Because of the cultural environment in which the participants lived at the time of this story, they were destined to never achieve egalitarian status with the strongman elite, no matter how hard they worked.

On the managed care battlefield, there were even wars among groups of the strongman elite. One participant stated that one of her responsibilities was to ensure "that 
the quality process [within her organization] doesn't become a battleground for competing physician groups." She was talking about physician groups, external to the organization, competing with each other for her organization's business. Further in the interview, she mentioned the "war stories" that the physicians were telling to the organization staff.

The strongman elite group of physicians presented numerous conflicts for many participants. As an example, one participant, in talking about her encounters with "old guard physicians," the group that is "just now beginning to realize that there is health care reform out there," would advise new nurse executives to "know your political landmines," especially in dealing with the physician community.

The "in vivo" codes from participant data brought the concept of market competition into the battlefield. One participant, in talking about a response to the concern for the survival of her health care system told me, "So what is going on in the Southern Region, is certainly more of a slash and burn and reorganize." Another participant used similar words when she described the impact of a system-wide integration and centralization which had occurred under the umbrella objective of cost-containment: "...you try to build a nation, but the states are on fire." A third participant talked about all the "consolidations going on" between physician groups and various health care networks, and stated: "Amidst all that chaos, you've got a ship that you're trying to run here..." Metaphorically speaking, the battlefield was not confined to land.

The idea of the health care economic revolution, portrayed as a patriarchal battlefield in Southern California, where wars between various groups were being fought in the name of market competition, was synthesized from the interview texts of a fair 
number of participants in this study. The impact of market competition on organizational life, on interpersonal relationships, and on study participants will become more evident as the rest of this story unfolds.

\section{Calls to Action}

The dimensions which serve as conditions, and which influenced the processes by which participants defined their major responsibilities can be thought of as "calls to action" for this group of participants. A discussion by Berman (1994) on the meaning of "being called" shed light on the meaning of calls to action in this study. Berman (1994) stated that figuratively speaking, a call normally involves attention to one listening and one speaking, and it requires an inner dialogue which culminates in a response. Forming a response means reflecting upon one's historical experiences, and then deciding a future direction, which is congruent with the way one has intended to live her or his life. A call may be subtle, or dramatic, and it is sustained by a sense of responsibility (Berman, 1994).

The calls to action, which influenced how participant responsibilities were defined, formed into two groups. Corporate bottom line, and the players were external organizational influences on the participants. The condition of participant beliefs/values was an internal influence for the participants, and consists of subdimensions of beliefs/values about (a) being a nurse, (b) caring for the patient, and (c) having a balanced life.

This subsection gives a brief definition of each of these dimensions, or calls to action, and subdimensions, and the interplay which occurred among them. The next section on typology, and the next two chapters, will more fully illuminate the meanings of 
these conditions in the development of the participants' leadership actions and professional identities.

\section{Corporate Bottom Line}

The term, "bottom line," was brought up several times in the interview with one particular participant, and selected because it best incorporated the meanings of other related words and concepts which emerged from the data. This participant first used the word in describing her responsibilities, stating, "I'm an administrator, my responsibility is to the bottom line--to the corporation..." Further in the interview, she stated, "...we have a good bottom line, we are not anywhere close to the red." Corporate bottom line is a term which connoted the financial picture of a health care system, or of a particular organizational entity within a system. It referred to the business aspect of health care delivery. Corporate bottom line strongly influenced the dimensions of players and of beliefs/values for these participants in defining their missions.

A number of participants alluded to the concept of corporate bottom line when they described their organizations. For example, one participant characterized her organization as "a predominant player in the [name of city] market, it's probably one of the most financially viable in that market, and so, a very progressive organization." Therefore, a good bottom line indicated financial viability, or survival, on the managed care battlefield. The converse of a good bottom line was conveyed by another participant, who asserted "that in this environment, a stand-alone system that does not have deep pocket resources, or is capital-rich, needs to partner with someone..." 
The relationship of the condition of corporate bottom line to other conditions was revealed in the interview text of one participant, who claimed, "...the executive leadership at the corporate level doesn't think like that, it's a dollars and cents organization, and not a relationship-driven organization." From this statement, the concept of corporate bottom line specifically meant money, and excluded the human relations aspects of running a business. The perception of this participant, that the business and human relations aspects of organizational life were conflictual, was important in understanding the interplay between the conditions of corporate bottom line and the players, and will become even clearer in the discussion on typology.

The Players

The "players" were simply people, or groups of people, who significantly impacted the participants' processes of defining their missions. While the term, "players," was used by some participants to describe more than just people, such as organizational entities, several participants used the term in different ways to describe people. For example, one participant, in making a specific point, stated, "...we are all players on the same team." As another example, one participant stated, during a discussion about decision-making, "I'm using some other players to assist me..." The term "players" seemed to fit best with an image of war games being played on the managed care battlefield.

The relationships between participants and certain groups of players significantly influenced how participants defined their missions. Players in this study included organization staff members, such as nursing staff; corporate-level staff members; and those with whom the organizations had contractual arrangements, such as physicians. All key 
players in this study were in some way impacted by the managed care environment, and/or the corporate bottom line. The overall impact of the managed care environment on key players, and the players' responses to the changing economic pictures of that environment, had a subsequent impact on how participants conceived of their missions and formed their professional identities, as well as their experiences with those identities. Perceptions of the impacts of the condition of players differed among various groups of participants, a finding which will be demonstrated in the next two chapters. However, the players which had some impact upon all participants were physicians and participant immediate supervisors, or bosses.

\section{Beliefs/Values}

Midway through data collection and analysis, what I began to hear from participant interviews, was that participants somehow had to deal with two competing aspects of organizational life; finances and human relations. Where they would position themselves, and see themselves as having the greatest degree of responsibility, involved some other internalized factors, which either served to shape their ideas about their responsibilities, or at some point in their careers had to change to accommodate changing responsibilities. These internalized factors, which include (a) being a nurse, (b) caring for the patient, and (c) having a balanced life, I chose to call "beliefs/values."

Being a nurse. The idea of being a nurse was a theme I intentionally tracked throughout this study, and several of my interview questions were designed to try and find out how the participants perceived themselves as nurses in the managed care environment. For example, I specifically asked questions about participant relationships with nursing 
staff. I also asked all participants how they came to serve in their current position. After the first interview, when one participant talked about a perception that nursing had been viewed as a "favored child" in her organization, I began to ask participants questions about how they thought they were perceived as nurses in their organizations and in their roles. I also began to pursue the theme of professional connections with the nursing community. There was a wide range of responses. Some participants viewed themselves as operating primarily out of a position as a nursing administrator, while others saw themselves primarily as health care executives with nursing backgrounds. There were differing degrees of distancing from what might be thought of as a traditional nursing administration role among various participants, a finding which was important to the discovery of a typology or classification of participants.

How participants saw themselves as nurses took on even more significance for this study in light of the fact that, regardless of title or job description, not one participant still had exclusive responsibility for nursing services or nursing care delivery in this study. They all held the position of top nurse executive in their organizations for the Joint Commission on Healthcare Organizations, and for the State of California Title 22 accreditation purposes. However, for some participants, nursing department responsibilities still comprised a majority of their time and energy, while others had responsibility for all patient care activities and all clinical operations in their facilities.

Several participants told me about the "multiskilling" efforts of their organizations, meaning that groups of employees had been cross-trained to provide a multitude of patient care services. These efforts were designed to cut organizational costs and improve patient 
care quality. However, each participant told me a story about how recent organizational changes had expanded her responsibilities beyond those of a traditional chief nurse executive role. Participants had either experienced the evolution of role expansion, or been brought into their organizations to transition their roles into ones of extended responsibilities. In essence, the participants themselves were multiskilled workers, as a direct result of organization restructuring efforts to improve the corporate bottom line by thinning out the management ranks. Economics had clearly triggered role expansion for all participants, and was forcing all participants, in varying degrees, to take the profession of nursing into some uncharted terrain on the managed care battlefield.

Being a nurse presented some participants with major challenges, depending upon which other conditions impacted them most strongly, challenges which had to do with power. One participant perhaps best captured this challenge:

...[nursing] started out as a servant-type of profession. You know, when you are a nurse, you're not doing the glamorous, you're doing the subservient and the care-taking, and it was the doctors [who] were the strong guys and the nurses were the weak ones.

A number of participants in this study believed that they continually had to strive to overcome key organizational players' stereotypical perceptions of nurses as weak, subservient, and incapable of serving in expanded health care roles.

For the large majority of participants, the extension of their organizational responsibilities to include more than the nursing department influenced their thoughts about being a nurse, but in different ways for different groups of participants. Telling me 
their official titles and lists of organizational responsibilities did not tell the whole story of how these nurses determined their most important responsibilities or viewed themselves as nurses. The beliefs and values regarding being a nurse were different, for different groups of participants, depending upon what condition or conditions (corporate bottom line, players, or beliefs/values) they perceived as having the greatest influence in determining their priority responsibilities.

Caring for the patient. Closely associated with the belief/value of being a nurse is the subdimension of caring for the patient. This subdimension emerged from the data. A clue to the importance of the concept came from one particular participant when we were discussing changes in her role. She stated: "Up until about a couple of years ago, I rarely got involved in cost issues directly with patients, and now it's not unusual to get complaints directly from patients about their bills." She then added, "I just feel that certainly takes us away from some of the nursing essence." If the essence of nursing has been centered on patient care, then I wondered about what the participants were really saying about patient care in relationship to their expanded roles.

All participants seemed to see themselves dedicated to the patient in some way. They all seemed to see themselves operating out of a concern for patient well-being in the form of quality care. For example, one participant talked about her role as "...a game that you have to win for the sake of the patients." Another participant wanted to make sure that during all the changes occurring in health care, "the patient doesn't get lost in the process." A third participant stated, "Im very passionate about what I do, and I think the issue about making a difference around patient care is what keeps me going." 
Some participants had a more direct relationship to the patients than did others. One participant told me, "...I have influence over patient care delivery, but I also still have my finger a little bit in the bedside." This relationship to the patients is different from that of another participant, who stated, "Im here to serve the people that care for the patient." For some participants, patients were called "customers," and other participants referred to the business of patient care in their texts, reflecting the impact of economics on ideas about patients. The differences in participants' perceptions about their relationships to patients, and beliefs about patient care, were influenced by the other conditions of corporate bottom line and of the players, as well as the subdimension of being a nurse. The discussion on typology will illuminate these differences.

Having a balanced life. The notion of "a balanced life" came up spontaneously, and early in the interview process, so I intentionally traced this theme in the remainder of the interviews. In many instances, I didn't need to probe for information about this subject, as a number of participants initiated the topic. The idea of a balanced life was introduced with this participant's comment: "Luckily I have a life that's pretty in balance. I think that's the key. You've got to have your own stress reducers...you've got to lead a pretty healthful life, to be able to come to work every day and put a smile on your face." Further on in the interview, she added, "You have to have support at home." All participants agreed with the importance of balancing their personal and professional lives. Exercise, nutrition, and support from family members and significant others were considered important factors for a balanced life. These were all factors external to the participant's work life. 
A significant impediment to having a balanced life for all participants was not having enough time to do all of their work, and, in the words of one participant, getting "bombarded from the time I hit the door [at work]." A number of participants responded to my question about barriers to job accomplishment with answers such as, "Time, you know, there's never enough of it, no matter how much you prioritize..." A majority of participants talked about having to spend excess hours either at work, or taking work home to complete. The issue of not having enough time in the day to finish both professional and personal responsibilities was brought up repeatedly by participants.

Some participants had multiple family responsibilities in addition to their work responsibilities, and all agreed that with the expansion of their professional roles, balancing their professional and personal lives was becoming increasingly more difficult. The issue of being a woman with multiple responsibilities surfaced in this subdimension. One participant described "the unfaimess of being a woman" in talking about the challenges of being a woman executive: "Women--it's tough for women...you still have your mommy role, your wife role, and your professional role and it's all a balancing act...the stress to me isn't the job at all." Another participant supported her comments:

I love my job, and I love being a mom, and the hours that you have to put in...it's not really understood by anybody....that may be the difference between the male and female environment. I think it may not impact some of my male counterparts quite as well.

The fact that balance became a major theme in this study introduced a new dilemma that study participants had to resolve. In addition to facing professional 
dilemmas, such as balancing the business and human relations aspects of organizational life, they had to clarify the boundaries between their professional and personal lives as part of finding a professional identity. A study conducted by Mulqueen (1992) helped put this particular dilemma into perspective.

Mulqueen (1992) conducted a qualitative seven year longitudinal study of four women educators, all of whom attained doctoral degrees during her study. The study was driven by Mulqueen's (1992) quest to explore the major contradiction between competence and femininity for American women. According to Mulqueen (1992), competence has been valued by society, but considered inconsistent with femininity. Competence is culturally defined in ways associated with masculinity, and society highly values competence, which makes taking on a self-definition of competence troublesome for women (Mulqueen, 1992). It provokes issues of gender ambiguity and places women in confusing social positions. Femininity, according to Mulqueen (1992), is culturally the result of sex-role socialization, and this socialization has placed many women in a real bind when they wish to assume traditional roles associated with women, such as mothering, and yet achieve the masculine ideals of competence in the work force. Society devalues those traits and behaviors which are not perceived as portraying competence, such as those considered to express femininity, and yet both are central to women in forming a sense of self-esteem (Mulqueen, 1992).

From her findings, Mulqueen (1992) concluded that by redefining competence and femininity, a path to balancing becomes established. She defined balance as a positive experience of competence for women. It involves a continual process through which 
women prioritize how to live their lives, over the content of their lives (Mulqueen, 1992). Balance is a value-laden concept that must be understood, according to Mulqueen (1992), as a woman's conscientious apportionment of time and commitment based upon her desires. Balance, involves redefinitions of competence and femininity. Mulqueen (1992) maintained that definitions of competence need to be changed from those which embrace masculine ideals of effectiveness and competition. Femininity needs to be changed to simply mean that if one is female, she is feminine, and the sex-role stereotypes about the meaning of femininity must be dropped (Mulqueen, 1992).

Because the participants of this study operated in a patriarchal world, in some way all participants had to assess how they would deal with the conflicting societal norms of competence and femininity as it pertained to their lives. Much of the discussion in the remainder of this chapter will revolve around feminist ethics, and an ethic of care in relation to this study, but from a professional standpoint. The subdimension of having a balanced life added the notion of caring for self in this study. Caring for self was intertwined with all the other findings of this study, and became important in helping to explain other findings.

From this study, there was variation among participants in how well they seemed to be balancing their lives. Variations seemed to align to some degree with certain categories of participants, and were influenced by certain other conditions. The interplay among conditions regarding the subdimension of having a balanced life will be described more fully in the typology section and in the next two chapters. 


\section{Defining the Mission}

The action/interaction component of this story was a process by which participants defined their missions and the leadership actions that would support their missions. This mental process involved considering their most influential conditions, or calls to action, and prioritizing their most important responsibilities as foci of their leadership actions. The leadership action was the tangible outcome of this process. The process of defining the most salient condition to serve as a focus of responsibility for some participants meant a reshaping of their perceptions of other conditions in order to fit with their missions. For example, some participants who viewed themselves as aligned primarily with the dimension of corporate bottom line in determining their missions, experienced significant impacts upon the subdimension of a balanced life.

The body of literature which best helped to explain how study participants determined their focal responsibilities and leadership actions, and consequently defined their professional identities, was that of feminist ethics. Bowden (1997) defined ethics as a process of mutual responses and adjustments, where the inherent relationship between the practical details of the process, and the ethical possibilities of the response, are continuously assessed. Manning (1992) viewed ethics as a study of morality. Morality, according to Manning (1992), encompasses the actual beliefs and practices which guide us in our decisions, and ethics is a way of clarifying our moral commitments. Ethics might be conceptualized as a test of our morality.

According to Bowden (1997), ethics must be understood as essentially contextual, and as arising out of the actual experiences of actual persons. Gender-sensitive ethics 
considers that impartialist theories, such as theories of justice, have regularly ignored the gendered ascription of specific social roles and concerns to different groups.

Gender-sensitive ethics means that while attention is paid to the specific relations in which women are characteristically involved, relations which have been traditionally omitted from moral philosophical thought, such as caring relations, attention is stretched to include a full realm of possibilities for ethical caring practices (Bowden, 1997).

Therefore, by asking the question one more time, "What 'all' is involved here?" (Schatzman, 1991, p. 310), ethics provided the key for understanding the action/interaction of defining the mission. As indicated by their responses, the participants in this study seemed to be continuously engaged in trying to make sense of their personal and professional beliefs and values against the external organizational influences of interpersonal relationships and corporate economics, in a male-dominated environment. The decisions regarding the most important moral commitments for these participants were evidenced by how they defined their missions and leadership actions, and by how they perceived themselves in their environments.

All 17 participants seemed to perceive themselves functioning in ethical organizations, and the importance of values alignment with the organization was stressed by more than a few participants. The most ambivalent written response to the study question of relationship with organization was, "cautiously optimistic." Several participants proudly asserted that they had chosen to remain in their organizations because of the core values of their organizations. An example of the strength of these convictions was exemplified by one participant, who described her relationship with her organization 
as, "thriving, supporting, energizing, aligned with personal values of social purpose." Participants seemed to see themselves acting ethically, in ethical organizations, and in ethical alignment with their organizations. However, there were big differences in how they prioritized their most important calls to action, and defined their leadership actions, and professional identities.

Gilligan, in her pivotal work, In A Different Voice (1982), concluded that "in the different voice of women lies the truth of an ethic of care, the tie between relationship and responsibility, and the origins of aggression in the failure of connection" (p. 173). The "hypothesis" that participants' assessments and responses to their calls to action might somehow be linked to an underlying ethic of care and responsibility, meant journeying into unknown territory, because the literature regarding the concept of caring and nursing administration is sparse. Nyberg (1993) pointed out that the concept of caring as it relates to nursing administration has not been well-defined, and measures of caring behaviors have not been well-defined for nurse administrators. She stated that while there has been agreement between academicians and administrators about the fundamental importance of caring in nursing administrative practice, the essence and enactment of caring in nursing administration is not known. One of the difficulties, according to Nyberg (1993), is that nursing administration involves management theory, which breaks down into planning, controlling, organizing, and directing, while human caring stresses societal obligation, intuition, and equality between the caregiver and the recipient of that care (Nyberg, 1993). There does not seem to be an easy reconciliation between the two aspects of management and caring. 
Ray, Didominic, Dittman, Hurst, Seaver, Sorbello, and Ross (1995) made an attempt at a conceptual reconciliation between economics and caring for nursing management. Ray et al. (1995) specifically addressed the paradox which exists for nursing managers confronted with promoting caring and the organization "bottom line" (p. 49). Ray et al. (1995) stated that, on one hand, caring has come to be appreciated as the essential interpersonal element in nursing. On the other hand, the new perspectives of managed care and managed competition in health care financing, which mandate specific and tangible economic measures to meet system needs, seem to neglect the interpersonal aspects of health care delivery (Ray et al., 1995). The authors contended that caring and the bottom line have to be interconnected by the innovative actions of nurse managers, and they offered some general strategies for how nurse managers might make ethical choices (Ray et al., 1995). Calling their model, "ethical economic caring," (p. 49), Ray and her colleagues (1995) did not address how it might be operationalized. Furthermore, by making the nurse manager the central character at the junction of economics and caring, their model seemed to assign culpability to the nurse manager if the integration of economics and care is not successful.

One of the reasons for the difficulty in assessing caring in the situation of the nurse executive is that the executive has to contend with the competition between two oppositional aspects of life in health care organizations, economics and humanistic caring, in a patriarchal environment. In our society, economics has become aligned with masculine interests. As already pointed out in the section on economics, health care economics was founded upon theories containing inherent gender biases against women in a world where 
the door to understanding and engaging in economic theorizing has been closed to women. Steinem (1994) pointed out quite well the exclusionary gender bias of economics, when describing her own "economics anxiety" (p. 199). She claimed that "economics is seen as a mysterious set of forces manipulated from above" (p. 199). Further on she stated, "Soon I became convinced that if I studied very hard, I might one day understand what was being done to me--but never how to change it " (p. 201).

Largely as a result of the pioneering work of Gilligan (1982), humanistic caring has been associated with women. Gilligan's (1982) work has had a powerful influence in providing an ethic of care for nursing practice. Cooper (1989) made a strong case for how compatible Gilligan's (1982) ethic of care is with nursing's philosophical and historical traditions of relational caring.

What was found in this study, is that the contemporary female executive nurses had to somehow resolve the issue of standing at the bifurcation between care and cost, and depending on the strength of certain values, or organizational influences, had to make decisions about how to proceed. They straddled a "division of moral labor," a phrase originally coined by Held (1995, p. 165), and expounded by Friedman (1995). This morality, characterized by gender polarization, has its rationale rooted in historic developments involving family, state, and economy (Friedman, 1995). Special and distinctive moral projects have been associated with each gender. Men have considered, as their privileged domain, the tasks of governing, managing, and relegating social order in public institutions, and women have been tasked with the maintenance of privatized personal relationships (Friedman, 1995). The dual result of the division of moral labor is 
that each gender has been prepared for a respective socially defined domain, and rendered incompetent to function in the exclusionary domain (Friedman, 1995). Therefore, being a nurse is acceptable for a woman. Being an executive who is a woman and a nurse creates confusion about one's appropriate moral place.

Friedman's (1995) discussion posed a cautionary note regarding the ethic of care and the participants of this study. There could be a tendency to claim that executive nurses, because they might not be predominantly involved in the type of interpersonal relationships associated with women and nurses, are not involved, or could not be involved in caring practices. To date, there is little scientific knowledge about how women resolve the issue of straddling the division of moral labor, since until recently, women have not been well represented in the upper ranks of management in public institutions, and almost absent in the upper ranks of health care administration. Bowden (1997) stressed that the pressing needs to recognize insights acquired from ethical practices typically associated with women can hamper the ability to adequately conceptualize all ethical limitations and possibilities of caring practices. In other words, caring, as it has been defined by nursing, may be inadequate to explain moral reasoning and moral behaviors of nurse executives with their wide array of responsibilities.

Several murse authors have criticized the application of the concept of caring to various nursing practices. Vezeau and Schroeder (1991) stated that in the mursing literature, the term, "caring," has been liberally used and discussed as if there is one universal meaning for the domain of nursing. McCarthy, Craig, Bergstrom, Whitley, Stoner, and Magilvy (1991) found that the emphasis upon what occurs between 
individuals in definitions of nursing caring, were inadequate to explain caring in community health nursing practice. They proposed a redefinition of "person" to mean "community," as well as redefinitions of the other paradigm concepts of environment, health, and nursing.

According to Vezeau and Schroeder (1991), any discussion involving caring should always address the question: "Caring, according to whom?" (p. 1), since multiple authors have defined caring in a multitude of ways. This question became cardinal in trying to make sense out of the typology which emerged from the participant data in this study.

After tying together the data analysis and the review of the literature, I came to believe that the idea of an ethic of care was involved in this study in some way. However, the way in which data formed into four unique participant categories, suggested that either participants might be exhibiting different caring practices, or that some participants' moral decisions could not be explained by an ethic of care. Bowden's (1997) philosophical work on gender-sensitive ethics was very helpful. Bowden (1997) took issue with descriptions of ethics of care which center on predetermined principles of caring rather than on actual practices of caring. By "loosening the hold of perspectives that endorse a static, determinist view of the ethical possibilities of caring" (p. 18), Bowden (1997) claimed that we can extend an understanding of caring to a wide array of practices. Based upon Bowden's (1997) work, and the articles in the nursing literature by Vezeau and Schroeder (1991), and by McCarthy, Craig, Bergstrom, Whitley, Stoner, and Magilvy (1991), my contention was that caring could provide a clue in understanding participant responses, 
but that caring practices might not necessarily be those which have been associated with nursing.

Chinn (1994) stated that the human potential to care is like the human potential to be authentic in that neither conform to specific classifications. Caring can be envisioned, imagined, experienced, learned, nurtured, brought forth, and inspired according to Chinn (1994). By considering caring as a human potential (Bowden, 1997; Chinn, 1994), in a wide array of practices (Bowden, 1997), but understanding that ethics is fundamentally contextual (Bowden, 1997), a gender-sensitive approach in assessing participants' decisions about most important conditions and subsequent leadership actions could be used. That approach entailed a conscientious assessment of the specific cultural and socio-historical conditions which influenced how participants would resolve straddling the division of moral labor in all battlefield positions in a patriarchal environment.

One study was found which was helpful for explaining the typology of this study, and how it relates to feminist ethics. Jack and Jack (1988) conducted a qualitative study of female lawyers in order to explore the moral perspectives of women in a traditionally masculine role. From their data, they found three types of women lawyers, each of which had decided in a different way how to fit the caring self into the life of a practicing lawyer (Jack \& Jack, 1988). Some of their findings are similar to the findings of this study, and will be referenced throughout the next two chapters.

\section{Battlefield Position/Professional Identity: The Heroines}

The consequences of defining a mission, figuring out the most important responsibilities and determining the leadership action, were professional self-definitions for 
these participants. I chose "professional identity," because a majority of participants emphasized that they no longer had exclusive responsibility for nurses, the nursing department, or nursing services. The experience of serving in a particular battlefield position (professional identity) was also important in this study, and had much to do with the interplay among certain conditions. For example, some participants viewed themselves as "Champions," with an allegiance to the corporate bottom line. Many of these Champions shared with me the conflicts they had with physicians who could not accept them carrying out their missions from such a position. Therefore, if certain players on the battlefield had difficulty in accepting the battlefield positions of certain participants, then conflicts arose between the participants and those players. The discussions on typology elaborate extensively upon the dimension of battlefield position/professional identity.

I chose the term "heroine" to describe the participants of this study for several reasons: (a) it was part of an "in vivo" code in the data; (b) it conveyed my tremendous respect for all participants, but (c) it also communicated deeper messages highly relevant to this study. This term gave full credence to the subtle pervasiveness of gender polarization and androcentrism in our society. One dictionary definition of "hero" is "an illustrious warrior" (Mish et al., 1984, p. 566). A heroine is defined as "a mythological or legendary woman having the qualities of a hero," (Mish et al., 1984, p. 567), and also, "a woman admired and emulated for her achievements and qualities" (Mish et al., 1984, p. 567). Gender ambiguity regarding heroines was evidenced by these two definitions. Heroines merit praise when they are able to successfully emulate the male qualities of a warrior, yet they are recognized for having their own qualities and achievements. 
However, a hero is admired for his "noble qualities" (Mish et al., 1984, p. 566), whereas heroines just simply have qualities. Furthermore, one definition of "noble" is: ...possessing, characterized by, or arising from superiority of mind or character or of ideals or morals..." (Mish et al., 1984, p. 800). Combining all these definitions, the dictionary has told us that heroes are noble and that heroines, although they may have good qualities of their own, are only noble when they mimic heroes. The implication is that heroines can not be moral and superior in their own right. Even the dictionary contributes to the division of moral labor.

The numerous military and warfare references made by study participants indicated a subconscious awareness of functioning in a male-dominated society. They were courageously forging new paths for nursing leaders on the managed care battlefield, but regardless of what course they took, these heroines, as women and nurses, would never be perceived by the society of heroes, or strongman elite, as equal.

\section{A Typology of Heroines on the Managed Care Battlefield}

This section introduces the typology that became evident during data analysis. I found that there were similarities and differences among certain participants in the way they prioritized their calls to action and perceived themselves as health care professionals. Although all participants had in some way been influenced by health care economics, their beliefs and values differed, as did their perceptions of the organizational influences of finances and people. I found that certain groups of participants had similar perceptions of the most influential conditions, leadership actions, and professional identities, which subsequently resulted in a classification of participants. Figure 2 shows the typology which 
Figure Caption

Figure 2. The typology of heroines based upon the dimensions of defining the mission and battlefield position/professional identity, and the typology continuum. 


\begin{tabular}{|l|l|}
\hline Defining the Mission & \multicolumn{2}{|c|}{$\begin{array}{c}\text { Battlefield Position/ } \\
\text { Professional Identity }\end{array}$} \\
\hline $\begin{array}{l}\text { Moving Nursing } \\
\text { out of the } \\
\text { Ivory Tower }\end{array}$ & The Unsung Heroines \\
\hline Finding Middle Ground & The Engineers \\
\hline $\begin{array}{l}\text { Building, Caring for, } \\
\text { and Feeding the } \\
\text { Team }\end{array}$ & The Team Leaders \\
\hline Growing the Business & The Champions \\
\hline
\end{tabular}

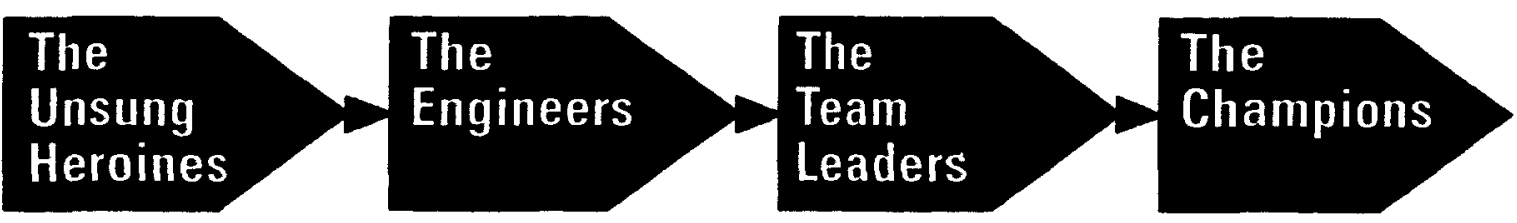


was synthesized from participant data, and how that typology formed into a continuum of participant battlefield positions/professional identities.

I discovered four unique groups of participants. Essentially, what distinguished groups from each other were differences in the way in which participants of a particular group defined their responsibilities, or primary moral commitments. Their leadership actions and professional identities were essentially demonstrations of different ethical beliefs. These dimensions portrayed how the participants made sense out of the dilemmas of cost versus care, and of competence versus femininity. Essentially, the participants were demonstrating how they responded to the gendered division of moral labor in their work settings. The similarities and differences between groups of participants were related to the types of organizations in which they worked, but not to integrated systems. The participants who worked in the same health systems, but in different organizational entities, did not match in the way they were influenced by certain conditions. For example, two participants worked for the same for-profit corporation, and their responses were very different, placing them in very different classifications. Additionally, participant demographics such as age, experience, and education, lent only weak explanations for the typology.

The typology consists of four classifications of participants, or heroines. The titles for each professional identity came out of participant "in vivo" codes, and include: (a) "the Unsung Heroines," (b) "the Engineers," (c) "the Team Leaders," and (d) "the Champions." 
There are several points I wish to emphasize about the typology which was formed out of this study. First, for the sake of discussion, I will present the findings in a somewhat linear fashion, but the process of discovering this classification was not so orderly. Methodology and analysis were intertwined. I first had a sense of how the consequences and leadership actions differed among various participants while I was still analyzing which dimensions were the conditions for this study, and my sense that there were unique differences between groups of participants was first triggered by my evaluation of my relationships with several of the participants. My discovery of a typology began somewhat intuitively, but was supported by the data. Second, placing participants into categories is an artificial process. While I will discuss the particular data and dimensions which were highlighted in certain classifications of participants, all participants in some way could be viewed in all categories. I do not wish to imply that participants were totally bound up within a particular category in the way they perceived of themselves or functioned. Synthesizing a typology simply meant that based upon the data, derived from the interviews I had with participants at a particular time and place, and written materials returned to me from participants, I found stronger support for certain dimensions and concepts among certain groups of participants.

The typology which emerged from the data in this study seemed to represent a continuum of participant professional identities as shown in Figure 2. The Unsung Heroine participants seemed to be relatively stable in their environment, comfortable in their positions, and not as influential in their organizations compared to other participants. They maintained strong affiliations with their nursing backgrounds. The Engineer participants 
were caught up in a chaotic environment, trying to respond to multiple forces, but more influential within the organization compared with the Unsung Heroine participants. Engineer participants maintained strong ties to their nursing foundations, but to a lesser degree than the Unsung Heroines. The last two groups, the Team Leaders and the Champions had more organizational influence and they were more settled in terms of their roles. They seemed to have resolved the dilemma of trying to meet the human relations needs and fiscal needs of their organizations by aligning with one aspect or another. The Champions, who aligned predominantly with the fiscal aspects of organizational life as a group, seemed to have more organizational influence than other participant groups. Both Team Leader and Champion participants exhibited the weakest nursing identities compared with the Unsung Heroine and Engineer participants.

\section{Summary}

The participants, or heroines, in this story faced a challenge of taking nursing executive roles into new territories as a result of health care economics. To do so, meant shaping and reshaping their professional identities in order to assume their battlefield positions, in the context of the managed care battlefield. They made sense of their realities by considering three salient conditions: corporate bottom line, the players, and their beliefs/values. These conditions served as their calls to action. Their perceptions of the interplay among various calls to action helped them prioritize their calls to action, and determine their most important responsibilities. Through a process of prioritizing, they determined their priority moral commitments and subsequent leadership actions in defining their missions. The way participants defined their missions determined their battlefield 
positions or professional identities. Their experiences in those positions depended also upon the interplay among the three core conditions. The heroines formed into four distinct groups by the way they defined their missions and battlefield positions.

In the next two chapters, I discuss in-depth the typology of heroines which emerged from this study. Chapter Five concentrates on the two participant classifications of (a) the Unsung Heroines and (b) the Engineers. Chapter Six focuses on (a) the Team Leaders and (b) the Champions. 


\section{CHAPTER FIVE}

\section{AWAKENING AND CHAOS: THE UNSUNG HEROINES AND THE ENGINEERS}

The typology continuum begins with the Unsung Heroines, followed by the Engineers. Therefore, this chapter breaks into two major sections, and first discusses the (a) Unsung Heroines and then the (b) Engineers. Each section breaks into subsections including (a) a brief introduction to the particular classification; the (b) conditions, or calls to action, beginning with the most influential condition; the (c) processes of defining the mission and the leadership actions; and finally the (d) the professional identity/ battlefield position and associated experiences. This chapter concludes with a summary of these two classifications.

\section{The Unsung Heroines}

Only two participants were considered to be unsung heroines. The term "unsung heroines" was taken from the interview data of one participant who told me, "...I just think that CNOs are generally, unsung heroines, or heroes." Compared with interview data from other participants, interview texts from these participants were peppered with references to themselves which included, "CNO," "nurse," "nursing administrator," "nursing essence," and "DON" (director of nursing).

\section{Beliefs/Values: Being a Nurse}

The subdimension of being a nurse seemed to be most central in prioritizing responsibilities for these participants. They expressed their sentiments about being a nurse 
most clearly and most enthusiastically compared to other participants. One participant stated: "I love nursing with a passion. I wouldn't want to do anything else but nursing." The other participant proclaimed: "I just-nursing is it, and it's been something that I've just loved, and you know, I still love it today,..." She also affirmed her alliance with nursing in talking about meetings with other organizational leaders: "Nursing is there, so I sit at that table."

The notion of being a nursing administrator seemed for these participants to be an addendum to being a nurse. One participant added to her statement, "I wouldn't want to do anything else but nursing," with the following comment: "I have organizational skill, I speak well,...for whatever other odd reasons, people think I'm a manager and/or leader. And I've just been struggling with it ever since." The other participant mentioned, "I never thought I would be a nursing administrator. I just wanted to be a nurse." Further in the interview, she stated, "I just loved nursing administration."

Close connections with their nursing foundations were implied by both participants. One participant believed that she was perceived by the nursing staff as a "nurse advocate." She also mentioned that she got involved in some "direct care, clinical issues, "more-so probably with the charge nurses as well as the nursing directors," and "occasionally with the staff nurses." The other participant thought the nursing staff would perceive her as "knowledgeable about nursing," and as "caring about what's happening as far as nursing..." These participants valued being seen as having connections with clinical nursing practices and with clinical nursing staff in enacting their roles. 
Being a nurse did present challenges for these participants in their administrative roles when they had to deal with physicians. Interactions with physicians could be difficult because, "they still see you as a nurse...you're still a nurse, you're still a woman." Being a nurse for this category of participants, as well as for other categories, carried the stereotypical baggage of nurses as subservient to physicians. The long history of nursing's subservience to physicians (Ashley, 1976; Bowden, 1997; Reverby, 1987) somehow carried over into the contemporary lives of all participants in this study.

\section{Beliefs/Values: Caring for the Patient}

The subdimension of caring for the patient also was an important influence for these Unsung Heroine participants in defining their missions. Interview data from one participant in this category revealed a close connection to patient care via the role of being a nurse. This participant claimed, "I'm the only one that speaks for patients from a clinical side. Everybody else is either 'admin,' or monetarily specialized, and unless a doctor is there, the CNO is it." She also talked about the "nursing essence," in dealing with patient issues, believing that having to get involved in reimbursement issues with patients detracted her from the "nursing essence." This participant implied, that from the perspective of a nurse who advocates on behalf of patient care, economics should only play a small role.

\section{Beliefs/Values: Having a Balanced Life.}

Based upon the interview data, the subdimension of having a balanced life was very important to the participants, and both seemed to be experiencing lives very much in balance. A healthy lifestyle, humor, and support from husbands were some factors which 
helped them to achieve and maintain a balanced life. Their success in maintaining a balanced life could be evidenced by their tenures of 16 and 20 years in top nursing leadership positions.

Despite the fact that gender discrimination was experienced by both participants, primarily because of their allegiances to being a nurse, both participants seemed to have come to terms with the potentially conflictual aspects of competence and femininity as described by Mulqueen (1992). They saw themselves as competent and content in their nursing administration roles, and seemed to be managing full personal lives. Caring for self was as important as caring for the profession and the patient for these participants.

\section{Corporate Bottom Line.}

These participants seemed to be more on the receiving end of organizational changes related to economics, with less direct involvement in cost issues, when compared to other categories of participants. One participant shared that as a result of changes in the cost structure of her organization, two management positions which had reported to her had been eliminated. Her involvement in recent organization-wide changes consisted of being asked for "assistance and ideas and all those kind of things as far as in the planning and implementation phases of it." The other participant shared, "unless there's an issue about the patient stay, which is focused on an economical side, I don't get involved in the 'nitty-gritty' too often."

\section{The Players}

The participants in this category did experience the impact of economics and the corporate bottom line via the behaviors of some key players. These players include 
physicians, and "the corporate gurus." Only a few comments were made about the immediate supervisor, or boss.

One participant described how organizational changes which impacted the physicians, in turn affected the nursing staff. Because lengths of hospital stays for patients had been shortened in order to comply with payor guidelines, she stated that "doctors are in and out of the hospital all day, all aftemoon, all evening....In fact, if anything, we have to be careful that they're not discharging them at 11 p.m. and 12 midnight, because that's inappropriate."

This participant's response represented the first of many responses by participants in all classifications about how the impacts of economic changes on physicians were subsequently impacting the lives of participants and their staffs. The situation described by this participant provided an interesting twist to a discussion by Kalisch and Kalisch about nurse-physician conflicts, published in 1977 . These authors talked about the two systems of authority to which hospital nurses had to respond, which were especially problematic when the systems had overlapping jurisdiction. Conflicts arose when one system was dedicated to the maintenance of the operation of the organization, and the other dedicated to the provision of service. Conflicts arose when dual orders contradicted each other, and the nurse was left to resolve the conflict (Kalisch \& Kalisch, 1977).

Reverby (1987) talked about how the urbanization of industrial capitalism, combined with changes in medical practices and education, transformed hospitals into revenue centers to sell nursing and medical care. The physician historically stood at the economic helm of health care. Bowden (1997), in describing impediments to nurse caring, 
talked about how the economic interests of physicians resulted in the erosion of nursing's culture of female obligation into one in which wifely obedience to male doctors became the expectation. However, in this case in this study, the physician was not at the economic helm, but caught up in service to the contracting organization. The nurses were still caught in the middle between service to the patients and to the organization. They had accountability to provide care to patients despite continuous interruptions in their schedules, and also to respond obediently to physician orders. In this case, the conflict was not about two competing lines of authority, it was about the conflict raised when the two lines of authority converged in deference to economics, and not for the benefit of nursing or patient care. The nurses were left alone to respond, not an uncommon situation when nurses are caught between the institution and the patient regarding their loyalties, according to Bowden (1997).

This same participant talked about how decisions made by the "corporate gurus" impacted the hospital staff, and patient care. She described one of the barriers to accomplishing her job as "having a good or better data information system within our institution....that includes order entry on the floors." She added: "Smaller hospitals have not...had the luxury of those capital dollars, it's a little harder to convince the corporate gurus that we need it even though we're small."

This participant's comment exemplified a long tradition of nursing's political weakness, which can be ascribed to an ideology of duty, obedience, and submission, and a long history of cultural subordination (Bowden, 1997). Political weakness presents an impediment to caring practices, by preventing nursing departments from getting a fair 
share of organizational resources. Hospitals have benefited from selling nursing care (Bowden, 1997; Reverby, 1987), but invisibility in billing has made nursing care the most obvious source of cost control, and the most disproportionately constrained by system budgets (Bowden, 1997). A statement made by Steinem (1994), in her discussion on economics, summed up the whole scenario for these participants: "Work is valued by the social value of the worker" (p. 210).

There was a sense from both of these participants of the isolation of nursing staff in relation to other organization staff, which would make competing for scarce resources difficult. The term "unsung heroines," coined by one participant, conveyed a lack of organization-wide recognition for nurse administrators. She explained her use of this term: "I do think that very few people, even those in the hospital administrative ranks, do not realize the complexities of nursing administration." The other participant claimed that prior to her employment in her organization, "the nursing department was seen as kind of like an ivory tower, and no one could touch it..." She also described the nursing department as a "sacred cow."

The comments of several participants of other categories shed light on the meaning of nursing as existing in an "ivory tower." One participant commented that in her organization, nursing had been perceived as a "favored child," meaning that nursing always got the most resources. From the comments of other participants, being viewed as a "favored child" or "sacred cow" in an "ivory tower" led to a sort of organizational backlash in competing for scarce resources. The nursing department, which usually had the greatest number of full-time equivalent positions (FTEs) according to several 
participants, could become a ready target for economic cutbacks by administrative staff of other departments.

The alienation of the nursing department from other health system departments dates back to the times of Florence Nightingale and Victorian thinking. Nightingale, herself a victim of Victorian thinking, has been credited with perpetuating gender separation among the health occupations (Baer, 1985; Bradley, 1989). By asserting that nursing was an expression of femininity and an extension of mothering, she initiated and supported the idea that nursing was an exclusively female profession (Bradley, 1989), devoted to domestic labor (Baer, 1985). More than a century after the establishment of organized nursing services by Florence Nightingale (Baer, 1985), the terms "favored child," "sacred cow," and "ivory tower," all attested to the continuing stereotype of the nursing department as being female, separate, invisible, and subordinate in relationship to other hospital departments.

\section{Defining the Mission: Moving Nursing out of the Ivory Tower.}

The condition of most influence for the participants who most strongly fit with the Unsung Heroine classification, was beliefs/values, and in particular, the subdimensions of being a nurse, and caring for the patient. All other conditions seemed to influence the participants via the subdimension of being a nurse. Therefore, the priority responsibility in defining the mission for these participants seemed to focus on the condition of being a nurse, but with an intention of making the nursing department more visible within the organization. To make nursing more visible meant moving nursing out of the "ivory 
tower" of isolation, as already described, in its relationship with all hospital departments. One participant summarized this mission:

...I want to see nursing seen in good light and all that sort of thing, but I also want to make sure that [nurses] don't see that it's a persona non-touchable kind of thing...this is a sacred cow kind of thing, because I think that...nowadays, nursing can't stand alone by itself.

The other participant supported the sentiment of needing to extend the image of nursing in the eyes of other organizational players when she stated that physicians needed to "grow up" in accepting her in an administrative role. The subsequent leadership action for these participants, primarily committed to advocating for nursing and patient care, involved making nursing more visible to other organizational players. In essence, participants perceived the need to shed the shackles of Victorian thinking about nurses and nursing.

The Unsung Heroines seemed to be responding to an ethic of care. Their primary stimuli consisted of the nursing profession and direct patient care; care provided by nurses. They also managed to sufficiently care for self. Compared with participants of other categories, the sense of caring for the organization was not as strong. Not directly involved in direct patient care, their leadership actions were largely the result of nurses caring for nurses and nursing.

\section{Battlefield Position/Professional Identity: The Unsung Heroines.}

Both Unsung Heroine participants experienced a great deal of satisfaction in their roles. One participant perhaps best summarized the sentiments of both participants about serving in a nurse executive position: "It's been a fabulous ride, even with it's bumps 
(laughing)....It's given me my greatest highs and my greatest lows....I would never have done anything else."

As the following discussions will show, of all groups of participants, the Unsung Heroines maintained the closest affiliations with their nursing foundations and with nursing staff, and they seemed to be more on the receiving end of organizational economic practices via key players. Although their official titles in their organizations did not include the word "nursing," during the interviews they referred to themselves as a "CNO," (chief nursing officer) and as a "DON" (Director of Nursing). Although they seemed to view themselves serving in a somewhat traditional nursing executive role, both participants had experienced recent organizational changes, and were beginning to extend their responsibilities to include more than nursing administration as a result of these changes.

The term "unsung heroine," coined by one of the participants, presents a picture of a nurse executive, deeply committed to nursing and patient care, but with a weak voice regarding economics on the managed care battlefield. The participants of this classification seemed to have only an emerging awareness that they, as advocates for nursing and patient care, were impacted by the decisions made by others regarding resource allocation, and that the nursing department needed to increase that voice within the organization. The Unsung Heroines did not straddle the division of moral labor, they stayed on the side of humanistic care, but one of them was beginning to think about how to redefine that care in the context of pressures from the opposing side of economics stating, "the more you share [as nurses], and get involved in other areas, the more your value is for the organization." 
However, the other participant provided contradictory statements. She described having "a problem" with the organizational structuring of her position. She was the only member of an administrative team in her organization who reported through someone else to the CEO (chief executive officer), but she stated that her unique reporting arrangement worked well because of the person to whom she reported. In a later written response to me regarding her relationship with her organization, she stated: "Excellent. Best organization I've ever worked for and that is primarily due to the excellent relationship with all members of the Administrative Team....I like to think I deserve them, and they deserve me." By this statement, she seemed to be denying allegations made during her interview regarding discrimination against nursing, indicating that perhaps she had only a partial awareness of her oppressive circumstances. The other possibility was that after reading her own interview transcript, she wished to portray herself in relation to her organization in a more favorable light.

The conflicts experienced by these participants in their positions seemed mostly to be physician-related. One participant claimed, "I think nursing has had long-term friction with the physicians, physicians wanting control." However, this group of participants still viewed themselves as responding to physician needs in a somewhat traditional and deferent way as exemplified by, keeping "them abreast of what's going on," and "if I don't know the answer, or can't handle things, [the physicians know] IIl get it to the right person." From these participants' statements, the physicians were still largely viewed in a "captain of the ship role" (p. 52) as described by Kalisch and Kalisch in 1977, and participants did not seem to be challenging that perception. 
This conflict of being a nurse and a woman, and dealing with physicians, came up for a majority of participants. However, with this group of participants, the control issue seemed a more traditional one, and less acute, when compared with data from other categories of participants; participants who were more directly influenced by corporate bottom line and organizational players. The impediments in advocating for nursing care were largely those which have been described extensively in the literature as being impediments to the provision of nursing care by clinical practicing nurses (Ashley, 1976; Bowden, 1997; Kalisch \& Kalisch, 1977; Reverby, 1987). For the Unsung Heroines, the conflicts experienced by the nurses involved in direct care seemed to have just reached an additional layer in the nursing administrative hierarchy.

The Engineers

Three participants exhibited similarities which placed them in classification of their own. However, this was the most difficult group to understand, and yet the most important in understanding the battlefield positions/professional identities of other participants. In many ways, they were a hybrid group of the other groups, at times able to define their missions differently to fit different situations. At various points during data analysis, each of the three participants seemed to fit with other classifications. Whereas certain conditions stood out as most salient with other participant classifications, all conditions competed for attention with this group, and I found some mixed messages as I tried to figure out how to define each condition based upon what these participants were telling me. The competition among all conditions was triggered by economics. Therefore, 
discussing conditions in a sequential fashion from most salient to least salient was not possible for this group.

Searching the data for clues to their identities was not easy. At one point, I almost thought that they had not yet defined their identity on the managed care battlefield. However, one comment from one participant shed significant light for understanding this participant group. In talking about the impact that managed care was having on the nurse executive role, she said:

Well, the effect it's had today is to reduce the cost of care.... The effect that it has in the future could be even more disastrous, if the staff nurse at the bedside isn't brought forward to better understand what's going on in that environment. And, that will be problematic, so, how do you find balance in trying to engineer that correctly I think is the skill set that we need....I think it's trial and error now every year.

Essentially, these participants were engineers, but engineers in the social sense. The term "engineer" as it applies to these participants does not convey the commonly accepted definition of "engineer" as one who is "a designer or builder of engines" (Mish et al., 1984, p. 412). The dictionary definition of "engineer" which applies to this participant group is, "a person who carries through an enterprise by skillful or artful contrivance" (Mish et al., 1984, p. 412). For this group, "engineering" meant "the calculated manipulation or direction (as of behavior) (social )..." (Mish et al, 1984, p. 412). These participants were trying, through skillful management, to find balance among all of the conditions which seemed to be exerting an equal influence on them. 
The essence of the texts from these participants was a little different from those of other participants. The emotional tone coming from the narratives of these participants was one of more anxiety and uncertainty compared with other groups. Additionally, while references to war were numerous among all study participants, there was a particular concentration of them in data from these participants. Words such as "battles," "sabotage," "battlefield," "political landmines," "slash and burn" were used by these participants as they shared their experiences with me.

\section{Corporate Bottom Line}

Compared with the participants classified as Unsung Heroines, the Engineer executives experienced a more direct link with the corporate bottom line, although there seemed to be differences in the financial pictures of their organizations. In two cases, the organizations seemed to be viable, but in one case, the financial picture of the entire health system reflected "a downward spiral." However, all three participants were faced with trying to figure out how to "do more with less." All three were somehow engaged in the battle of competing for limited resources. In discussing the impact that managed care was having on her role, one participant shared:

It has a couple of direct impacts. One is certainly trying to figure out where the money is going to come from, especially when you look at any nurse executive usually has the largest...expense base and generally not a big revenue base. We just finished taking out four million dollars out of the expense base, and we are charged with taking out a few more million. 
Another participant told me, "..I think probably the biggest thing that most of us are facing is the...financial predicament of most hospitals is not what it used to be, and constantly faced with that challenge of...trying to do more with less." She later shared with me the difficulties of being in her position in a small specialty hospital, where services such as supply, housekeeping, and dietary were contracted from a larger health care organization. She told me: "Having the shared services relationship is difficult. We're not perceived [by the contractor] necessarily as valuable..." She went on to mention that her organization was "not a huge revenue generator, it tends not to be a big area of focus," and further on, "So one of the things that I'm often faced with is making sure that they don't forget [her organization]." The third participant told me that in her facility, "It becomes more and more difficult to manage your costs, to manage the care--the quality care that you're trying to deliver."

Confronted by the challenges of doing "more with less," several participants implied that they weren't sure how much longer they would be able to successfully meet the challenges. One participant told me that she thought she had done a fairly good job in cutting costs, protecting employees, and protecting quality, stating, "I think I'm a pretty good salesperson. But I don't know how much further I can come with that." Confronted with another round of financial cutbacks, and trying to achieve the same end result of good quality care with "less expensive people," she claimed, "Pushing the envelope on this is a little bit different. I'm a little bit questioning, how much more we can push the system." Another participant, who had designated responsibility for adequate staffing and 
supplies, as well as for "planning, preparing and presenting an annual budget," shared a similar concern:

I'm concerned. I don't know where things are going, and I see everyone working so hard and furiously to stay ahead and do more with less, and to have fewer people to do what you have to get done, and...I often wonder, where will it end? What will be the breaking point?

\section{The Players}

The group of players that had the largest influence according to these participants were the employees for whom they had designated responsibility. These players included both nurses and non-nurses, and in many cases consisted of organizational staff members responsible for some clinical aspect of patient care delivery. Of all groups of participants, the impacts that economic cutbacks were having on the lives of organizational employees seemed to be most acutely felt by these Engineer participants. One participant captured the pain:

If you take the general housekeeper, or you take the nursing assistant, or the transport orderly, who has been here 15 years and say, "We're not going to do the same [promotions and benefits] for you in the future, " the whole walls just caved in. How do you keep that employee focused? It's very tough. Very tough. Motivating employees, when "the whole walls just caved in," was also impacting patient care from another participant's text: "I think as people [staff] feel they're more and more pressed, to put out more and more, they become less inclined to be friendly with the patients, and that's very frustrating to me." 
Another group of players influenced several of these participants in defining and carrying out their missions. Competition among senior-level administrative staff in the organizations particularly impacted two participants, and trust became an issue. One participant attributed the lack of trust to "a bureaucratic environment," claiming that "people who work in them don't trust each other, they don't cooperate..." In the face of severe economic cutbacks, in an organization which did not have an "infrastructure" to encourage group decision-making about scarce resources, I was told that, "behind the scenes, everybody's playing a game to try to hang onto their job," and there's a good bit of "sabotage that goes on." Another participant commented, "I would say, in times of increased workload, people's trust tends to decrease at higher levels in the organization." For these two participants, lack of cooperation among senior staff meant, in the words of one participant, "you really, in each department, are almost trying to figure this out in a solo attempt, which is not...pleasant, it's very difficult to do."

This isolation was not the "ivory tower" type of isolation mentioned by the Unsung Heroine participants. Nursing cuts were not perceived as the only financial solution for organizational survival. The impact of economics on participants' organizations had triggered intra-system competition. Economics had actually contributed to a climate of competitive egalitarianism, where all system departments had an equal opportunity to be chosen for financial cuts.

The issue of trust in the physician community, directly related to economics, impacted one participant. She conveyed that she believed the physicians were having a "very difficult time with all the changes that are happening, and that's pretty specifically 
related to managed care. They're fighting, it's become a lot more competitive." One of her responsibilities in role as quality assurance coordinator was to make sure that "the quality process doesn't become a battleground for competing physician groups, " and that the cases presented, as part of the physician quality peer review process, were "based on what's really happened, and not who the practitioner is."

Policing the physicians in this way added a new perspective to the article about nurse-physician conflict by Kalisch and Kalisch (1977). The issue in this case did not involve the power struggles which have traditionally occurred when nurses question physicians about their clinical decisions as described by Kalisch and Kalisch (1977). The participant in this case had entered a new realm of responsibility for resolving physician-physician conflicts and issues involving physician professional ethics, which has traditionally been out of bounds for nurses.

Physicians impacted another participant, not so much because they were competing against each other for the hospital's business, but because, quoting from this participant, these "old guard physicians" felt "they've built this house--this hospital--brick by brick, and it's their hospital, and they'll tell us how to run it, and they'll tell us what to pay the nurses..." These physicians, were "just now beginning to realize that there is health care reform out there," and "it [was] very scary to some of them." They caused significant problems for this participant when they tried to have a nurse manager fired for no apparent reason, and wouldn't discuss the reason with the participant. These physicians might have been acting out in response to fears about economic changes, and the nurse executive 
became the target of their frustrations. A similar situation will be discussed in the section on the Team Leader participants.

The boss, or immediate supervisor had varying degrees of impact on these participants. Two of the participants had praise for their bosses, and the bosses provided support for them in making sure their concerns were appreciated at the corporate levels. One boss (a male) was extremely influential in resolving the conflicts the participant was having with physicians, and had brought in an outside consultant to facilitate communication between the participant and the physicians, leading to improved relationships. Another participant's boss (a female), shared with the participant, the stress of competing with larger system facilities for a fair share of resources, and the participant considered her working relationship with her boss to be good. The third participant had a "good working relationship" with her boss (a female), and mostly talked about keeping her informed of situations. This participant, because of her institution's particularly tenuous financial situation, also had direct report responsibilities to several other organization temporary senior staff.

\section{Beliefs/Values: Being a Nurse.}

Data from these participants revealed a close affiliation with nursing, and nursing staff, but contained some mixed messages. The texts of two of them contained a number of references to the "nurse executive," and one participant seemed to see herself as a nursing administrator with many operational responsibilities in her role as director of patient care. 
Strong connections to nursing were displayed in data from all participants. One of the participants, in her role, "still [had] her finger a little in the bedside," in that she was able to make patient rounds and, on occasion, perform clinical nursing duties. In responding to several general questions, two participants spontaneously answered with responses which focused on nursing. In response to a question about her ability to impact change within her organization, one participant talked almost exclusively about nursing personnel. Of interest, this participant had oversight responsibilities for half of the hospital departments, including the pharmacy, yet she proudly described her impacts upon nursing staff. She believed she had fostered the growth of nurses by involving them in finding better ways to staff the units. She also talked about the members of the Nurse Practice Committee at the hospital as a group of "movers and shakers" in making change.

The other participant, in responding to what advice she would give to a new nurse executive, directed the conversation to what she believed about the staff nurse of the future. In her opinion, the nurse of the future should be, "The most articulate, the most clinically savvy, the most knowledgeable person there is, in the health care delivery system." She added, "with a touch of business thrown in, they could take health care where it needed to go." All three participants seemed to be proud to be nurses.

The same participant who emphasized the attributes of the bedside nurse of the future, also claimed that "nursing needs to change its focus." She offered her opinion about nursing: "I think we got into a trap when we always talked about the nursing department. It's a patient care department. These are patient care floors." 
These participants seemed to follow the Unsung Heroine participants on the typology continuum regarding the subdimension of being a nurse. They differed from the Unsung Heroine participants, because although they spontaneously talked about the nursing profession in their narratives, they also talked about their responsibilities for other personnel in addition to nurses.

Being a nurse for two of these participants had specific connotations regarding nurse-physician relationships. As previously described, one of these participants had been involved in a power struggle with physicians regarding nursing personnel, and laughingly stated she was now, "just trying to train 'em not to call me the Head Nurse.' Another participant attributed a perceived lack of power within the nurse executive community to be a result of the history of nurses as being subservient to physicians. For these two participants, as for a majority of study participants, the barriers of the paternalistic attitudes of physicians toward nurses, so aptly described by Ashley (1976) more than 20 years ago, plagued them regardless of their scope of responsibility.

Being a nurse was advantageous according to one participant, during a time when health care administrators were competing for a limited number of positions due to management cutbacks. She stated that the nurse executive, because of a clinical background, could supervise a variety of areas compared to an executive with a strictly administrative health care background. However, as a result, she claimed, "Nobody wants to see the nurse be too articulate, too strong, because there's always another Associate Administrator who could get bumped." 
There was an important message concealed in this participant's statement. Probably for the first time in history, nurses were perceived as powerful enough to be threatening to other groups of health care providers and administrators, which placed them in a tenuous position. Miller (1986) stated that women have been in a position where their nature was determined by the dominant culture, which has undermined their self-determination. The best definition she gave for self-determination, was a sense of feeling free and effective, and strongly connected with other people (Miller, 1986). Nursing, as an overwhelmingly female occupation, has continually had to grapple with threats to professional self-determination by a dominant masculine culture of administrators and physicians, which was shown to be true in this study. Miller (1986) said power is required for women to fully exercise their self-determination, but women's fear of this power has been thoroughly ingrained by the dominant masculine culture. Self-determined women who move out of their restricted places threaten men (Miller, 1986). The analogy can be made, that self-determined nurses, who move out of their restricted places, threaten the dominant masculine culture of hospital administration.

Miller (1986) emphasized for women to give up their roles as subordinates, they would have to reclaim the conflict associated with gender inequality. They would have to value reclaiming conflict as a necessary step toward gender equality, recognizing the difficulty in doing so when organizations and institutions lack new models for dealing with conflicts which relate to gender issues (Miller, 1986). In light of Miller's (1986) discussion, this participant's statement implied that economics and competition were forcing nurses into the managed care battlefield, and that nurses could enter it fully armed 
with their combined clinical and administrative expertise. The underlying question is whether they would be willing and able to use their power and exercise their self-determination in the face of conflict.

\section{Beliefs/Values: Caring for the Patient}

The concept of patient care in relationship to their responsibilities was not consistent among these participants. One participant emphasized that part of her responsibilities consisted of "representing the patient care needs." Another participant emphasized the need for "clinically savvy nurses at the bedside." The third participant of this category referred to patients as "customers," and was heavily involved in organization-wide customer service efforts to attract patients, in order to "put more dollars to [the] bottom line." These different conceptions of the patient attested to the balancing acts these participants faced in trying to blend their fiscal and clinical care responsibilities.

\section{Beliefs/Values: Having a Balanced Life}

There was agreement among these participants about the need for having a balanced life. The differences among them regarding this subdimension were extreme. Two of these participants displayed the strongest commitment to a balanced life in comparison with all study participants. In fact, the notion of a balanced life was first brought up by a participant in this classification. She emphasized that her need for a balanced life was crucial during the time frame of this study: "...especially now,...I have a commitment to myself to even make sure my life is in more balance than I usually keep it. So that I can present a better front, and encourage people through the next wave of tough 
times." She also stated that her life was "very rigid." She had a specific schedule for exercise, she made sure she had enough sleep, she watched what she ate and drank. The other participant asserted, "if you don't take care of yourself, there's no way you'll survive in this job." This participant went "to the gym at least six days a week."

The third participant in this category perceived her life as not in balance. Having an infant at home who had been born prematurely, she was very ambivalent about continuing in her career. She informed me, "...that if you left the health care industry, there would be very few other professions that you would go into where you would work as hard." Explaining how "the time element is incredible," she claimed, "I was just thinking the other day-it's like I don't think Ive ever sat down and ate lunch....today, I was driving between the two facilities, I was eating lunch in the car."

Professional networking varied among these participants. One participant, who did not talk about any family or significant other support systems, had held an office in a professional organization, and valued her professional contacts. The other two participants, who did talk about having families, admitted that they were detached from outside professional connections because of their workload. The detachment from having a life as a professional nurse due to workload was portrayed in two ways by these participants. One participant had difficulty answering the question about how she perceived the future of the nurse executive role, guiltily admitting she had not even thought about it. Another participant returned her transcribed interview to me with her corrections, but responded to the question about relationship with organization in the 
following fashion: "This is not something I have the time to address right now. If absolutely necessary, Ill do at a later time."

Caring for self was very important for the Engineer participants. They served as a particularly good example of what Mulqueen (1992) meant regarding the notion of choice in resolving the competence-femininity dilemma. Balancing provides a positive sense of competence and self-esteem for women, but it involves making personal and public choices. In the most ideal sense, the choices should be intentionally made to fit women's lives, and not out of a reaction to their life's circumstances (Mulqueen, 1992). Although two participants seemed to perceive themselves as making choices to fit their lives, in actuality, their rigid personal schedules implied they were reacting to their life's circumstances. Neither seemed to view themselves as sacrificing either femininity or competence, but they paid a large price to achieve self-esteem and balance. The third participant, who attested to a life out of balance, seemed to recognize feelings of fitting her life around choices, and in that sense, was beginning to question the meanings of competence and femininity for herself in an environment which valued public efficiency and effectiveness at the expense of personal concerns about family and parenting.

\section{Defining the Mission: Finding Middle Ground}

Equally influenced by the three conditions of the corporate bottom line, the players, and beliefs/values, these participants seemed to be involved in a very dynamic struggle to find middle ground in a rapidly changing managed care environment. One participant very clearly described this process: 
...my role really is a balance. It's representing the administrative needs of the hospital and also representing the patient care needs. And you know, there's always a lot of conflict between those two, because one is dollars and one is undefined quality if you will, and I think that they [the nursing staff] believe that I do a good job to find the middle ground.

Another participant supported her statement: "It becomes more and more difficult to manage your costs, to manage the care, the quality care you're trying to deliver." The changing economic pictures of Engineers' organizations clearly impacted how they defined and carried out their missions.

In many ways, these participants were like a group of female participants who fell into a category of "splitting the self" (p. 277) in a study of lawyers by Jack and Jack (1988). In that study, the "split self" participants carried their care orientation into their professional role, but they also tried to play the game of justice by men's rules (Jack \& Jack, 1988). The Engineer participants of this study were trying to be caring nurses, and caring toward organization staff, but also trying to play the male game of finances.

Compared with participants of other classifications, who defined their missions out of primary allegiances to one or two conditions, these participants perceived their calls to action arising out of all of them. These participants, more than any other group truly straddled the division of moral labor. They felt responsible to players, especially their staff; they felt responsible for the corporate bottom line; and they also felt responsible to the nursing profession and the patient. Having a balanced life was severely impacted as they juggled all of their responsibilities. The variations they expressed regarding the 
subdimensions of being a nurse, and the patient, perhaps reflected confusion about their professional allegiances, as they struggled to resolve the friction among their competing responsibilities to the human relations and the fiscal aspects of organizational life. If a true ethic of care for women is the tie between relationships and responsibility as Gilligan (1982) proclaimed, the tie seemed very stretched and vulnerable for these participants. Their ethic of care embraced nursing care, patient care, and organizational employees, but was definitely in competition with economics, as they struggled with their responsibilities to profession, organization, organization employees, and themselves. They seemed to have yet to sort out their most important calls to action, and were trying to respond to all calls in this study.

Finding middle ground among their responsibilities meant the Engineer participants often found themselves representing or defending one condition under the strong influence of another. Several participants believed that good interpersonal relationships, and good communication, were essential to their successes or failures. However, challenged by distrust among players resulting from competition due to the corporate bottom line, they had to work especially hard at interpersonal relationships. One participant told me that she was going to begin weekly rounds with the physicians, because "sitting in meetings is not always how you engender friendships and trust..." Reaching out and trying to understand the players was important in their roles. Trying to protect certain players from devastating impacts of the corporate bottom line also meant you had "to be a pretty good salesperson." 
On the other hand, participants found themselves representing the corporate bottom line to the players in a way which was not protective. The comments of two participants reflected this action very well. One participant shared with me how she had responded to a nurse who had lodged a complaint about poor staffing. The staff member had sent the following message via electronic mail to the participant: "The staffing still stinks, you don't understand, we're working ourselves to the bone, and you have to stop this. You don't care about us." The participant's response was, "I care about you, but yeah, you do need to work yourself into a comer, and I can't give you everything you want, and are you aware that we may sell this part of the business?" The participant told me, that as she sent it, she thought, "Maybe I shouldn't tell you this, but I've had about enough. I can't be your mother and I won't be your mother."

A similar situation was shared by another participant. She was trying to educate her staff about the "real world." She told them:

Health care is changing...The money tree that was out front, is not bearing fruit any longer, and we can't just go to the money tree and get what you want because you want it, and if you want to see what it's like in the rest of the world, try working somewhere else.

She added, "And that was one of the scariest things I had ever said to anybody." The additions to the emotionally charged messages, communicated to the employees by these participants, seemed to be justifications for making such harsh statements to the employees. Heavily influenced by the corporate bottom line, these participants seemed to have experienced some guilt about not being able to protect their 
employees. Like the "split self" group of participants in the Jack and Jack (1988) study, the Engineer participants found that although they might try to subjugate their caring selves into the background in their professional roles, the caring selves kept intruding in actual practice. The "split self" lawyers had learned to use psychological defenses such as dissociation to deal with natural emotions which arose out of concern for others (Jack \& Jack, 1988), and the Engineer participants of this study also exhibited similar dissociative behaviors. The objective and rational way they responded to employee concerns belied the empathy they felt toward the employees, as conveyed by the guilt they expressed for their responses.

In their roles as Engineers, finding the middle ground among all the conditions competing for their attention required a great deal of strategizing, compared to participants of other classifications. Negotiation was one way of accomplishing the mission, as conveyed by the participant who had to mediate between competing physician groups in making sure the quality concerns raised were not a smoke screen for underlying hostilities among physician groups. One participant shared her advice about strategizing: "Don't be too judgmental, sit back and take it all in...before you decide to stir the pot if you're going to stir the pot. Make sure you've got the right spoon to stir it with." This same participant also emphasized the importance of getting "to know your political landmines, before you step on 'em," in dealing with physicians. In responding to my question about whether she had a voice equal to other players in her organization, one participant described her organization as "very controlling," and informed me, "I'm using some other players to assist me in making sure that voice comes across." "Being able to 
express yourself professionally when there [are] differences in opinions, are when there are battles that need to be fought, "was one piece of advice on participant would offer to new nurse executives. All these ways of strategizing could be summed up in the advice given by one participant: "Be politically smart." Being politically smart meant learning to play some games by men's rules.

\section{Battlefield Position/Professional Identity: The Engineers}

Compared to other classifications of participants, the Engineer executives were definitely struggling more to figure out the balance among competing conditions in the face of rapidly changing economic realities. When they were successful in finding the middle ground, they expressed a perception their position was only temporary. They were unsure how much further they could "push the envelope," and unclear as to what would be "the breaking point." One participant believed that the managed care environment would continue "to squeeze us [her organization] until the general public becomes more educated."

The Engineer participants seemed to have a stronger voice on the managed care battlefield compared to the Unsung Heroine participants, but what will be revealed in the next chapter was that it was weaker than the voices of the Team Leader and Champion participants. Engineers saw their missions as consisting of more than representing and extending nursing into the battlefield, perhaps because they were more directly exposed to the effects of managed care upon their organizations. However, they seemed to not be consistently sure of their positions, vacillating among various responsibilities as they tried to resolve the cost versus care dilemmas challenging them. Among all groups of 
participants, Engineer participants seemed more isolated in trying to figure out their responsibilities.

These participants seemed to be experiencing a great deal more stress in their battlefield positions compared to participants in other classifications. Yet, all three of them claimed to really like their jobs, although one participant was experiencing some ambivalent feelings about her professional future. One participant told me: "Some days I absolutely hate it, but 99 percent of the time, it's a challenge....I really enjoy it. I really, really do. And I find it very fulfilling." Another participant shared her thoughts about being a nursing leader: "And I would do it over again, absolutely. Without a doubt in my mind, it's been the best enriching experience that I've had."

However, particularly evident for this group of participants, was the degree in which the struggles to find balance in their professional lives clearly carried over into their personal lives. The need to be very disciplined about maintaining a balanced life for two of these participants attested to the profound potential impacts of a significant amount of stress in their work lives. The third participant, who admitted to a life not in balance, had mixed feelings about being able to continue in her role. Telling me she was not "one hundred percent happy," she stated:

I have good doctors, I've a good staff that I work with, I have a pretty good reporting relationship with my boss. So those things I feel okay about. Now, not enough hours in the day, and the fact that the expectation is that you'll just do whatever it takes to get the job done, and Ill always do more, I don't feel good about. 
This participant was similar to several "split self" participants in the Jack and Jack (1988) lawyer study, who also expressed uncertainties about their continuing professional commitment because of the difficulties of trying to act like a woman in a man's world, and of trying to integrate their personal and professional lives. These "split self" participants and this Engineer participant all seemed about to enter a period of renegotiating priorities, as described in the study by Mulqueen on competence and femininity (1992). Like the Mulqueen (1992) study participants, these women were becoming acutely aware of how their career and personal life choices would either facilitate a sense of a life in balance, or cause them to feel dissatisfied and possibly depressed.

\section{Summary}

The story begins with two groups of heroines, the Unsung Heroines, and the Engineer Heroines. Both groups of heroines perceived and defined their calls to action very differently, as they began the journey of forging new paths on the managed care battlefield. The Unsung Heroines were just beginning their journey, and the Engineer Heroines were caught in a fork in the road, trying to figure out the best direction, and trying to go in all directions.

The Unsung Heroines determined their battlefield position by defining their mission as moving nursing out of the ivory tower. Carrying the banner of some traditional nursing beliefs and values into the battlefield, and experiencing a minimum of stress in their personal and professional lives compared with other heroines, they were just beginning to appreciate the impact that economics could have on their organizational lives. 
The Engineers determined their battlefield position by defining their mission as finding middle ground. Being called to action by both the financial and human relations aspects of organizational life, they were a little unclear about the banners of professional nursing, and patient care. The competition among their calls to action and their professional banners also greatly impacted how well they balanced their personal and professional lives. Their mission was to find balance between the competing elements of finances and human relations, while staying strong and healthy in their personal lives. Well aware that economics was a major factor in all of their actions, when they were able to skillfully balance all the calls to action, as well as their personal and professional lives, they weren't sure how long they could maintain their battlefield positions. The Engineers overall had the most stressful positions on the managed care battlefield.

In the next chapter, the stories of the Team Leader Heroines and the Champion Heroines will unfold. Their stories will show that they were more settled in their battlefield positions compared with Engineer Heroines, with stronger organizational voices than both Unsung Heroines and Engineer Heroines. 


\section{CHAPTER SIX}

\section{RESOLUTION: THE TEAM LEADERS AND THE CHAMPIONS}

In this chapter, I continue with my description and discussion of the heroine typology. On the typology continuum, the Team Leaders follow the Engineers, and the Champions follow the Team Leaders. This chapter begins with the section describing the (a) the Team Leaders, followed by the section on the (b) Champions. Each section breaks into subsections which include (a) a brief introduction to the particular classification, the (b) conditions, or calls to action, beginning with the most influential condition; the (c) processes of defining the mission and the leadership actions, and finally the (d) professional identity and battlefield position and associated experiences. This chapter concludes with a summary of these two classifications.

\section{The Team Leaders}

Five participants in this study together formed into a "Team Leader" category. The title, "Team Leader," was derived from a composite of participant interviews, and seemed to best capture the essence of the mission, and of the conditions most influential in shaping the identity of this particular group of participants. One participant's narrative expressed the meaning of "Team Leader" especially well. She commented: "Many nurses would know that I'm a nurse, but they're not looking to me to be a clinician. They are looking to me to be a leader." However, as a leader, and a member of a "senior management team," she stated with conviction: "...we've really just attempted to provide both an environment 
and the resources to allow people to succeed, but to succeed in a team environment. We've set our goals around team goals rather than individual goals, sole individual goals." Interview texts of Team Leaders could be easily differentiated from those of other participants through the liberal use of words such as, "leader," "teams," "teamwork," "facilitating," "relationship," and "multidisciplinary" by participants.

\section{The Players}

The participants in this category seemed to view the condition of players as the central influence in shaping their responsibilities. Their relationships with various groups of key organizational people tempered the degrees of influence that the conditions of corporate bottom line and beliefs/values had upon their perceived missions.

The most influential players for this group of participants were the immediate supervisors, or bosses, all of whom were male. From participants' comments, their bosses' approval was very important to them, because approval meant support and empowerment so they could define and carry out their missions.

The importance of a good relationship between bosses and participants was demonstrated in the data from most participants of this category. One participant had accepted her current position because of the "chemistry" between herself and her boss, and shared her philosophy that "how goes the relationship of senior management will dictate the survival of that organization." Several participants expressed the importance of "learning the boss." One participant, who had a new boss, told me that she "actually called around and did some reference checks on him personally..." prior to his arrival at her facility. She claimed, "he's come out very, very strong, so I'm excited about it." Another 
participant, reported to a "team" of three men. She had worked with one of them the longest, but she stated, "I'm still kind of learning the other two."

Several participants spontaneously talked about their bosses in a way that almost expressed reverence. One participant proclaimed: "He is, without a doubt, the brightest and the best and most of the time I think he's scary." Another participant, in responding to a question about role, inserted: "I work for a very progressive administrator." At another point in the interview, while discussing her role, she again shifted the focus of our conversation entirely to her boss: "One of his strengths is he's a young man, he's 35 , he has a lot of energy. A lot of ego, but in the right place..." Of interest, this participant was eleven years older than her boss.

Several participants attributed their successes in their organizations to their bosses. One participant shared: "And because of the work he's done, people see me as someone who's very responsive to their needs." Another participant believed that the management team in her organization was "very cohesive, again, kudos to my boss." This participant, in introducing a story about how she had asked her boss for permission to attend a Finance Committee Meeting, described how fortunate she believed she was in her organization because "no one's ever said No' to me."

The bosses played the role of mediator for several participants, especially regarding physician issues. One participant told me that her boss specifically directed physicians to her when they tended to ignore her on important issues of mutual concern. Another participant shared that she was delighted because her new boss was a physician, 
and could now help improve relationships between hospital administration and the physician community.

The relationships between this particular group of participants and their male bosses could lend support for one aspect of Morgan's (1986) metaphor of organizations as psychic prisons, where the concept of organization becomes an unconscious expression of patriarchy for certain organizational members. Morgan (1986) related that many writers on the relationship between organization and gender view the dominant influence of the males in organizations as derived from the hierarchical relationships of the patriarchal family. In formal organizations, a child's submission to parental rule is played out by the way a person submits to authority. In that way, dependency becomes institutionalized, and people look to others to resolve problematic concerns (Morgan, 1986). The way one Team Leader participant sought permission from her boss to attend a meeting, and another looked to her boss to resolve physician issues, perhaps indicated a childlike deference to organizational authority.

Additionally, Morgan (1986) claimed that important organizational members often cultivate fatherly roles in the way they mentor those who need protection and help (Morgan, 1986). In the eyes of most of the Team Leader participants, the boss seemed to exhibit a father-like protectiveness. To ensure that protectiveness, they had to "learn" their bosses in order to gain approval, so that they would be supported in their successes and shielded from conflictual relationships. From their data, they seemed to take on the persona of an organizational mother in relationship to a benevolent father in their relationships with their bosses. Unfortunately, none of the bosses for the Team Leader 
participants were women, because that situation would have contributed meaningful insights about the nature of the participant-boss relationship and the patriarchal family in organizations.

Despite the interventions by the bosses in some cases, Team Leader participants all seemed to be directly influenced by physicians. One participant perhaps best summarized the sentiments of all participants when she referred to physicians as "men behaving badly." She told me: "They're acting out. There's a new television show, it's called, Men Behaving Badly,' and that's how they're acting. I haven't seen the show, but I thought of that caption the other day when I was in the medical staff meeting." She explained that the physician behaviors were because "they all have their own managed care issues-I know they're tough." She added that "nothing will make them happy right now." The physicians had an impact upon her because they were "coming back to...all of these little complaint things." An example of a "complaint thing" was nurse staffing. The impact of economics on the physicians was filtering down to this participant in the form of adverse physician behaviors. From the interviews of several of these participants, the physicians seemed to be targeting the nursing staff as scapegoats for their economic woes. Additionally, as was true for other classifications of participants, the "old guard" physicians, consisting of the "almost-ready-to-retire, [the] 55-60 year-old physician or older, who remembers what it used to be like," and tended to view the Team Leader participant "as just the typical director of nursing," was the group making the most noise.

Another participant described the impact physicians had in carrying out her mission, which again related to economics. One of her major challenges was "to help 
providers see that why what's convenient for them isn't convenient for someone else." As the interview progressed, she talked about how physicians in private practice had control over their hours of operations, and how patients would have to adjust their schedules to fit the physicians' schedules. In her position, in an HMO, a major challenge was helping physicians new to the organization learn to accommodate to patients' needs, and not expect that the patients would accommodate to physicians' needs.

These participants recognized that physicians were vital to the financial successes of their organizations, and several talked about going to great lengths to maintain a solid relationship between physicians and organizations. One participant described efforts to become "strategically aligned" with the physicians, and the importance of "partnering with our physicians." Another participant told me, "when it comes right down to making this hospital successful, they line up with us." Further in the interview, she claimed:

"Day-to-day, they're a pain in the ass." She proceeded to tell me how she "covered a physician's backside" during a Department of Health Services' visit in order to make sure her organization received a favorable review.

The main message heard from these participants' narratives regarding physicians was that physicians were major players on the managed care environment. However, physicians' behaviors, in responding to major economic changes, had impacted at least three participants of this category in mostly negative ways. When physicians' self-concepts of omnipotence (Kalisch \& Kalisch, 1977) were challenged by economic changes, they roared in response. Unwilling to surrender their "captain of the ship role" (Kalisch \& Kalisch, 1977 , p. 52), they asserted control in other ways, by targeting the normally 
submissive group of nurses, or by passively-aggressively refusing to comply with organizational regulations.

Deference to the physicians was communicated by several of the Team Leaders. Miller (1986) explained that subordinate groups often know more about dominant groups than vice versa, and the subordinates become particularly attuned to the dominants in predicting their reactions of displeasure and pleasure. Therefore, one participant stressed the importance of organizational efforts to "partner" with physicians in recognition of their economic strength. For other participants, the behaviors of physicians who were acting out seemed to be trivialized through rationalization and by a cover-up, in order to prevent further provocation of physicians, and not rock the organizational boats.

One group of players who significantly influenced these participants, and who served as the primary focus of their interactions, consisted of the employees of their institutions, especially those for whom they had designated responsibility. Like the group of participants of the Engineer category, the lives of the employees of the Team Leader participants had also been affected by the corporate bottom line. However, the participants of the Team Leader categories defined their missions very differently from those in the Engineer category. What probably accounted for that difference, was the degree of support they received from the senior management team players, and the organizational dynamics which resulted from the behaviors of these players. In other words, the bosses and the senior management team set the tone for how these executives could respond to the dilemma of ensuring a good corporate bottom line when employee groups were the targets of financial cutbacks. Their corresponding actions will be discussed further in the 
section on defining the mission. Additionally, the condition of beliefs/values played a major role in how these participants defined their responsibilities, especially in regard to the employees on their staffs.

\section{Beliefs/Values: Being a Nurse}

The subdimension of being a nurse was different for the Team Leader executives compared to other participants of other classifications. One participant captured particularly well the beliefs and values which seemed prevalent for this category of participants:

I think that...without being forced to be responsible...I probably would have continued to think like a nurse, and I think at the executive level...health care needs...inpatient executive nurses, who bring...the broad breadth of care for patients from our nursing tenets. You have to expand your role.

She went on to say, "[nursing is] the comerstone of how you think and talk, but as an executive, you really have to have that broad back of responsibility." This participant also talked about the "need to grow my talents, and get away from my clinical bent." The "cornerstone" of nursing was important for other participants in how they responded to having responsibilities for staff who were not all nurses. One participant mentioned that her "background as a nurse, in terms of the patient needs" was something she could always "come back to...in trying to solve problems or issues or whatever." She added: "I think it keeps me grounded in terms of what am I in this for, anyway." A third participant, in discussing problem-solving, stated that she would "go back to the nursing process" in assessing situations. However, this participant summarized the opinions of the 
other participants when she added: "The real way to think of things is the multidisciplinary way." Being a nurse for these participants was viewed as a stepping stone to an expanded administrative role.

Being a murse had advantages and disadvantages. The common theme of physicians bypassing and ignoring these participants in their executive roles, erupted in this category, as it did in other categories. Being a nurse did have an advantage, however, as was pointed out to me by one participant. In dealing with physicians, and other hospital administrators, being a nurse gave her "kind of a one-up, when...talking about clinical issues in terms of more of an equal footing." The downside of this statement is that it implied she was not perceived as an equal among the organization leadership ranks.

\section{Beliefs/Values: Caring for the Patient}

Closely related to being a nurse was the belief/value of caring for the patient. How the condition of the players related to this subdimension was shown in the following assertion by one participant in this category: "I'm here to serve the people that care for the patient." Therefore, in this discussion, talking about patient care is almost impossible without talking about the organization staff. The implication from these participants was that high quality patient care would happen if particular attention was paid to the organization employee relationships.

Patient care could be best achieved through teams of staff members in the opinions of these participants. The concept of "the team" was central to understanding how staff would provide quality patient care, and how the organization would maintain a good bottom line. The word, "teams" came up over and over in Team Leader participant 
interview texts. A "team" was a generic word which described groups of people with shared responsibilities for some aspect of patient care or organizational life. Nursing staff were viewed as only a portion of the team. According to one participant, nursing delivered a service as part of the patient care team. Teams were not limited to internal organization staff either. Several participants talked about the physicians on various teams, and two participants made several references to the senior management team of their respective organizations. The notion of team, in relation to the patient, played an essential part in how these participants defined their missions.

In becoming the focus of a team of people, the patient was seen as part of a system, and as someone who moved around that system. High quality patient care seemed to become more equated with the patient's experience of receiving that care, rather than the actual care received. By the words of several participants, the identity of "the patient" had changed to "member," or "customer." The majority of these participants referred to a "continuum of care," and for the need to make that "seamless" for the patients. Organizing employees into teams with shared responsibilities meant improving delivery systems, resulting in better patient experiences in moving throughout the systems. One participant summarized this sense of responsibility for the patient experience quite well in giving advice for future nurse executives:

...the most important thing about her role, is to remember the extreme importance of serving the patient. And being sure in her relationships with others...the one goal of establishing a delivery system that keeps the patient as a center focus is what she needs to do. 


\section{Beliefs/Values: Having a Balanced Life}

The idea of having a balanced life came up spontaneously in interviews with several of these Team Leader participants. While achieving a balanced life was perceived as very difficult by these participants, they either admitted to having, or seemed to have, a balanced life. All of them were married, and four of the five participants had children. All participants talked about their families with ease. Achieving balance was maintained by exercise and nutrition; living a "simple life;" support from husbands; employing a "nanny;" and in one case, from the people of a church group.

One participant's situation stood out among the narratives of other participants. This participant had her secretary cancel our first interview appointment because she had to provide transportation for her stranded child. In listening to what participants of other classifications were telling me, this ability to suddenly leave work might not have been so easy for them, suggesting that perhaps participants in this category might have experienced a greater degree of organizational support in balancing their lives.

In analyzing the data from this group, there was one factor related to a balanced life which stood out when compared with data from other participant groups. These women as a collective group seemed to have very few professional connections outside of their organizations. One participant told me, "I'm probably not as well-connected into the local community, because I have so much support internally." Another participant told me,

I have colleagues in [various counties], not a lot of them. It's not by choice, it's just a matter of time....to maintain those relationships, you need some time to put into 
them. If I can go to lunch with a colleague...once every other month, I consider myself fortunate.

The conditions of the players (internal organizational support) and organization bottom line (time) could be considered contributors to this aspect of a balanced professional life. A participant from another classification shed additional light on this finding. She told me that in trying to fulfill multiple expectations as executive, wife and mother, having professional connections outside of one's organization would receive the lowest priority.

Balancing one's life was different for these participants compared to other groups of participants. To achieve self-esteem through balancing meant defining competence and femininity in new ways for these participants. Like the participants of Mulqueen's (1992) study on competence and femininity, the Team Leader participants seemed to have gone through a period of renegotiating priorities and redefining competence and femininity for themselves. The Team Leader participants, like the four participants in the Mulqueen (1992) study, by marrying and having children, had been forced to confront their sex-role identity, and make it congruent with their own actions rather than societal expectations about organizational commitment (Mulqueen, 1992). Expressions of femininity for them meant being married and having a family, but what will be revealed in the next section, is that compared with the Champion participants, Team Leaders would sacrifice career progression to care for their families.

Additionally, Mulqueen's (1992) finding that competence for women was not defined by full-time commitment, was also a finding regarding the Team Leaders. The Team Leaders perhaps best exemplified this adjustment by eliminating outside professional 
connections from their self definitions of commitment. They could not balance organizational commitment, professional commitment, and personal commitment. More than for any other group of participants, the idea of self, in caring for self, extended to include family/spouse. One Team Leader participant clearly summed this process of renegotiating priorities and redefining competence and femininity:

...a lot of the women that I see...aren't balanced, their personal feminineness isn't taken care of they aren't in a relationship that's nurturing or they haven't had children...their goals as a woman haven't been accomplished...

Further in the interview, she added:

The balance of family and work will always to a struggle for women, and you will always be evaluated by male rules. No matter what. So if you choose to balance your life by not working as much as they're working because you want to spend time with your kids, you will never be an equal. Just get over it. You're making a choice, you are making a choice. Not them, you.

\section{Corporate Bottom Line}

The Team Leader executives were not as directly influenced by cost-containment measures compared with other categories of participants, or if they were, the impact was felt through their relationships with key organizational players as already described. Of course, some of them had certain fiscal responsibilities, and some of them were quite knowledgeable about the financial pictures of their organizations. Additionally, they had all been involved in organizational reengineering, redesign, and restructuring efforts to some degree, so they had been exposed to employee cutbacks. However, compared to the 
narratives of other categories of participants, this group seemed to distance themselves from issues directly involving corporate or organization bottom line. What was interesting about these participants, was that they all worked for organizations which had good bottom lines during the time of data collection; organizations which either had a competitive edge financially within a particular region, or had experienced a only mild degree of managed care market penetration.

Several participants admitted to not needing or wanting to be involved in the financial aspects of organizational life. In some way, they had all been protected from such involvement. One participant, who worked for an $\mathrm{HMO}$, explained to me that her organization,

...never had the economic incentives to keep patients in the hospital longer....the physicians are not reimbursed for the procedures that they do. So there's no economic advantage for anyone to do things either one way or another way, because it all comes out in the wash, I think.

Another participant admitted to not wanting to get involved in finances, stating, I've had the good fortune of working with a very strong financial person whose office was across the hallway....I would tell her in concept what I needed and I didn't sit behind a computer and count or spend my time on numbers....my personal belief is...that's not where we do our best work...we need to understand it....but for us to spend [time] doing that, I don't think is time well-spent.

A third participant in this category told me that she had asked her boss for permission to audit the Finance Committee meeting of her organization. Her motives for attending this 
meeting were to build relationships with the members, to be the first nurse and "girl" to attend this meeting, and "to grow and learn" by being "included." She attended the Finance Committee meeting by choice and not out of necessity.

\section{Defining the Mission: Building Caring for, and Feeding the Team.}

The way the Team Leader executives defined their mission and leadership actions was best exemplified in the narrative of one participant. This participant emphatically offered, near the end of our interview, "...as administrators or CNEs, we have to spend time, caring [for] and feeding the team." She added, "I mean, health care is changing so quickly, we forget about the team-building piece of it." Synthesizing her statement into a process dimension of building, caring for, and feeding the team seemed to encompass all of the other leadership actions participants described, and all viewed themselves primarily responsible to the people of the organization who served the patients. The conditions of players and beliefs/values, particularly the subdimensions of being a nurse and caring for the patient, all merged into the idea of promoting and sustaining teams of people, and became the top mission for the Team Leader participants on the managed care battlefield. Building, caring for, and feeding teams was also the major way participants saw themselves contributing positively to their organizations' bottom lines by means of the players.

In order to form teams, "...nursing with the other professional services really needs to think out of the box," according to one participant. Another participant elaborated how everyone in her organization needed to be "able to manage outside our boxes." Therefore, team-building involved, to quote from one participant, "a concentrated focus on 
system-think," and "a strong focus push on trying to be more like a system, and less like unique little entities that have kingdoms all their own."

All of these participants had been actively involved in some way, in making the necessary organization-wide changes which would support the idea of teams under the umbrella idea of "multidisciplinary" teams. A number of participants had helped redesign the organizational chart of employee positions. Several had initiated the redesign of their own roles to encompass more responsibilities. Employee reeducation was another way in which participants were involved. Several talked about their extensive participation in multiskilling efforts of all employees.

A good example of building the team, and the concept of teamwork, came from the narrative of one participant. She shared with me at great length how she had changed her organization's practice of putting peoples' names on the organizational charts. She stated: "I will put the function, so that our staff can understand where they report and who's available for them, but if their director is not there, I expect any director in the facility to be able to answer that employee's need..." She added that this change was only one of several organization-wide initiatives in place so that, "...people [would] stop thinking of themselves as one individual patient care unit, or one individual department.

To form teams, one had to downplay nursing and emphasize the equality of all team members. One participant informed me: "Potentially, one of the worst things you can say...is 'well, in nursing.' I'm better off saying, 'other departments.' Another participant told me how she expanded her responsibilities to include non-nursing patient care staff: 
Just fundamentally changed my approach to, "This is an inpatient services department, this is not a nurse running your staff." And just consciously forced repeatedly, "This is Inpatient Services, there is no more Nursing Department, this is an Inpatient Services Department, we are all equal, we are all players on the same team."

Caring for and feeding the team did mean participant visibility in the organization, but not as a nurse, as previously mentioned. "You have to be able to walk the talk, you have to be visible, " was emphasized by one participant. Another told me, "...we must demonstrate the values in how we conduct business and how we conduct our relationships with each other, and how we promote teamwork." A third participant stressed, "I think...that as a nurse executive you have to be visible..." However, this last participant had also stressed the need to downplay the fact she was a nurse. Being a nurse seemed to carry a negative stigma in promoting teamwork.

Caring for and feeding the team as a means to promote teamwork was also done through open communication. All participants strongly emphasized communication during our interviews. One participant operationalized communication as follows: "I like to think that the majority of my energy is coaching, working with the directors, facilitating shared governance, shepherding, and a fair amount of time in strategic discussions." All emphasized employee involvement in decision-making. One participant stated that when issues arose with her staff, she and the staff would all go on a retreat away from the organization, all members would be encouraged to share their opinions, and they would 
continue to discuss the issues until they were resolved. Another participant stated that when issues arose in her organization, a team would be formed to work on them.

Caring for and feeding the team also meant paying attention to employee development as a means of facilitating teamwork. One participant told me, "I like working with people and trying to maximize their abilities." Another claimed to get "excited by watching people who are in organizations succeed." A third participant described how her support of employees had "usually allowed them to kind of move to the next step." A fourth participant summarized the philosophies of all participants about employee success: "...we've really just attempted to provide an environment and the resources to allow people to succeed, but to succeed in a team environment."

For several Team Leader participants, building, caring for, and feeding teams also served as a way to help redirect the concerns of employees troubled by changes in their lives as a result of health care economics. These Team Leaders were very different from the Engineers in how they approached their employees regarding these economic impacts, and seemed less sensitive to their employees regarding these impacts. For these participants, the team became a substitute for the traditionally stable health care "family." One participant informed me:

In health care, it's really easy to be a family....I've heard people in staff meetings talk to me about how it's really sad that we are no longer a family, and they're really angry because their entitlements....have gone away every year. And my answer to that is, "Yes, but isn't it exciting that we're now a team." Because I can't 
afford to tolerate in my teams...the same kinds of behaviors I tolerate in my family setting.

The study by Jack and Jack (1988) involving female lawyers helped explain this particular finding. There was one group of participants in that study who were strongly care-oriented women, who chose not to emulate the masculine successful lawyer stereotype, and who were able to shape their roles in ways consistent with their personal morality. However, those participants were highly exposed to the stress of always being perceived as a caring advocate according to Jack and Jack (1988). Some participants, who were able to integrate a care orientation into their law practices fairly well, found that they had to change their understanding of responsibility and morality to avoid being consumed by self-sacrifice and hurt. They included caring for self in their definition of caring for others, and in that way, were able to let go of the ideal of feminine unselfishness. They did not hold others accountable for their own satisfaction and professional competence, and they realized that they could not hold themselves ultimately responsible for the happiness and well-being of others. They separated a care orientation from the stereotype of a self-sacrificing woman (Jack \& Jack, 1988).

Building and nurturing teams then, might have been a useful and protective mechanism for Team Leader participants. It allowed them to operate out of an ethic of care, but the team focus provided them with an outlet, and a way of caring for themselves in a stressful environment. Compared to the Engineer participants, who felt some anguish about what was happening with the employees, Team Leader participants could put some distance between themselves and employees. Building and nurturing teams might have 
been a shield from certain unpleasant economic realities, but ones over which they personally had little control.

The idea of team-building was not confined to more junior-level organization employees. Participants saw team-building with their colleagues and senior-level staff as crucial to their ability to carry out their organizational responsibilities, as well as to the successes of their organizations. Two participants specifically asserted that a "relationship driven organization," or a "very relational organization," had a better chance of succeeding in the current environment compared to a "dollars and cents organization." Participants were therefore "very aware of the kind of communication styles that [were] going on," and emphasized that to accomplish goals, one should not work "downward through nursing," but "laterally" and "collaboratively with a team of individuals." However, what was noticeably absent with this group, in their team-building efforts, was networking with peers in the community.

Bowden's (1997) discussion about friendship caring practices provided some insights for understanding the behaviors of Team Leader participants. In the most ideal sense, friendship caring is a type of social intercourse characterized by informality and diminished presence of fixed rituals, conventions, and controlling institutions (Bowden, 1997). By loosening these boundaries, interpersonal caring possibilities are liberated to a wide range of possibilities according to Bowden (1997). Reflection on friendship for many feminist ethicists has emerged from the acknowledgment of the central importance of the maintenance of caring relationships in the moral lives of women, such as mothering and 
nursing, but friendship caring relationships add the actively chosen components of sharing and reciprocity (Bowden, 1977).

These participants seemed to shift between a type of friendship caring and a type of nursing caring, both in keeping with their experiences as women. When serving on teams, or in developing their teams, the ideas of equality, sharing, and accountability among members were stressed, connoting some degree of reciprocity characteristic of friendship relations. However, friendship caring in the most ideal sense could not occur, since as Bowden (1997) pointed out, the idea of reciprocity is antithetical to patriarchal social structures. No matter how "flat" the organizational structures had become, or how informal the organizational culture, some sort of hierarchy still existed in these participants' organizations.

In their primary responsibilities for building, caring for, and feeding teams, Team Leader participants seemed to be trying to foster friendship caring relations within groups, while they themselves engaged in activities that were more like definitions of nursing relations as described by Bowden (1997). Bowden (1997) defined nursing care relations as characterized by a connection between people for the purpose of one person responding to and servicing the needs of the other. In this way nursing was still the "comerstone of how you think and talk, " as one participant proclaimed. In extending the "cornerstone" to teams, McCarthy, Craig, Bergstrom, Whitley, Stoner, and Magilvy (1991) provided guidance, by proposing the substitution of community for person to explain caring in community health nursing practice. Perhaps by substituting the concept of team for person, the idea of nursing caring could be extended to explain Team Leader participant 
behaviors, although there is an interesting contradiction in that participants really strove to downplay the fact of their nursing backgrounds. Participants were affirming the continuing existence of the stereotype about nursing as an inferior, female profession, while they practiced an extended form of nursing caring.

\section{Battlefield Position/Professional Identity: The Team Leaders}

Several key factors helped differentiate this group of participants from those of other classifications. Compared to the Unsung Heroine participants, these participants seemed more distanced from their nursing foundations. Regardless of their titles, or the words they used to describe themselves, they no longer thought of themselves as nurse administrators or executives. They had become Team Leader executives, having extended their responsibilities to include many organization staff members in addition to nurses. They were also less directly connected to the patient in how they saw their missions. To achieve quality patient care, they stressed speaking on behalf of the people who cared for the patients, rather than directly speaking on behalf of the patients, as did the Unsung Heroine and the Engineer participants. Furthermore, they emphasized the patient experience more than the actual care of the patient. Compared to the Engineer executives, the Team Leader executives clearly saw themselves aligned with the organization players in defining their missions, and not seeking middle ground between cost and care. They held the belief that organizational successes depended upon the players, and they focused almost exclusively on that condition. Compared to Engineer executives, these participants were more shielded from the financial realities of their organizations, either by choice, or 
because of other players in the organization. Furthermore, all of this groups' organizations were financially successful.

Conflicts experienced by these participants seemed to be less intense compared with the Engineer participants. There were the traditional conflicts with physicians having to do with control, not perceived by these participants as a major factor in how they carried out their responsibilities. Conflicts, when they were important, had to do with teams. One participant perceived a major barrier for her as:

the challenge of a public elected board...to empower staff, to work with them on a project and to feel you've done a very good job...And then to have the board not vote for a project is very demoralizing to yourself and the people that you work with.

The vote did not seem as important as the impact it had upon the team. Later during the interview, this participant talked about how much she enjoyed her job, but added, "The only time I don't enjoy it, [is] if I work very closely with people on the team that are not a part of the team. They can really drain, or take a piece out of you."

There was one additional gender conflict addressed by these participants which could be interpreted in one of two ways. One Team Leader in this category asserted that a woman would never serve in the top administrative ranks of the parent corporation of her organization, because of gender discrimination in the surtounding patriarchal environment. She emphasized however, that she was very content to serve in her current position, and stated: "I'm not a person that has to be in the number one position, I do very well at doing 
operational stuff and being in the background and just getting excited by watching people who are in organizations succeed."

One way this statement can be interpreted relates to the findings and conclusions of Mulqueen's (1992) study on competence and femininity. This participant might have been defining competence for herself in a new way, believing Mulqueen's (1992) thesis that competence for women has to be defined in a way which does not involve competition.

The darker interpretation of this statement is that it may be representative of a psychological defense mechanism in a culture which thwarts competence development for women. In the metaphor of organizations as psychic prisons, Morgan (1986) described some of the psychological processes that people use to cope with desires and impulses in repressive organizations; repressive in the Freudian sense of repressed sexuality. Among these are denial, displacement, and rationalization (Morgan, 1986). Perhaps this participant was really communicating her use of a coping mechanism to justify her perceived inability for career progression within the patriarchal corporate hierarchy of her health system, in a way which met her self-esteem needs.

Overall, the Team Leader participants seemed to operate out of a position on the managed care battlefield where they did not necessarily play by men's rules, although they were fully aware that men still controlled the game. Team Leaders seemed to have firmer stand and a louder voice on the managed care battlefield compared to the Unsung Heroine or the Engineer participants. In response to the division of moral labor, they sided with humanistic caring practices, and reshaped them. Like the Unsung Heroines, and the 
Engineers, the Team Leaders seemed to be functioning in a way which was consistent with a human relations care orientation associated with women. However, unlike the Unsung Heroines, and the Engineers, their caring focus was directed exclusively toward organizational employees of which nurses were only a portion, and almost not at all toward the nursing profession outside of their organizational lives.

Expressing a great deal of contentment with their work roles, Team Leader participants had redefined competence and femininity to meet their personal needs as women, recognizing that they lived in a patriarchal world. Unlike the care-oriented participants of the lawyer study by Jack and Jack (1988), these participants really hadn't been confronted with the game of functioning in a masculine work world, so they hadn't needed to learn to play by men's rules, or to change the rules of the game. Their contact with the "masculine" aspects of organizational life, such as finances, was minimal. Their abilities to be themselves; to be authentically "feminine" in their work was largely the result of organizational dynamics and bosses. However, some Team Leaders may have been locked in their own psychic prisons regarding the true impacts of patriarchy, as suggested by their somewhat submissive relationships with male bosses and physicians.

\section{The Champions}

One participant, while talking about what helped her to perform her job to the best of her abilities, told me, "...feedback is the breakfast of champions." In keeping with the battlefield metaphor, "Champions" seemed the best overall descriptor for the six participants of this classification. Dictionary definitions of "champion" include: (a) "a militant advocate or defender," and (b) "a winner of a first prize in competition " (Mish et 
al., 1984, p. 225). The feeling conveyed by these participants, summed up by one participant, was that ..."if you're a nurse, if you want to change or impact the decision-making process,...either lead or get out of the way." Leading, for several of them, meant making massive organizational changes. Several had been "hired under the gauntlet of change, "and they viewed themselves as "change agents." Winning "the war" was more important to this group compared to other groups of participants. One participant reinforced: "I think about work and the challenges as sort of the battle,...I want to win the war..."

Winning the war, for this group of participants, meant a close connection to the corporate bottom line in how they enacted their roles. In describing their organizations, many of these participants offered to give me statistics about their organizations, a direct contrast with Team Leader participants who talked at length about teams of people, or who pulled out an organizational chart. Concerned with efficiency, and the business of their organizations, I had to pay particular attention to the clock in conducting interviews with this group, and make sure that our conversations stayed within a certain time limit. Additionally, believing that the managed care environments surrounding them were "very aggressive environments, " their interview texts contained more aggressive-sounding words and phrases, when compared with the texts of other participants.

\section{Corporate Bottom Line}

The position taken by this group of participants, and the way they defined their missions, were mostly influenced by their allegiances to the corporate bottom line. Even the conditions of players and beliefs/values seemed to influence these participants through 
the condition of corporate bottom line. One participant clearly told me, "...my responsibility is to the bottom line, to the corporation, and I understand needs because I am a nurse." This participant, in talking about physicians, emphasized at another point in the interview, "...that this is a business, and they [the physicians] need to understand it in a managed care arena."

In response to questions about the impact of a managed care environment on their roles, answers largely had to do with the business of health care. The comments of several participants highlighted this finding. One participant readily offered: "I think a major barrier in success, whether it's a barrier for me personally or not, is the way the reimbursement system is structured right now." Another participant claimed that a major challenge for her, as for her entire organization, was "just trying to stay ahead," during a time when there were "no more rabbits to pull out of the hat." She described the organizational dilemma, which had also become her dilemma, of trying "to provide care, at the best price, for the best value, and make a profit." One participant perceived her major challenge as getting her organization "the recognition I think it deserves, and [establishing] the relationships with each of the hospitals, which will influence our ability to grow the business."

An interesting finding regarding these participants was that all but one of the participants' organizations were financially sound during the time of data collection. Participants of financially successful organizations seemed proud of that fact. One participant told me how her organization had been publicly praised for having one of the "best bottom lines for a medium-sized hospital." Another told me how her organization 
had responsibility for "administering to a large community, and [had] learned to do it in a cost-effective manner." The third participant, at the very beginning of the interview, shared that her organization was "basically the largest and most financially well-off of all the system hospitals." A fourth participant claimed that her institution had done fairly well in making a profit, elaborating, "I think our budget is based on about 25 to 27 cents on the dollar."

Data from one participant revealed a particularly strong allegiance to corporate bottom line, despite the severe impact it seemed to be having upon her professional life. This participant's health care system was in serious financial trouble during the time of data collection, but it did not seem to phase her much, or else she was good at concealing the impact. She told me, "the barometer reading" of her organization was consistently changing, and admitted how frustrating those changes were for her, and yet, she described her relationship with her organization as "cautiously optimistic." She explained, she had been "right-sized out of [her] job, twice, in the last couple years," but found the saying "when one door closes, another opens," to be true, and claimed to be an "Erma Bombeck fan." She believed that "life is what you make of it." Believing, "it's such a competitive market, and either you produce or don't produce," this participant, who was directly impacted by a shaky corporate bottom line, still showed how strong her allegiance was to her organization, and the corporate bottom line.

\section{The Players}

There were several groups of players which helped shape how these participants defined their missions and professional identities. The players who had the greatest degree 
of influence upon these participants, largely as a result of how they influenced the corporate bottom line, were the physicians.

As a result of economics, the physicians influenced these participants in different ways compared with participants of other groups. Several participants had designated responsibilities for physician contracts. One participant had acquired this responsibility "by default," when there was a time that her organization needed someone to negotiate certain contracts, and no one else available to assume this responsibility. As a result, she stated, "my relationship with the physicians is probably the strongest of any administrative person in the health system. And it has strengthened...because I do negotiate contracts with them." The power differential between nursing and medicine had diminished for this participant as a result of her close ties to the dollars and cents aspects of organizational life.

The converse of improved relationships was found to be true for several of these participants. One participant shared that she was very uncomfortable holding physician contracts. Implying that her relationships with physicians were not so pleasant, she asserted:

I think that when physicians and the nurses objectively come together around patient care issues, there are no issues. That's because there's a common end. When we sit across the table about some of the contractual issues in health care financing and reimbursement, that's a separate issue.

The traditional friction between nurses and physicians over control, in day-to-day practices, was not perceived by this participant. The addition of economic control, largely 
influenced by a nurse, converted the nurse-physician relationship into a battle. Like several other participants in this study, her expanded responsibilities in a managed competition environment were forcing her into physician management areas, which have traditionally been out of bounds for nurses. Along with the new responsibilities came new conflicts.

The large impact of physicians on the corporate bottom line was communicated by several participants of this classification. One participant explained, "In reality, people in my position fail if they do not get along well with the medical staff, so I work very hard to develop good...relationships and work as best I can with the medical staff, because they also are the people who bring the patients." Another participant reinforced this perception: "I thought that politically it would make sense for me to have co-medical directors because those would be the people that would influence what's happening." Co-medical directors would be "the eyes and ears of support" for this person. Additionally, she was spending time with individual physicians in order to learn, "... what do we need to change to get their business, to maintain their business, that sort of thing."

Physicians, because of their economic influence, presented major challenges to some participants. A significant issue had to do with physician reimbursement. One participant told me that she and the physicians were at "cross-purposes," because, physicians are still paid to visit patients daily....the hospital is paid on a case rate, so our objective is to get patients out of the hospital as quickly as possible and their objective is to keep them in...I can't admit and I can't discharge and I can't transfer. So I have to work with the doctors who are paid differently. 
The influence of physicians on the corporate bottom line was the source of another participant's major frustration. She explained:

my CEO and our board very much...put a huge credence in what some of the traditional medical staff leaders have to say about anything. And these are the same medical staff leaders who continue to be primarily in specialty areas of practice, who are getting crunched and beat up badly by managed care,...and they're going to the last bastions of any fee-for-services around.

Once again, the group of "old guard" physicians had interfered with the performance of another participant in this study. In this participant's situation, she was allowed to make changes and take risks, as long as she didn't "make any noise" about situations involving these physicians. By these statements, physicians were still seen as very much a part of the strongman elite.

However, the traditional perception of the physicians as the strongman elite was beginning to fracture as a result of health care economics according to this same participant. She claimed:

...the real nuts and bolts of your medical staff, the primary care docs, are out there, working 12 hour days to take care of patients in a capitated environment, those are the ones that don't even have time to raise their heads from the grindstone. And they're the ones that really I think we should be listening to.

This participant was the first one to suggest that a managed care environment could actually enhance nurse-physician relationships. In a world of chaos, traditional control 
battles consumed too much time and energy. Chaos could help build alliances between nurses and physicians, especially those in primary care practices.

The bosses of this group of participants, who were both male and female, did not seem to have as much influence on the participants, in comparing data between groups of participants. They either were viewed as people more in the background, or as people to work around or manipulate. Regardless of whether they saw their bosses in a positive or negative light, participants of this classification seemed less dependent on the bosses for protection or for problem-solving, especially compared to Team Leader and some Engineer participants. One participant perceived her boss to be someone "who just facilitates when I need a little assistance." She continued, " and I think when you get to this level, you don't need someone who supervises you, you need someone who can be a colleague..." One participant shared that she and her boss could "agree to disagree." Of particular interest, two bosses who received favorable comments by participants were female health care administrators, and one of these female bosses was praised because of the unique sensitivity and intuition she displayed in her role.

The only negative comments about bosses in this entire study came from two participants of this category, and both bosses were men. In talking about her new boss, one participant shared:

You need to manipulate him, that's the word. [You] need to manipulate the folks who have the power to give you what you want....manipulate the situation 'til you can get what you want, or you keep going back. I keep going back. 
The other participant talked about her boss's "intolerance for noise." This boss exhibited primary loyalty to the specialist physicians in making decisions, because of their influence in the community. Perhaps with their closer connections to the organization bottom lines, these participants had a better picture of how their bosses' performances impacted entire systems, and subsequently were more able to identify their bosses' weaknesses compared with participants of other classifications.

Compared with the participants of other classifications, these participants did not talk as much about other organizational players. Some participants talked about the value of teams, and teamwork in their roles and in their organizations, but it did not seem to be a major topic when their data was compared with other participant data. When teams were discussed, the focus was not on the relational aspects of teamwork, but on the business. For example, one participant, in talking about her organization's financial success, related: "I attribute that to the fact that we as a management team in the past have been very proactive in looking at ways to do business better." The group of players which seemed to be important for a number of them, were professional contacts outside of their organizations. The discussion on having a balanced life describes this finding in more depth.

\section{Beliefs/Values: Being a Nurse}

This group of participants exhibited the greatest degree of distance from their nursing foundations compared to participants of other classifications. One participant clarified her position for me: "...I think I'm seen in the organization as an executive first, and a nurse second, and a woman third....and that's exactly how I want it. Additionally she 
informed me: "I live in administration. I don't live in the nursing office." Further in the interview, in response to my question about her relationships with nursing staff, she stated: ...my initial reaction is that you're asking me a very traditional nursing question, and your question is probably out of date....I don't only represent nurses." Another participant, in discussing how her role had changed, said: "...so here you've gone from a world of really knowing about patient care, which is still kind of the core of what I do, to also being much more business-oriented." A third participant, in describing her relationships with nursing staff guessed: "I don't think they see me as much as a nurse, as one of the administrative people who happens to be responsible for nursing." Still another participant proclaimed, "I don't necessarily think of myself as a nurse first. I'm an administrator, my responsibility is to the corporation, but I can better understand needs because I am a nurse." Further support came from a fifth participant: "...I also probably diluted my role a little bit because I also attend the chief nurse executive meeting of [name of health care system].

Essentially, these participants viewed themselves primarily as health care administrators, responsible to the corporate bottom line, who happened to have nursing backgrounds. As a collective group, this was the only group of participants for whom being a nurse had the most negative connotations. Where the Team Leaders downplayed nursing, some Champions took on different identities, afraid to "dilute" their power by being seen as a nurse. They attested to the stereotype that nursing is a female, inferior profession.

These participants did seem to believe their nursing background was a benefit for them in their expanded roles, but it was insufficient in enabling them to fulfill their full 
realm of responsibilities. One participant commented: "I think a nurse can understand their [non-nursing patient care staff] issues, maybe more than an absolutely straight administrator that doesn't have a good feel for what happens on the floor." However, compared to the Team Leader participants, nursing was not a "cornerstone" which could be expanded to include additional responsibilities. The Champion participants asserted that their responsibilities required knowledge and preparation different from nursing, supplemental to their nursing core. Their thoughts of the future of the nurse executive role supported this perceived need for additional knowledge. In one participant's opinion, "...the script as far as nurse executives...is not very clear. So the loyalties in nursing versus operating a hospital is going to blur." Another participant opined: "I don't think there's going to be discipline-based leaders in organizations of the future."

More strongly desirous of being perceived as equals among the senior ranks of their organizations compared with other groups of participants, being a nurse seemed to heighten the conflicts between the participants and certain organizational players. Being perceived in a traditional nursing role for them meant being "put in a box." One participant complained:

...the one negative of this hospital that I've not particularly enjoyed is there is a very strong male culture. And there is the medical center [and a] very traditional view of nursing. They [the senior management leaders, influenced by physicians] really want to put you in a box about what's appropriate for your role. 
Another participant shared: "I think so often, there's the perception that if you're a nurse, that if you have so much of a patient focus, quality of care, that you're not as business-minded, as visionary as you need to be."

Being a nurse in these primarily administrative roles also created new sets of problems with physicians, because, in the words of one participant, "they don't know whether you're fish or fowl." She elaborated: "Being a nurse, and being a woman, and being an administrator," meant that "you're always seen as a nursing system....the physicians still see you as a nursing person." Another participant commented, "I'm an administrator." She added,

But I don't tell the physicians that, because the physicians don't see the nurse executive in that light. They see them-a nurse is a nurse is a nurse.... They see you as the Chief Nursing Officer.... The physicians will never perceive nursing as an equal. Whatever role you're in, if you are a nurse...and a female to boot, they will never think you're equal.

As shown in the above statement, the conflict over being seen as "fish or fowl" by physicians resulted in a game of "switching hats" by participants to accomplish certain goals. One participant described this tactic in talking about her relationships with physicians: "In this particular system, it [being a nurse] hasn't been a detriment, rather, a plus, in that there are....times when there is a benefit to me to play the traditional nursing role." Regarding this subject, she claimed: "And I can usually wear, and switch hats fairly rapidly." Another participant could play this game when necessary. Telling me that she believed in being direct with physicians, she also shared: "...I can flirt with them if I need 
to flirt with them..." Working with physicians who were around her same age was also helpful: "I can even identify with their wives, and so I can connect with them in that way." What was interesting in this study, was that the issue of "flirting" as a strategy had been brought up by one participant in another category, but the highest concentration of participants who employed "switching hats" tactics were found among participants of this classification. Participants of other categories seemed less aware of the subservient roles they assumed regarding physicians compared to the participants of this group. Perhaps these participants, with their strong desire "to win the war," found that on occasion, deliberately moving back into "the box" of being a traditional nurse served as a useful tactic.

The switching hats tactics used by these participants with physicians really demonstrated the complexity of the dilemma of being a woman, as well as a nurse, in a public administrative role. In many ways, Stivers' (1993) discussion of women in public administration was highly relevant for Champion participants, especially with their close connections to all organizational operations. Women in public administration face dissonance between expectations of being a professional expert, and expectations as women. Professional expertise in their public roles has been defined by men (Stivers, 1993). Professional expertise in nursing roles is associated with being a woman in a female profession.

The compounded dilemma nurse administrators face has also been addressed by Stivers (1991), and the "switching hats" participants provided a great example of that peculiar dilemma of being a nurse and a woman in a predominantly male work world. 
Professional expertise for these "switching hats" participants was situational, and could be defined in two opposing ways. Displaying professional expertise for these participants in their administrative roles meant largely taking on masculine behaviors, and downplaying their femininity. However, professional expertise for nurses, in the eyes of physicians, was considered to be characteristic of a female profession. Therefore, participants had to convince physicians of their clinical credibility by taking on either strongly feminine behaviors, or "traditional" nursing behaviors, and downplaying the more masculine behaviors which they mostly tried to emulate in their administrative roles. However, when they, as nurses, worked with physicians out of their more "masculine" roles as administrators, they experienced discomfort. These participants didn't straddle the division of moral labor regarding issues involving physicians, they hopped from side to side.

\section{Beliefs/Values: Caring for the Patient}

Patient care was conceptualized differently for these participants compared to other study participants. Their responsibilities to patients stemmed less from a focus on patient care needs, or on patient experiences, and more on patient care as a business. Quality care was important, because quality impacted the cost of that care. One participant described her challenge, related to patient care: "I'm trying to find the highest quality care at the lowest possible cost, and that means I've gotta move these patients through the hospital." Another participant conveyed a similar challenge: "To try to provide care, at the best price for the best value, and make a profit." This same participant, while talking about health care finances, stated, "By the time everybody takes a cut of that piece of the pie, by the time it gets to the patient, in the hospital, there's not a whole lot left over." Later she 
commented, "...when you see the patient there in the bed, you realize the business that we're in."

Patient care was directly related to cost issues for a majority of these participants, and in their perceptions, the clinical aspects of patient care were only a small portion of how patients influenced their responsibility to patient care. One participant opined: "...when you can blend the operations and the clinical and the business, to me it makes better sense for patient care."

\section{Beliefs/Values: Having a Balanced Life}

The data of the Champion participants stood out among the data from other participants regarding the subdimension of having a balanced life. All these participants valued the need for a balanced life, and all struggled with it. However, for five of these participants, either they had significant problems maintaining a balanced life, or if they thought their lives were in balance, their behaviors betrayed them.

Some of these participants exhibited similarities to the Engineer executives in their intense struggles to maintain a balanced life. One participant shared:

I love my job, and I love being a mom, and, the hours that you have to put in as far as meeting hours and flexibility and the expectations...it's not really understood by anybody....the need to be a mother, and that responsibility and the guilt that our society, or that we put on ourselves in being a mother is very difficult... Another participant had similar thoughts: "...you still have your mommy role, your wife role, and your professional role... The stress is balancing that, so that not any one area 
suffers." She shared with me that her first marriage suffered, because she was "too competitive and too 'workaholic."'

The concept of "workaholic" seemed to be demonstrated by this group of participants. Work invaded the private lives of the Champion executives. A good example was found in the story of one participant:

I usually have an hour-and-a-half to two hours of homework. That I do every evening. Just to kind of stay on top...Now do I need to do that? Probably not, it's a personal need that I have, I can't come in behind every day. On weekends it's the same thing, maybe on weekends it's two to three hours on a Sunday...

This participant added: "...my philosophy is, it's like is...and I just kind of deal with it....but I also take vacations..." Another participant, who considered herself to have a life in balance, told me that she could easily get away from work. Then she proceeded to tell me: "I'm attached to a beeper and a cellular phone and I can be a whole lot of different places, but I don't have to be at the hospital." In learning how to balance her life, she had previously stated: "I follow my male models, who actually do it very well." Still another participant described that she was fortunate to be able to balance her work and family responsibilities because she lived so close to the hospital and had a supportive husband. Claiming that her workload was not a problem for her, she related:

I do take things home....I have what I call my marathon days, where I'll come in on a Sunday, and spend six hours and just clear a whole lot of stuff out of my office. But, I try really, really hard not to take stuff home....I'm in my office between six and seven in the morning...I don't get home until six at night. So I figure, twelve 
hours a day in just enough. And that's with the caveat that I don't have any night meetings.

Participants of this classification did not seem to mind the workload, and they seemed to work hard to separate their work and personal lives. One participant explained: ...being a mother is difficult, but it's not something that can be very visible in organizations....you have to kind of juggle it, and deal with it, but it's not part of your work environment....My family concerns are not the concerns of this health system. They're my concerns...

This participant's narrative seemed to significantly contrast with the narrative of the Team Leader participant who had left work in midday to provide transportation for her child.

The dilemma of balancing competence and femininity (Mulqueen, 1992) for Champion participants arose out of their allegiance to a masculine definition of competence. They are similar to one female participant who Jack and Jack (1988) considered as emulating the male model in their lawyer study. In that woman's perceptions, successful male lawyers had adjusted their private lives to the public sphere, and she felt compelled to exhibit the same behavior. In his metaphor of organizations as instruments of domination, Morgan (1986) talked about the undue stresses organizational employees experience when they believe they must completely identify with what the organization stands for at the expense of a healthy personal life. Additionally, Stivers (1993) described the dilemma that dominating organizations present for women. Because women in the public sector have been anomalies, and because they suffer the consequences of economic arrangements that support accepted bureaucratic practices, 
women pay a greater price for trying to stay on the fast track (Stivers, 1993). Therefore, a woman who defines competence in a traditional masculine way, but feels a need to nourish a female identity as a mother, is vulnerable to experiences of anxiety and guilt as some participants in this study clearly demonstrated.

The factor of professional networking differed dramatically between Team Leader and Champion participants regarding the subdimension of having a balanced life. Two of the Champion participants had held high visibility positions in professional organizations at state and national levels. Professional networking, outside of the organization was emphasized by a number of them, and they admitted to receiving a great deal of support and mentorship from nursing colleagues of other facilities. Asserting that "you probably need to be the person to reach out," one participant emphasized, "I just can't encourage people enough to get out of your own organization." Their need to network outside of the organization exemplified the loneliness of trying to carve out new roles in unfamiliar and hostile territories unaided.

\section{Defining the Mission: Growing the Business}

The action of growing the business seemed to best encompass all the other actions participants of these classification deemed important in defining and carrying out their missions. In the case of at least two participants, failure of their organizations to grow the business could directly impact their jobs. "Grow the business" was taken from the text of one participant, who specifically described that she was attempting to get recognition for her organization, which would influence the organization's "ability to grow the business."

Defining their most important responsibility as the corporate bottom line, meant 
changing traditional nursing thinking about being a nurse and about patient care. In order to have an impact on corporate bottom line, and have a voice in that mission equal to all other organization senior administrative staff, a number of participants believed that one had to "think like a businessman," to quote from one participant.

The importance of learning to think like a businessman was emphasized by one participant: "...for a long time in nursing, we used to have this attitude about, well, financing needs to learn to talk our language. And they're never going to do it. You need to learn to talk their language." Another participant (the only participant with an earned doctorate in this study) asserted:

...nurses in those positions need to have doctoral preparation, need to have a very strong financial and business background, really need to be able to speak on an equal basis with every other person that's sitting around the table, and very frequently it is gentlemen, and be able to look outside of just nursing.

Learning this new language was done in several ways. Several participants stressed the need for nurses in positions similar to theirs' to have MBAs. One participant would advise the nurse executive of the future to "absolutely get an MBA. An MBA....because then you're an equal. I mean, as far as education." Several participants, who held graduate nursing degrees, described the experiences of learning the new language as going "from expert to novice," and as "baptism by fire." Both of these participants had been helped by strong mentors, who had helped them grasp the financial aspects of organizational life. Acting like a businessman had specific implications for the behaviors of certain participants. "Having a thick skin," and dealing "without emotion," were important in 
carrying out the mission. One participant explained: "Because men don't-when you're dealing with men, and you want to be seen as an equal, you've got to deal without emotion." Furthermore, being seen as strong was considered an asset for this participant, as well as several others: "You need to be strong, and you need to not be afraid to come right back at them forcefully....If they're swearing at you, you need to come right back with the same word." In direct contrast with the Team Leader participants, these participants were less accepting of maintaining their femininity in a situation "where the species is it." These participants seemed to shape their behaviors to fit a masculine image of a businessman.

Making change was important to these participants in growing the business, and being able to make change required a central role in organization-wide decision-making. The services of several participants had been procured "under the gauntlet of change." One participant shared: "I never envisioned that I would be running whole-I'm basically running a majority of the hospital from the operations standpoint." Another participant described herself as needing "to pull all the pieces together," for an organization which seemed very fragmented in terms of structure.

Comparing and contrasting the narratives from all study participants, Champion participants were determined to "win the war" and would exercise power either overtly or covertly to do so. One participant told me, in a joking fashion, "I have no difficulty influencing change. I have difficulty in not being responsible for it after I bring up the idea." "Picking your battles" was important to several participants in winning the war, but had two slightly different connotations regarding risk. One participant, in proclaiming that 
she wanted to "win the war," made choices regarding, "Is this the hill I want to die on today?" This participant seemed able to exert power by selecting her battles. Another participant, had less choice in selecting battles, and shared:

You learn, over the years in management, what battle to pick. What battle you know might be worth fighting because you might have a chance to win, and what battles don't waste your energy on because you are not going to win.

This last participant had expressed needing to "manipulate" her boss to effect change. Experiencing less control in her organization meant strategizing to exert power, and unless she could win the war, certain battles were not worth pursuing. Champion participants seemed to have a particularly low tolerance for losing battles.

"Growing the business," in and of itself, does not convey a strong gender message. A strong "warrior mentality" in growing the business does bring up important points about masquerading in a man's world. Lorber (1994) stated that women usually do not challenge the social institution of gender. They may, in fact, reinforce it, but there is a cost for an affirmation of male superiority (Lorber, 1994). The fact that a number of these participants seemed to perceive themselves as warriors, either engaged in battle or winning wars, conveyed an unwitting collaboration with an androcentric environment of male domination. Furthermore, there was a stronger emphasis from a number of these participants compared with other participant classifications about the need to downplay a feminine identity to survive in the corporate health care environment. When women affirm male supremacy by taking on a masculine identities, they send mixed messages which 
contribute to confusion and suspicion regarding their behaviors (Lorber, 1994; Stivers, 1991; Stivers, 1993).

Lorber (1994), using Joan of Arc as an example, pointed out that when Joan of Arc was elevated to sainthood in 1920 , "she was presented as a sexless virgin, amenorrheic and possibly anorectic" (p. 89). The only way she could be historically accepted as being virtuous was to be seen in an androgynous way. Being portrayed as a woman conveyed lack of virtue and power, but borrowing a powerful and virtuous masculine persona was also unacceptable (Lorber, 1994). Lorber (1994) claimed that by today's standards, Joan of Arc would most likely be viewed as a woman warrior, but her gender representation still contributes to ambiguous interpretations by various societal institutions. As one example, Lorber (1994) pointed out the heightened awkwardness one female cadet experienced when she saw Joan of Arc depicted in a mural representing history's greatest warriors in the dining hall of West Point. The same awkwardness, or discomfort, was felt by these participants in defining their mission in a masculine way, especially in their relations with physicians, with some bosses and corporate managers, and with themselves as women, especially in their personal lives.

"Growing the business" did not necessarily mean that the voice of care could not have been present in their execution of organizational responsibilities, and I do not wish to imply that these participants were not caring individuals. However, based upon the data, and compared with data of other participants, a humanistic voice of caring had been reduced to a whisper for the Champion participants, and I listened for a new voice which I couldn't hear. The Champions overall seemed to have aligned themselves with the 
masculine side of the division of moral labor in their organizational lives, yet a voice of caring for the profession, and for each other, was present in their extra-organizational lives.

The problem confronting these participants was that philosophical discourses about justice and caring as they relate to women had outpaced societal institutions which sustained moral divisions of labor. A number of feminist philosophers have made strong cases that caring practices can be carried into the public sphere of life (Bowden, 1997; Card, 1995; Friedman, 1995; Held, 1995); into those realms which have been traditionally considered masculine realms of existence, but there is not much evidence to support their assertions since women have been largely omitted from the public sphere.

For example, Card (1995) argued convincingly for how caring might extend into the public realm. She claimed that attachment to individuals does not make caring a virtue, yet the values of attachment are necessary for an ethics of interpersonal relationships. In reviewing Gilligan's (1982) work, Card (1995) found what she described as a less dominant hypothesis; that different ethical concepts, priorities, methods and preoccupations arise out of the responsibilities of different kinds of relationships. Taking responsibility for someone or something means that the focus is on well-being, and not on control, as traditional contracterian and utilitarian ethics would claim (Card, 1995), and which have supported a masculinist viewpoint of public life. Endorsing a perspective that extends beyond the gender polarization of justice and care, Card (1995) argued for a stance in which the moral relationship between persons is that which grounds responsibilities. Card (1995) claimed that when a focus is on well-being, responsiveness to 
needs takes precedence. Irrespective of what she said about justice, care, and responsibility, Card's (1995) conception of morality was people-centered.

This idea of "people-centeredness" offered one way for assessing the way the Champion participants defined their leadership actions. However, the Champions in this study made only weak allusions to the importance of peoples' well-being in growing the business. One participant's comment brought up a sense of obligation to the patient in her statement: "...when you see the patient there in the bed, you realize the business that we're in." In that sense, growing the business took on an ethical tone by suggesting that the business enhanced patients' well-being. However, one participant claimed that competition between health systems shouldn't interfere with the sharing of information that would benefit patient care and yet, that same participant, who worked in a for-profit system, had also shared the importance of a good bottom line in the statement, "We've got stockholders that we've got to placate." Another participant made a similar statement related to finances: "I'm trying to find the highest quality care at the lowest possible cost, and that means Ive gotta move these patients through the hospital." The allegiance to the stockholders, and the objectification of patients into cost units communicated by these last two comments did not suggest a focus of responsibility geared toward the well-being of people in an ethical sense.

In order to be gender-sensitive, there is an important point to be made regarding the diminished caring voice for this group. These women had been propelled into arenas previously considered to be parts of the male domain. More than any other group of participants, they had taken risks, or taught themselves certain aspects of organizational 
management in order to survive in their changing positions. More than any other classification of participants, they were probably most like the women who go into public administration described by Stivers (1993), with their close affiliation to the organization and corporate bottom lines.

Bowden's (1997) and Stivers' (1993) discussions about women in public service, especially pertain to these participants in the ways in which they defined their missions. Bowden (1997) described a type of caring practice she referred to as citizen relations, where caring values associated typically with interpersonal relations would be carried into the public realm, and transform caring values into public ideals. Bowden (1997) admitted that this transformation would be difficult, because the formal practices of caring have been largely assigned to women in the private realm of existence. Stivers (1993) countered the view of transforming the idea of public virtue in defense of administrative authority, which seemed to be what Bowden (1997) was suggesting. She stated that advocates of an idea of public virtue, which would be imbued by qualities that have been associated with women, would be an insurmountable task. The problem is not about public virtue according to Stivers (1993), it is about the possibility of its existence without a clear understanding of the gendered division of life in this society. She contended that the practice of public administration must be revised.

Stivers (1993) raised an important concern regarding this study. No matter what the philosophical potentialities are for the extension of caring practices, the sociological factors which inhibit those potentialities have to be considered. In many ways, these participants exhibited the characteristics of oppressed group behaviors as described by 
Roberts (1983) in the way they defined their leadership actions. They aligned with the strongman elite oppressors in order to be viewed as powerful and have economic control, although they were different in that they didn't seem to exhibit oppressive behaviors toward other organizational staff. They certainly had taken nursing farther in terms of power and control when compared with the status of nurses in Ashley's 1976 work on paternalism in the hospital setting. They seemed to honestly believe that the nursing profession would benefit by learning more about the oppressor, and by assimilating many oppressor behaviors in order to gain power.

\section{Battlefield Position/Professional Identity: The Champions}

Compared to participants of other categories, the Champions overall perceived themselves having a great deal of influence in their organizations, a more direct connection with the organization bottom line, and in some cases, a more direct link to the managed care environment. In some cases, they were as equally effected by economics as the Engineer executives in carrying out their missions, but they took a firm position in choosing their primary responsibilities. Compared with Team Leader, Unsung Heroine and some Engineer participants, they seemed less dependent upon other organizational players in determining their missions, and serving people was only a small part of their calls to action. Although isolated within their organizations, they were more connected to each other through professional organizations and deliberate networking efforts, particularly when compared with Team Leader participants.

Serving in their positions required a greater change in how they thought about themselves as nurses, compared to all other classifications of participants. There was a 
marked difference between the Champions' and the Unsung Heroines' perceptions of being a nurse. The Champions, more than any other classification of participants, seemed to be leaving their nursing identities behind as they carved out their missions. Changing their thoughts about being a nurse, and maintaining a primary allegiance to the corporate bottom line, also required a shift in the way they thought about patients in their daily operations. Quality patient care was important because of its financial impact upon their organizations.

The Champion participants, for the most part, loved their jobs, in spite of the sacrifices they made in their personal lives to accommodate their work lives. Their sentiments about this sacrifice seemed to be covered in one participant's narrative:

Women executives today, I think they make it on their merits, and if some people say they have to work harder at it, maybe they do, maybe they don't....it's such a competitive market, and either you produce or you don't produce.

Only one participant stated that she knew she didn't want to stay in her position for a long time, and defended that thought as being normal for people in her position. This same participant shared:

Well, you know, it's not the workload that bothers me. It's some of the parochial views you have to combat. And I think, you know, health care is still a service provided by women and managed by men. And that's kind of the bottom line. Compared with other participants, the Champions were more tolerant of an unbalanced life and less tolerant of some of the outside organizational forces impacting their missions. They seemed less tolerant of not being in control, less tolerant of not being seen as equal 
in their organizations, and less tolerant of being stereotyped as a "traditional" nursing administrator.

The Champions seemed to be reclaiming conflict, but not in the healthy way Miller (1986) described, because as a group, they did not seem authentic, or true to their own identities. They were intensely fighting the subordination associated with being a woman and a nurse on a patriarchal battlefield by trying to be warriors, although they were still perceived as heroines.

The voice of the Champion participants was louder than the voices of other participants in this study, but it was a voice which was very different from the Unsung Heroine, the Engineer, and the Team Leader voices in that it was less people-centered, and more influential both within and outside of the organization. It was also largely a masculine voice, although some times it cracked in deference to its feminine foundations. Although this voice portrayed confidence in its battlefield position, it also communicated a certain fragility and vulnerability by continually echoing off the socially-defined walls of gender.

\section{Summary}

The story of the heroines continues with the Team Leaders and ends with the Champions. On the heroine typology continuum, the Team Leader and Champion participants were more stable regarding their calls to action, or primary moral commitments, compared with the Unsung Heroine and Engineer participants. They had made decisions regarding their allegiances to either the human resources or the financial aspects of organizational life. 
The Team Leaders determined their battlefield positions out of their allegiances to the people of their organizations. Carrying the banners of the patient care team, and the patient's experience, and having relatively balanced lives, they were totally committed to their mission of building, caring for, and feeding the teams who served the patients. Shielded to some degree by other organization staff from the direct impact of economics, they were less concerned with winning health care battles, and more concerned that battles would result in a win-win for everyone involved. Armed with their patient care team banner, they maintained that nurturing the team was the best way of sustaining the organization in tough economic times. Consumed with their organizational and personal lives, they were particularly isolated from outside professional contacts on the managed care battlefield, compared to other heroines.

The Champions were perhaps the most visible heroines, with the loudest voice on the managed care battlefield. They defined their primary mission as growing the business of their health care organizations. More directly engaged in battles related to economics compared with other participants, they carried the banners of the health care business and the cost of patient care. Willing to sacrifice a balanced personal/professional life, these heroines were driven by visions of winning the war and running the ship. As organizational change agents, they tended to minimize their nursing backgrounds, and learned to play new games by new rules. They also worked to build and sustain alliances with outside organizational contacts.

The story of the heroines provided some critical insights about the future of professional nursing in institutional health care settings. From this study, there are strong 
implications for nursing administration, nursing education, nursing research, and the entire nursing profession. The next chapter will discuss the conclusions and implications which were drawn from this study. 


\section{CHAPTER SEVEN}

\section{CONCLUSIONS AND IMPLICATIONS}

This chapter concludes the report of this study. The chapter includes a (a) a study summary, (b) a critique, (c) conclusions, and (d) future implications. The section on implications involves (a) nursing administration and leadership, (b) nursing education, (c) nursing and health care research, and the (d) macro-organizational perspective. The chapter ends with some final thoughts about the study.

Summary: A Story of Heroines on the Managed Care Battlefield

This is a story about four groups of heroines on the managed care battlefield of Southern California. This story took place during a time in history which might be called, "The Managed Care Revolution." In response to the economic challenges arising out of this revolution, these heroines were tasked with finding their battlefield positions and taking nursing into some uncharted terrain. All heroines served as top nurse executives in institutions which provided patient care, and all but one were stationed in hospital settings.

While greatly influenced by the support and dynamics of the organizations in which they functioned, there were no guidebooks to help the heroines determine their most important calls to action, define and carry out their missions, and find their battlefield positions, or professional identities, especially because Southern California was a leader in the overall revolution. All heroines had begun their careers as clinical nurses, and all had a wide variety of backgrounds and experiences. All had served at one time in Chief Nurse 
Officer, or Director of Nursing roles. One group all heroines had to confront on the managed care battle battlefield was the physicians, for nurse-physician conflicts had clearly been carried into the battlefield. In determining their most important calls to action, missions, and battlefield positions, the heroines had to confront the dilemmas between cost and care, and femininity and competence; they had to figure out where they stood in response to the gendered division of moral labor. The heroines formed into four distinct groups.

The Unsung Heroines determined their battlefield position by defining their mission as moving nursing out of the ivory tower. Carrying the banner of some traditional nursing beliefs and values into the battlefield, and experiencing a minimum of stress in their personal and professional lives compared with other heroines, they were just beginning to appreciate the impact that economics could have on their organizational lives.

The Engineers determined their battlefield position by defining their mission as finding middle ground. Being called to action by both the financial and human relations aspects of organizational life, they were a little unclear about the banners of professional nursing, and patient care. The competition among their calls to action and their professional banners also greatly impacted how well they balanced their personal and professional lives. Their mission was to find balance between the competing elements of finances and human relations, while staying strong and healthy in their personal lives. Well aware that economics was a major factor in all of their actions, when they were able to skillfully balance all the calls to action, as well as their personal and professional lives, they 
weren't sure how long they could maintain their battlefield positions. The Engineers overall had the most stressful positions on the managed care battlefield.

The Team Leaders determined their battlefield positions out of their allegiances to the people of their organizations. Carrying the banners of the patient care team, and the patient's experience, and having relatively balanced lives, they were totally committed to their mission of building, caring for, and feeding the teams who served the patients.

Shielded to some degree by other organization staff from the direct impact of economics, they were less concerned with winning health care battles, and more concerned that battles would result in a win-win for everyone involved. Armed with their patient care team banner, they maintained that nurturing the team was the best way of sustaining the organization in tough economic times. Consumed with their organizational and personal lives, they were particularly isolated from outside professional contacts on the managed care battlefield, compared to other heroines.

The Champions were perhaps the most visible heroines, with the loudest voice on the managed care battlefield. They defined their primary mission as growing the business of their health care organizations. More directly engaged in battles related to economics compared with other participants, they carried the banners of the health care business and the cost of patient care. Willing to sacrifice a balanced personal/professional life, these heroines were driven by visions of winning the war and running the ship. As organizational change agents, they tended to minimize their nursing backgrounds, and learned to play new games by new rules. They also worked to build and sustain alliances with outside organizational contacts. 
Study Critique

This study asked the question: What are the perspectives of the woman/nurse/executive working in the managed care environment of Southern California? The study question was answered in the form of an explanatory matrix which was synthesized from participant data, and which led to a typology of participants. However, because this was qualitative research, generalizing to other populations can not be assumed. In the best case, the responses of participants in this study might be thought of as providing one snapshot of the lives of a certain group of nurse executives at a particular point in time. However, a critique of that snapshot is necessary. Was the snapshot an appropriate and dependable representation of the participants (Hall and Stevens, 1991) of this study?

Adequacy, or standards of rigor, and their assessments were discussed in Chapter Three on Methodology. Adequacy was ensured using those standards. However, there are two standards which are important regarding the adequacy of this study, and which must be discussed as limitations. These include theoretical sensitivity under the standard of reflexivity as I operationalized it for this study, and credibility.

In assessing theoretical sensitivity, sampling must be addressed. The sample of convenience for this study had both negative and positive implications. Had I been able to recruit nurses who had moved into COO or CEO positions, as well as nurses who had recently left nursing executive positions, the overall findings of this study might have been either greatly strengthened, or very different. The responses of COO or CEO nurses would have shed considerable light on the typology which emerged from this study, or 
may have actually altered it. Also, more information about organizational and corporate influences on nurse executive promotion would have been obtained. Furthermore, while the responses from study participants seemed to show depth and honesty, a greater degree of insight and honesty might have been possible from responses of recently-departed nurse executives, which would have served as a check for the depth and honesty of responses of currently employed participants. However, the relative homogeneity of the sample has advantages in that the findings were exclusively those of the practicing nurse executive community, and can be considered relevant in other understanding nurse executives serving in line positions of authority in for-profit and not-for-profit institutional health care settings in a heavily managed care environment.

The other concern which must be addressed is credibility. According to Hall and Stevens (1991), feminist research reports are most credible when interpretations of participants' experiences are considered as faithful representations by actual participants. Because of the time limitations of this study, the logistical issues in gaining entree to participants, and the length of time participants took to review and return transcripts to me, involving them during the study to validate my interpretations of their experiences was not feasible.

Because participants were not involved in discussions about the findings, the possibility of my bias interfering with the data analysis and interpretation of results exists. While I tried very hard to keep my feminist voice from intruding during these phases, I have to claim total responsibility for the way the findings were synthesized into framework, and the interpretation of that framework. For that reason, I suggest that the 
findings of this study be presented, shared, and discussed throughout the Southern California nurse executive community, and I strongly encourage an extension of this research with participant validation of findings.

\section{Conclusions}

At this point, the question is raised: What new information did this study contribute to the body of nursing knowledge? This question is particularly important, because there is such a paucity of research and knowledge about female nurse executives, and the findings of this study invoke serious concerns for the nursing discipline, especially regarding future viability in acute care institutional settings. My hope is that this study will serve as a wake-up call for the entire nursing profession.

The irony of this study was that it was feminist, and yet a patriarchal metaphor of a battlefield as the study context was so strongly supported by participant data. The women in this study were collaborators in the perpetuation of the androcentric and inequality lenses of gender as defined by Bem (1993). Androcentrism was the unchallenged societal norm for all the heroines on the battlefield. Androcentrism, or male-centeredness, defends male experiences as the standards for our social reality, and defines female experiences as deviations from those normative standards (Bem, 1993). Gender inequality was an additional norm unwittingly accepted by participants of the Unsung Heroine, Engineer, and Team Leader categories. Gender inequality highlights and asserts male superiority in male-female differences (Bem, 1993). All heroines in this study overtly communicated perceptions that they were pioneers in health care delivery while conveying deeper 
messages that they were second class citizens because of being a nurse and being a woman.

I have already mentioned credibility as one of the study limitations. Data analysis and interpretation of findings were not checked with participants. Participants did not have an opportunity to validate my findings with their experiences. While I have tremendous respect for all of the participants, my suspicion is that many of them would either challenge or deny the conclusion that they all perpetuated androcentric thinking and gender inequality, which would be typical of oppressed group thinking (Roberts, 1983). I believe that they truly envision themselves as pioneer women forging new professional paths. However, are these paths for the benefit of their organizations, which are dominated by masculine thinking, or for the nursing profession?

I don't think any of the participants realized just how deeply embedded androcentric thinking is in health care delivery systems. Amazingly, over 20 years have lapsed since Ashley (1976) published her seminal book, Hospitals, Paternalism and the Role of the Nurse, and while nurse leaders have come a long way, this study revealed they are still dealing with significant amounts of paternalism in the hospital setting. According to the participants of this study, nursing still is largely perceived as a female, subordinate profession. Achterberg (1990) predicted that the patriarchal layers would increase with new systems of health care delivery, and the data of this study revealed that female nurse executives working in managed care environments now also have to confront patriarchal attitudes at the corporate levels of health systems. Furthermore, physicians, especially the group of specialist physicians and middle-aged or older physicians, are still major 
contributors to androcentric thinking and gender inequality in their domineering attitudes and behaviors toward nurses according to study data.

A great example of gender discrimination of which participants were unaware was found when I was doing the organizational analysis part of this study. Two participants worked for the same health system. One participant told me that in her opinion, because of the corporate patriarchal culture, a woman would never be admitted into the corporate ranks. The other participant worked in an entirely different organization for the same corporation, but in a role where she was more directly responsible to corporate headquarters. However, her reporting arrangements were different from those of the men at comparable levels in the corporate hierarchy. She reported to corporate headquarters via another individual, a male, and therefore was essentially denied the full corporate membership to which she was entitled. In evaluating these two cases, what seemed evident was that the corporate fathers were staying true to their convictions. A woman was not going to be fully admitted into the corporate hierarchy in that system. Nurse administrators and executives are going to have to acknowledge system-wide gender oppression in order to be able to eliminate it.

My discoveries in this study worry me because they suggest that nurses in service leadership positions perceive the only way to become more powerful in organizational settings is to suppress the caring voice of nursing. This finding is curious at a time when the nursing administration literature has endorsed the inclusion of caring in nurse administrative practices (Miller 1988; 1991; Nyberg, 1993; Ray et al. 1995). The Role and Function of Nurses in Executive Practice, published by the American Organization of 
Nurse Executives (AONE) in 1995 describes the role transition occurring in nurse executive practice: "The role of nurses in executive practice has evolved from a focus on nursing services to a broader accountability for patient care services across the continuum." However, the preamble to this document states: "The essence and values of nursing form the basis for all nursing roles and are the foundation for the advanced practice of nursing administration."

The responses of the Unsung Heroine, the Engineer, and the Team Leader participants did seem to endorse administrative practices based upon nursing foundations. In particular, the Team Leaders presented the most hopeful picture for expanding the nursing executive role in a way consistent with nursing philosophy. They seemed able to extend the idea of nursing service and patient care to include all personnel involved in patient care. However, the Team Leaders communicated an unfortunate message to the nursing profession by suggesting that the nurse executive downplay being a nurse. Their responses conveyed that in order to gain power, the nurse executive must change her professional identity to something other than being a nurse. The underlying message is that caring, people-oriented, administrative practices are possible for executive women, but not for executive female nurses.

Additionally, the open acceptance of androcentrism and gender inequality in Health Services Organizations by the Team Leader participants was especially disturbing. According to Team Leader participants, executive women could sustain caring, people-oriented administrative practices by resigning themselves to the fact that they live and work in a male-dominated society where women will never be equals. 
From the patriarchal managed care battlefield of this study, there was only a weak feminist voice coming from some study participants. The only group as a whole that challenged gender inequality consisted of the Champions. Many Champions communicated ideas consistent with a liberal feminist viewpoint. Liberal feminism stresses equality of opportunity for women, and is critical of unequal distribution of wealth, power, and position based on family, sex, or race (Chinn \& Wheeler, 1985). One way women solve their leadership dilemmas about working in a male-dominated world is by taking a pragmatic stance and setting out to eliminate the barriers to progression in the leadership hierarchy (Stivers, 1991), which is consistent with a liberal feminist viewpoint of achieving equal opportunity for women. The expectation is that as women show they can be as tough and as bold as men, leadership characteristics will no longer be seen as masculine, and the barriers which impede women from getting to top leadership roles will weaken. Women who operate out of this belief learn men's games and try to beat them at it. They try to learn the strategies which will enable them to fit into the organization (Stivers, 1991).

Most of the Champions in this study had learned to play men's games by men's rules very well in attaining organizational success. The Champion participants were like those women Lipman-Blumen (1991) found in her studies of female executives who were beginning to imitate male colleagues at the risk of undermining their own leadership advantage as women. The hero, or warrior mentality, of these participants embraced the masculine American ego-ideal of rugged individuals, creative and visionary, who take control by pitting themselves against almost insurmountable odds and winning 
(Lipman-Blumen, 1991). The suppression of any "female" style of behavior in these participants may have been out of a fear of the societal association between female behavior and powerlessness (Lipman-Blumen, 1991). The Champions communicated beliefs that organizational success depends on displaying a masculine business persona, and requires shedding both nursing and female identities.

If nursing is to survive in institutional health care settings, a radical approach which requires systems change is necessary. We must challenge the systems which perpetuate masculinist ideas about leadership in health care delivery. I do not believe that aligning with patriarchal thinking by nurse executives is a useful strategy. I believe that woman/nurse/executive empowerment should not require changing either one's gender identity or professional identity. Taking on oppressor characteristics by nurse executives in institutional health care settings is not going to gain for the nursing profession the autonomy and status necessary to enhance the essence and values of nursing in this environment of cost-containment.

Stivers (1993) asserted that the institution of public administration must change before the issue of the division of moral labor (Held, 1995) can be resolved. Her statement is relevant for systems of health care delivery. These systems must change if the practice of professional nursing in institutional settings is to be supported. No participants in this study suggested or even alluded to the need to change systems of health care delivery in a way which would enhance professional nursing practice. Any systems changes in which they had been involved were primarily for the benefit of their organizations, and advancing the profession of nursing was a secondary gain. 
There is some thought that nurses are becoming invisible in the hospital industry (Anderson, 1995), and the findings from this study imply that as the nurse executive role expands and merges with other executive roles this invisibility might be happening. I could not find evidence that nurse executive role expansion was benefiting professional nursing practice. If health care leadership in acute care institutional settings is becoming less discipline-based, as several participants predicted, then several questions are raised: What is the value of being a nurse in hospital leadership roles? Furthermore, who will advocate for professional nursing in hospitals? Finally, a deeper, more troubling question arises: Is professional nursing in institutional hospital settings becoming obsolete?

\section{Implications}

\section{Nursing Administration and Leadership}

The findings of this study raise grave concerns regarding nursing executive practice. Based upon the data from this study, nurse executives are clearly transitioning into new roles as a result of changes in health care financing in Southern California. From the responses of several participants, the merger of the hospital roles of nurse executive and of chief operations officer in a environment where layers of organizational hierarchies are being flattened is just a matter of time. The nursing service leadership community must pay attention to figuring out the value, if any, that a nursing background adds to health care executive roles, as well what professional nursing contributes in institutional health care settings.

There is little doubt that the nurse executive role is becoming more influential in organizational settings. This increase in power was conveyed by the Engineer participant 
who stated that the nurse executive was becoming a threat in the community, because she or he could supervise a variety of clinical areas in addition to non-clinical areas. For that reason, nobody wanted the nurse executive to become too articulate or strong, because his or her own job would be threatened. By the participant's statement, nurses, as a result of their clinical background, clearly have an advantage in assuming new roles not previously attainable. The statement also implied that institutional and societal gender barriers would be erected to try to inhibit nurses from moving into these roles. Will nursing leaders blindly accept these barriers, or actively work to remove them without surrendering their identities as nurses?

If nurses executives are poised to move in new directions; directions which will take them into mostly traditional male terrain, the issue of the division of moral labor has to be addressed. One key process of nurse executive practice according to the AONE (1997) is: "Advancing the Discipline of Nursing." How can one advance the discipline of nursing, while downplaying the fact of being a nurse?

There is little doubt that the responses of the participants in this study may have been largely the reflections of the organizational cultures in which they practiced, and this study tried to get a sense of organizational culture, but wasn't specifically designed to evaluate it. Kerfoot (1997) stated that many organizations are involved in trying to decide if they are business-driven or mission driven. The Unsung Heroines may have been functioning in organizations which were either just beginning to engage in the debate, or had long-resolved the debate and were quite stable. The Engineer participants may have been a reflection of organizations in the middle of this debate. Many Team Leader 
participants openly referred to their organizations as mission-driven, and Champion participants may have reflected an organizational culture which was largely business-driven. Furthermore, participants mostly likely chose to work in certain organizations which were congruent with their values.

However, if participant responses largely mirrored organizational cultures, the implications are even stronger for the nursing administration community. Kerfoot (1997) claimed that the culture of an organization reflects its soul. Soul was defined as the essence, substance, fervor, energy, and leading spirit behind the driving forces of organizational culture. Organizations which are only bottom-line driven hamper the development of that soul, resulting in alienation and burnout (Kerfoot, 1997).

Nursing administration professional organizations must stop being reactionary in their responses to the changing picture of health care finances, and start looking at organizational practices from ethical perspectives. Maybe the time has come to start assessing the souls of organizations. Nurses did not create the concept of managed competition, but they are now left having to figure out how to survive in a climate where managed competition is a reality.

A more radical thought is that perhaps professional nursing will never flourish in institutional health care settings. History, along with the findings of this study, reveals clues that should be considered in planning for the future of nursing and nursing leadership. First, hospital nurses have worked, and continue to worked in patriarchal healthcare settings, where the conditions of nurses have correlated closely with the attitudes toward women over the last 150 years. Second, the status of professional nursing 
in institutional acute care settings has not been and still is not favorable to autonomous nursing practice with its fundamental ethic of caring. Third, the role of the nursing leader, whether matron or executive, has always been under the tight control of other healthcare workers, with a premium placed on alliances to the institution versus the leader's own professional colleagues.

I was surprised that overall, study participants were not very visionary in their predictions for the future of nurse executive practices. Few participants in this study mentioned the need for strong nursing executive leadership in settings other than hospitals. Ambulatory care, public health, home health, alternative health, occupational health, case management, etc., all represent arenas outside the confines of the hospital walls where * strong nursing leadership and professional advocacy might better flourish. Perhaps those settings are where the nursing executive community should be making inroads in defining and supporting professional nursing practices. At the same time, the ethical question of whether patients in hospital settings have a right to receive professional nursing care must be considered. Additionally, if patients have this right, then how will the nursing executive community advocate for them?

Kerfoot (1997) asserted the need for the health care leaders of the new era to have the courage to care. The new leaders need to go beyond bottom-line performance, and care for organizational staff as well as for the contributions of the organization to the community (Kerfoot, 1997). Nurse executives need the courage to communicate pride in being a nurse. Therefore, while nurse executives need to be knowledgeable about, and involved in the business aspects of health care delivery, suppressing the nursing identity 
and taking on masculine leadership traits are not the answers for either patient or nursing advocacy.

The issues of what impact managed competition is having on professional nursing practice and on the administrative practices of nurse executives must be exposed, discussed, argued and debated among the entire nursing leadership community. This is not the time for silence from this community. The findings from this study suggest that the organizational commitment of nurse executives in this managed care environment is becoming more deeply entrenched than professional commitment, and these findings forecast a tenuous future for professional nursing practice in hospital settings.

\section{Nursing Education}

Study findings indicate that there is no time like the present for nursing academic and service partnerships. I don't think the entire nursing profession has fully accepted that the meaning of being a nurse in today's society still connotes a subservient status in the eyes of other health care professionals. Having the courage to advocate for professional nursing requires reinforcements and support, and this study hints that the work demands of the community of nurse executives seem to be isolating them from their profession, as they become consumed by organizational expectations and commitments.

Nursing educators need to be focusing on these new nursing leaders, studying what they are doing in their expanded roles, and helping them to support ethical, caring, professional nursing practices if nursing is to survive in hospital settings. If we agree that professional nursing practice should continue in hospital settings, then we need new 
definitions of leadership in organizational health care settings which are not based upon a masculine perspective.

The problem faced by most participants in this study was a lack of adequate preparation for their expanded roles. Most learned how to function in their roles by "trial and error." "Baptism by fire," and going "from expert to novice," were painful ways of gaining the necessary education and experiences. Since women and nurses have not been included in the upper echelons of health systems management, female and male mentors for advanced nursing executive roles are non-existent. Seeking help from male models, as well as avoiding conflictual issues, were both natural behaviors for study participants. A strict nursing background was helpful, but not enough to manage the rapidly changing demands of organizational leadership. Even the most highly educated participant in this study, who held a nursing doctorate, admitted that doctoral level preparation was very important, but that a strict nursing focus was inadequate for these expanded roles.

Furthermore, a fair number of participants had ended up in nursing administration roles by chance, or "by default." Even the doctorally-prepared participant admitted:

I wouldn't say that it was necessarily a well-thought-out career track, because I wanted to do this, and then I wanted to do this, but I really just had opportunities that were presented to me, and I just took a risk on some of them.

From the responses of participants in this study, my guess is that none of them had been exposed to courses in feminist perspectives or feminist theory. Nursing administration curriculums must include a heavy dose of feminist perspectives along with topics of business and finance. Potential nurse administrators need to be well-versed in the 
business, organizational, and economic aspects of organizational life, but they also need to have their consciousness raised regarding of all the gender issues which will confront them. These nurses need to know that caring for people is the key to leadership in organizations, and that surrendering the caring values associated with women and nurses does not make a good leader. They must understand and accept the challenge of redefining nursing leadership in institutional health care settings.

If we believe in the value of having nurses in executive health care roles, then we need to convince aspiring nursing leaders that following a leadership or administrative career track is acceptable early in their careers. This track can be built upon and combined with a solid clinical foundation. Some of the reasons nurses don't intentionally pursue leadership opportunities may have to do with what Miller (1988) called the leadership versus constituency issue in nursing. Nurse administrators have been perceived as distanced from the actual work of nursing, and therefore not in a valuable role. Furthermore, there has been a stigma of being a nurse administrator because of the perception that nurses in these roles were aligning with the patriarchy in order to acquire power (Roberts, 1983).

The nurse executive role seems to be getting so complex, that better career planning, with years of education and experience, will be the only way a nurse can survive in such a demanding role. If nursing is to continue making headway in expanding into advanced leadership roles, and if the expectation is that the nurse executive has a mission to advance the discipline of nursing, doctoral preparation in nursing must become a prerequisite for a nurse executive role. That preparation is going to require courses in 
feminist perspectives, advanced nursing theory, and leadership ethics, as well as in business and economics.

\section{Nursing and Health Care Research}

This study points out the tremendous need for research about the nurse executive community. Qualitative studies like this one need to be continued to learn more about the experiences of serving in these roles in order to plan for the future of nursing.

In relating this study to previous research about nursing executive experiences, this study is probably most like that done by Irurita (1994), which was mentioned in the review of the literature in Chapter Two. Irurita conducted a grounded theory study of top nurse administrators, during a time of tremendous change in the health care climate of Western Australia, and found that three major values of personal values, commitment, and optimism were the conditions which influenced nurses' leadership. Values included client-centered, staff-related, or profession/organization values. Commitment was also a condition Irurita's study, but commitment meant to staff, clients, profession or organization. The context was one of retardation and turbulence. Some participants used a process of leadership called "optimizing", which had three realms of surviving, investing and transforming. Failure to optimize led to "floundering."

There were similarities between the findings of this study and Irurita's (1994) study. All participants in this study might have been considered to be practicing optimizing leadership by Irurita's definitions. Despite the environmental stresses, none were really floundering. The Engineer participants in this study were probably surviving, and the Team Leader and Unsung Heroine participants were more like those participants in 
Irurita's study who were investing. However, "investing" in Irurita's study meant developing potential resources and focusing on the development of nursing leaders. Team Leaders focused on the development of nurses and non-nurses. In Irurita's (1994) study, those participants who she considered to be practicing transforming leadership were almost fanatical in their commitment to the organization, much like the Champion participants of this study.

The major differences between this study and Irurita's study were the involvement of economics on the organizational lives of the Southern California participants, and the expanded responsibilities inclusive of more than nursing services. Irurita's (1994) study was outdated by Southern California standards, considering all of the recent changes in health care financing. Her findings had more relevance for the nursing executive community of Southern California in the late 1980s prior to managed care. Furthermore, Irurita's (1994) participants all seemed to demonstrate a people-focus, even those largely dedicated to the organization. The transforming leaders of Irurita's study could have been the "ancestors" to the Champions of this study prior to becoming involved in organizational economics. The implication that economics might be the driving force in reshaping the values of nursing leaders, and moving nurse executives away from a people-orientation is disquieting.

The findings from this study, compared with the findings of Irurita's (1994) study, point out the tremendous impact that health care financing has had on the nurse executive community. While some nurse executives in my study exhibited degrees of organizational influence not previously possible for nurse administrators as a result of overall health 
systems changes, I could not really see how nurse executive role expansion was supporting or advancing professional nursing. The need for additional feminist studies such as this in order to learn more about the experiences and behaviors of nurse executives in such a dynamic environment can not be overemphasized in order to plan and prepare for the future of professional nursing in institutional settings. This study only provided a glimpse into the lives and experiences of a small group of female nurse executives.

This study was designed to be very inductive; to find out what was most salient in the experiences and lives of participants. The study did not probe the notion of ethical decision-making in great depth, but revealed enough information to generate concern about the nurse executive community in the context of major changes in health care delivery financing. This study highlights the need for studies about this population which focus specifically on ethics in study design, especially gender-sensitive ethics. This study did pursue participants' nursing backgrounds, and how participants came to be in their present positions, but it did not explore why some participants held onto more traditional nursing values and why others changed their values and beliefs. The study did not explore at what career point the values changed for some participants. Studies geared toward in-depth explorations of the values and beliefs of this population are strongly urged.

Studies using a variety of research methods are encouraged, but more qualitative work is needed for theory-building in nursing administration. In fact, a single nursing administration theory may be insufficient to describe the full realm of nursing leadership practice. The expansion of the nurse executive role which encompasses a wide range of non-clinical and non-nursing aspects of organizational life might not be best explained by a 
nursing administration theory. Executive-level nursing practice seems to be outgrowing knowledge about nursing administration. Even the participants in this study who had graduate degrees in nursing administration admitted they had needed to supplement that knowledge.

This study was limited by the number and degree of field observations that could be made. One way of really grasping the complexity of the nurse executive role would be to conduct ethnographic field studies, where participants would be observed in actual practice over a period of time. This study has pointed out some of the organizational factors which either impede or facilitate the nurse executive in her role from her perspective. Ethnographic studies could really help us learn even more about the contexts of nurse executives, and how those contexts impact behaviors.

A number of additional gender issues came up during this research which were not described or discussed, either because they did not fall into any sort of pattern, or because they could not be well-traced because of logistical problems. For example, physicians in this study were largely portrayed as men who erect barriers for the nurse executive in her practice, but a fair number of participants suggested their relationships with female physicians were better than with male physicians. Another example has to do with male nurses in administrative roles. A number of participants thought that male nurses advanced more easily in their administrative careers, a number felt that gender made no difference, and a number felt that male nurses had to work harder to overcome stereotypes about being homosexual. A third example regarding gender had to do with the "glass ceiling," and promotion opportunities for nurses who wished to move into $\mathrm{COO}$ and $\mathrm{CEO}$ roles. A 
large majority of participants believed that being a woman and a nurse did impact opportunities for advancement. Therefore, research centering on nurse executive-physician relationships and research on nurse executives which includes male nurses is encouraged. Furthermore, a study of female and male nurses who have moved into $\mathrm{COO}$ and CEO roles would be invaluable in learning about the evolution of the nurse administrator role all the way to health care executive.

Another group which would lend greater explanation for this study would be female nurse executives who had recently left their positions, either by choice or for other reasons. This group really would provide key insights regarding the stress and the gender issues associated with trying to be a female and a nurse in these complex roles. This group could provide explanations about the evolution of the nurse executive role, and the personal impacts of this evolution in a turbulent environment.

Participants' secretaries were one group with whom I had a great deal of contact, and for whom I had a great deal of respect. A number of participants spontaneously talked about their secretaries and praised them for the support they provided. Secretaries really provided a front and a protective barrier for participants. One participant told me that the secretary is the one person who knows when the nurse executive is having a bad day, and can help screen her schedule and contacts accordingly. One participant informed me how she and her secretary were a balanced match. Some secretaries exhibited very nurturing behaviors toward the participants, and secretaries also spoke highly of participants. As the nurse executive role is becoming more complex, the nurse executive and executive assistant seem to be merging into a vital team. Research about this partnership would be 
invaluable, and may have ramifications for the paraprofessional education of executive assistants. Additionally, all secretaries in this study were women, which raises interesting questions about gender and gender roles.

The predominant theme of bosses found in this study also brings up another topic for future study. There were hints from this study that the gender of the boss might make some difference in the female nurse executive and boss relationship. Participants in this study with female bosses all described very good relationships with bosses. Responses about male bosses varied from someone to manipulate, to someone to be revered. Based upon the studies mentioned in Chapters One and Two of this study, the boss is critical to the success or failure of the nurse executive. This relationship merits in-depth exploration.

There is a final group which must be studied. The scope of the nurse executive role is expanding, and nursing service oversight is becoming only one segment of the executive responsibilities. The daily responsibilities for nursing management have to be occurring at lower levels in the nursing hierarchy. This raises concerns about the readiness and preparation of nurse managers and directors, who are assuming responsibilities traditionally associated with the nurse executive role. What are their insights and experiences about functioning under certain economic constraints imposed by a managed care environment? Additionally, what are the concerns of clinical practicing nurses in institutional settings working in this environment? How does gender influence their experiences?

In summary, this study introduced a wide array of issues regarding the woman/nurse/executive experience which are deserving of in-depth investigation in order 
to help build a substantial body of knowledge. The need for further investigations about this community of nurses can not be understated.

\section{The Macro-Organizational Perspective}

Because a number of concerns were raised in this study regarding gender inequality in an androcentric environment, I urge the entire nursing profession to take a close look at the societal institutions which surround its practices. Out of a commitment to social responsibility, the nursing profession, including the nursing executive community, needs to be especially sensitive to how organizational structures and organizational and corporate cultures are shaping their behaviors. Having the courage to care means taking risks (Kerfoot, 1997), and from the perspective of a woman and a nurse, I believe that means having the courage to reclaim conflict (Miller, 1986).

Miller (1988) described the three significant roles for nursing administrators which arise out of a feminist ideology: advocacy, empowerment, and consciousness-raising. All of these roles are people-oriented. However, advocacy for and empowerment of others can not really begin until the collective consciousness of the group responsible for these actions is raised. Although a number of participants in this study described gender issues, I am convinced they were unaware of how pervasive gender discrimination is for the nurse executive community. The entire professional nursing community must learn to value feminism as a means to effect societal change which will eliminate gender bias.

There was another major concern this study raised which has to do with our societal institutions. As female nurse executives move further into a health care world 
which has been traditionally male-dominated, they must confront the issues of competence and femininity, and the corresponding cultural definitions.

There is a gender paradox that these women face in getting to the upper echelons of health care administration. Lipman-Blumen (1992) pointed out that senior male executives, because they are no longer vying for promotion, are the most likely group to display leadership characteristics which are more relational and less competitive; more compatible with the behaviors of women. A number of bosses in this study may have exemplified this behavior, especially the Team Leader bosses. The paradox is that to get to these positions, competitive behaviors, which are characteristically aggressive and masculine, are required (Lipman-Blumen, 1992). This paradox makes advancement more difficult for women, who may be juggling a number of responsibilities in their multiple roles as spouses and parents. Society has yet to view men as being as involved as women in the private domains of life, inclusive of activities such as parenting and household management. A number of study participants talked about this dilemma. I recommend that the entire nursing profession start looking at labor practices which are unfair to women and rally support for family and child care legislation which will ultimately benefit all female nurses.

One group who is well-prepared to tackle the institutions which stifle caring activities are nurse executives themselves. With their breadth of organizational experience, nurse executives, with the backing of the entire nursing professional community, would make excellent candidates in the political arena to help produce necessary social changes. 
Also, desperately needed are nurses who are involved in policy-making, especially regarding health care economics. Nurse executives have been on the receiving ends of changes in health care financing. Nurses need to understand and be involved in shaping health care financing in ways which are favorable for nursing caring practices. As a predominantly female profession, nursing has backed away from involvement in economics, and as shown in earlier discussions of this study, economic theories are full of gender biases against women. A recent movement in economic theorizing has embraced feminist thinking, as described in Chapter Four. Nurse and feminist economist alliances would be a way of strengthening support for the necessary economic changes which would benefit women, nursing, and health care delivery.

Finally, the issues raised in this study need to be presented to the health care administrator and the physician communities. These two groups must be reeducated regarding the links between gender and role socialization. As health care delivery becomes more complex, time is wasted on interpersonal conflicts stemming from androcentric thinking and gender inequality. By exposing the roots of these conflicts, actions can be taken to remove the sources of conflict. Multidisciplinary collaboration, where all representatives of all disciplines have a equal voice, is essential for the collective redesign of health care delivery systems which are truly geared toward promoting and sustaining healthy communities.

\section{Final Thoughts}

This chapter concludes the discussion of this study. The overall conclusion based upon study findings is that the androcentric and inequality lenses of gender are alive and 
well in institutional health care delivery systems, and unintentionally perpetuated by nurse executives themselves. The feminist consciousness of the entire nursing service leadership community must be raised if professional nursing is to survive in institutional health care settings in a heavily managed care environment. The most important implications of this study involve revamping nursing administration education, continuing research about nurse executives, and increasing the role of nursing in developing health care policy in order to ensure that the voice of professional nursing in institutional health care is not silenced.

Donley (1996) used the metaphor of a crossroads to represent the choices about health care which face the American people, the health care providers, and the nursing profession. She envisions our profession as coming from a road which has been familiar, and one which has shaped our ideas about health care, but which is now leading us into new territories where we must confront the forces of managed care, and cost and quality issues. We can take the initiative and carve out new areas for nursing or we can retreat (Donley, 1996). I would like to believe that the nursing service leadership community will soon take the initiative in moving the profession of nursing in new directions which will ensure the availability of professional nursing care for all members of our society and protect the essence of nursing.

This study is considered to be only a small chip of knowledge off a tremendous iceberg of unknown information about the nurse executive community in a environment, so aptly described by one participant, as one in which "change is the only thing that's constant." Hopefully this study will trigger the critiques, discussions, and research which 
are sorely needed to provide direction for the nursing leadership of the future and to protect the profession of nursing. 
References

Abbey, F. B. (1995). Managed care and health care reform-Evolution or revolution? In P. R. Kongstvedt (Ed.), Essentials of Managed Health Care (pp. 10-23). Gaithersburg, MD: Aspen.

Achterberg, J. (1990). Woman as Healer. Boston: Shambala.

Acker, J. (1992). Gendering organizational theory. In A. Mills and P. Tancred (Eds.), Gendering Organizational Analysis (pp. 248-265). Newbury Park, California: Sage Publications.

Adams, C. E. (1993). The impact of problem-solving styles of nurse executives and executive officers on tenure. Journal of Nursing Administration, 23(12), 38-43.

Ahern, M. M. (1996). Nurses' and other experts' views of health care fraud and abuse. Nursing Economics, 14(1), 40-48.

American Organization of Nurse Executives. (1995). The Role and Function of Nurses in Executive Practice. Chicago: Author.

Anderson, C. A. (1995). Are nurses becoming invisible? Nursing Outlook, 43(3), 103-104.

Ashley, J. A. (1976). Hospitals, Paternalism, and the Role of the Nurse. New York, New York: Teachers College Press.

Ashley, J. A. (1980). Power in structured misogyny: Implications for the politics of care. Advances in Nursing Science, 2(3), 3-22. 
Astin, H. S., \& Leland, C. (1991). Women of Influence, Women of Vision: A Cross-Generational Study of Leaders and Social Change. San Francisco: Jossey-Bass Publishers.

Ayman, R. (1993). Leadership perception: The role of gender and culture. In M. Chemers and R. Ayman (Eds.), Leadership Theory and Research: Perspectives and Directions (pp. 137-166). San Diego, California: Academic Press, Inc.

Baer, E. D. (1985). Nursing's divided house. An historical view. Nursing Research, $\underline{34}(1), 32-38$.

Barker, A. M., \& Young, C. E. (1994). Transformational leadership: The feminist connection in postmodern organizations. Holistic Nursing Practice 9(1), 16-25.

Belenky, M. F., Clinchy, B. M., Goldberger, N. R., \& Tarule, J. M. (1986). Women's Ways of Knowing. New York: Basic Books.

Bell, L. B., \& Nkomo, S. M. (1992). Re-visioning women managers' lives. In A. Mills and P Tancred (Eds.), Gendering Organizational Analysis (pp. 235-247). Newbury Park, California: Sage Publications.

Bellah, R. N. (1992). The Broken Covenant: American Civil Religion in Time of Trial (2nd ed.). Chicago: The University of Chicago Press.

Bellah, R. N., Madsen, R., Sullivan, W. M., Swidler, A., \& Tipton, S. M. (1992). The Good Society. New York: Vintage Books.

Bem, S. L. (1993). The Lenses of Gender: Transforming the Debate on Sexual Inequality. New Haven, Connecticut: Yale University Press. 
Berman, L. (1994). What does it mean to be called to care? In M. E. Lashley, M T. Neal, E. T. Slunt, L. M. Berman, \& F. H. Hultgren (Eds.), Being Called to Care (pp. 1-16). Albany, New York: State University of New York Press.

Blank, R. M. (1993). What should mainstream economists learn from feminist theory? In M. A. Ferber \& J. A. Nelson (Eds.), Beyond Economic Man. Feminist Theory and Economics (pp. 133-143). Chicago: The University of Chicago Press.

Borman, J. (1993). Women and nurse executives: Finally some advantages. Journal of Nursing Administration, 23(10), 34-41.

Bowden, P. (1997). Caring: Gender-Sensitive Ethics. London: Routledge.

Bradley, H. (1989). Men's Work, Woman's Work. Minneapolis, Minnesota: University of Minnesota Press.

Buerhaus, P. (1994a). Economics of managed competition and consequences to nurses: Part I. Nursing Economics, 12(1), 10-17.

Buerhaus, P. (1994b). Economics of managed competition and consequences to nurses: Part II. Nursing Economics, 12(2), 75-80; 106.

Card, C. (1995). Gender and moral luck. In V. Held (Ed.), Justice and Care: Essential Readings in Feminist Ethics (pp. 79-98). Boulder, Colorado: Westview Press, Inc.

Chinn, P. L. (1994). Foreword. In In M. E. Lashley, M T. Neal, E. T. Slunt, L. M. Berman, \& F. H. Hultgren (Eds.), Being Called to Care (pp. vii-viii). Albany, New York: State University of New York Press.

Chinn, P. L. (1991). From the editor. Advances in Nursing Science, 13(3), ix. 
Chinn, P. L., \& Wheeler, C. E. (1985). Feminism and nursing: Can nursing afford to remain aloof from the women's movement? Nursing Outlook, 33(2), 74-77.

Christman, J. B. (1988). Working in the field as a female friend. Anthropological Education Quarterly, 19(2), 70-85.

Cole, E. B. (1993). Philosophy and Feminist Criticism: An Introduction. New York: Paragon House.

Cooper, M. C. (1989). Gilligan's different voice: A perspective for nursing. Journal of Professional Nursing $5(1), 10-16$.

Cummings, S. H. (1995). Attila the hun versus Attila the hen: Gender socialization of the American nurse. Nursing Administration Quarterly, 19(2), 19-29.

Donley, R. (1996). Nursing at the crossroads. Nursing Economics 14(6), 325-331.

Duffy, M., \& Hedin, B. A. (1988). New directions for nursing research. In N. F. Woods, \& M. Catanzaro (Eds.), Nursing Research. Theory and Practice (pp. 530-539). St. Louis, MO: The C. V. Mosby Company.

Dunham, J., \& Klafehn, K. (1990). Transformational leadershipand the nurse executive. Journal of Nursing Administration, 20(4), 28-34.

Edwards, D. S., \& Horn, P. A. (1995). War on many fronts: Troubling trends in healthcare delivery. Journal of Nursing Administration, 25(5), 5-7.

Eisler, R. (1988). The Chalice and the Blade: Our History, Our Future. San Francisco: Harper. 
England, P. (1993). The separate self: Androcentric bias in neoclassical assumptions. In M. A. Ferber \& J. A. Nelson (Eds.), Beyond Economic Man. Feminist Theory and Economics (pp. 23-36). Chicago: The University of Chicago Press.

Enthoven, A. C. (1993). The history and principles of managed competition. Health Affairs: The Quarterly Journal of the Health Sphere, 12(Supplement 1993), 24-48.

Executive chartbook: How markets evolve. (1995). Hospitals \& Health Networks, $\underline{69}(5), 48$.

Fagin, C. M. (1996). Executive leadership: Improving nursing practice, education, and research. Journal of Nursing Administration, 26(3), 30-37.

Ferber, M. A., and Nelson, J. A. (1993). Introduction: The social construction of economics and the social construction of gender. In M. A. Ferber \& J. A. Nelson (Eds.), Beyond Economic Man. Feminist Theory and Economics (pp. 1-22). Chicago: The University of Chicago Press.

Ferguson, K. E. (1984). The Feminist Case Against Bureaucracy. Philadelphia: Temple University Press.

Fikes, B. J. (1996). San Diego's healthcare revolution. San Diego Magazine, $\underline{48}(11), 66-70 ; 72 ; 74 ; 76$.

Folbre, N. (1994). Who Pays for the Kids? Gender and the Structures of Constraint. London: Routledge.

Friedman, M. Beyond caring: The de-moralization of gender. In V. Held (Ed.), Justice and Care: Essential Readings in Feminist Ethics (pp. 61-77). Boulder, Colorado: Westview Press, Inc. 
Gilligan, C. (1982). In A Different Voice: Psychological Theory and Women's

Development. Cambridge, Massachusetts: Harvard University Press.

Glazer, B. G., \& Strauss, A. L. (1967). The Discovery of Grounded Theory. Chicago: Aldine Publishing Company.

Greenleaf, N. P. (1980). Sex-segregated occupations: Relevance for nursing. Advances in Nursing Science, 2(3), 23-38.

Greenwald, D., Arnold, H., Blitzer, D. M., Brown, W. J., Koflowitz, L. I., Mattersdorff, G. H., \& Mayers, E. G. (1983). The McGraw-Hill Dictionary of Modern Economics. A Handbook of Terms and Organizations (third edition). New York: McGraw Hill Book Company.

Gutek, B. A., \& Cohen, A. G. (1993). Sex ratios, sex role spillover, and sex at work: A comparison of men's and women's experiences. In A. Mills and P. Tancred (Eds.), Gendering Organizational Analysis (pp. 133-150). Newbury Park: California: Sage Publications.

Hall, J. M., \& Stevens, P. E. (1991). Rigor in feminist research. Advances in Nursing Science, 13(3), 16-29.

HCIA, Inc. (1994). 1995 The Directory of Health Care Professionals. Volume 1: Hospital and Health Care System Professionals. Baltimore, Maryland: Author.

Hedin, B. A., \& Duffy, M. E. (1991). Researching: Designing research from a feminist perspective. In R. M. Neil \& R. Watts, (Eds.), Caring and Nursing: Explorations in Feminist Perspectives (NLN Publication No. 14-2369, pp. 227-235). New York: National League for Nursing. 
Hegyvary, S. T. (1983). The nursing administrator: Advocate or adversary. In N. Chaska (Ed.), The Nursing Profession: A Time to Speak (pp. 671-684). New York: McGraw-Hill Book Company.

Held, V. (1995). Feminist moral inquiry and the feminist future. In V. Held (Ed.), Justice and Care: Essential Readings in Feminist Ethics (pp. 153-176). Boulder, Colorado: Westriew Press, Inc.

Helgeson, S. (1990). The Female Advantage: Women's Ways of Leadership. New York, NY: Doubleday.

Irurita, V. E. (1994). Optimism, values, and commitment as forces in nursing leadership. Journal of Nursing Administration, 24(9), 61-71.

Jack, D., \& Jack, R. (1988). Women lawyers: Archetype and alternatives. In C. Gilligan, J. V. Ward, \& J. M. Taylor, with B. Bardige (Eds.), Mapping the Moral domain. A Contribution of Women's Thinking to Psychological Theory and Education (pp. 261-288). Cambridge, Massachusetts: Center for the Study of Gender, Education and Human Development, Harvard University Graduate School of Education.

Kalisch, B. J., \& Kalisch, P. A. (1977). An analysis of the sources of physician-nurse conflict. Journal of Nursing Administration, VII(1), 51-57.

Kelly, L. Y., \& Joel, L. A. (1995). Dimensions of Professional Nursing (7th ed). New York: McGraw-Hill, Inc.

Kerfoot, K. (1997). Leadership--the courage to care. Nursing Economics, 15(1), $50-51$. 
Kippenbrock, T. (1995). Turnover of hospital chief nursing officers. Nursing Economics, 13(6), 330-336.

Klakovich, M. D. (1994). Connective leadership for the 21st century: A historical perspective and future directions. Advances in Nursing Science, 16(4), 42-54.

Kohlberg, L. (1958). The development of modes of thinking and choices in years 10 to 16. Unpublished Doctoral Dissertation, University of Chicago.

Kohlberg, L. (1981). The Philosophy of Moral Development. San Francisco: Harper and Row.

Kohlberg, L. (1984). The Psychology of Moral Development. New York: Harper \& Row.

Kools, S., McCarthy, M., Durham, R, \& Robrecht, L. (1996). Dimensional analysis: Broadening the conception of grounded theory. Qualitative Health Research $\underline{6}(3), 312-330$.

Lamm, R. D. (Winter, 1994/1995). The ghost of health care future. Inquiry: The Journal of Health Care Organization, Provision, and Financing, 31(4), 365-367.

Leininger, M. (1974). The leadership crisis in nursing: A critical problem and challenge. Journal of Nursing Administration. IV(2), 28-34.

Libbus, M. K., \& Bowman, K. G. (1994). Sexual harassment of female registered nurses in hospitals. Journal of Nursing Administration, 24(6), 26-31.

Lipman-Blumen, J. (1992). Connective leadership: Female leadership styles in the 21st-century workplace. Sociological Perspectives, 35(1), 183-203.

Lorber, J. (1994). Paradoxes of Gender. New Haven, CT: Yale University Press. 
Lynaugh, J. E., \& Fagin, C. M. (1988). Nursing comes of age. Image: Journal of Nursing Scholarship. 20(4), 184-189.

MacLeod, G. K. (1995). An overview of managed health care. In P. R. Kongstvedt (Ed.), Essentials of Managed Health Care (pp. 1-9), Gaithersburg, MD: Aspen.

MacPherson, K. I. (1983). Feminist methods: A new paradigm for nursing research. Advances in Nursing Science, 5(2), 17-25.

MacPherson, K. I. (1987). Health care policy, values, and nursing. Advances in Nursing Science, 9(3), 1-11.

MacPherson, K. I. (1989). A new perspective on nursing and caring in a corporate context. Advances in Nursing Science, 11(4), 32-39.

Manning, R. C. (1992). Speaking from the Heart. A Feminist Perspective on Ethics. Lanham, Maryland: Rowman \& Littlefield Publishers, Inc.

Mason, D., Backer, B. A., \& Georges, A. (1991). Toward a feminist model for the political empowerment of nurses. Image: Journal of Nursing Scholarship. 23(2), 72-77.

McCarthy, M. P., Craig, C., Bergstrom, L., Whitley, E. M., Stoner, M. H., \& Magilvy, J. K. Caring conceptualized for community nursing practice: Beyond caring for individuals. In P. L. Chinn (Ed.), Anthology on Caring ( NLN Pub. No. 15-2392, pp. 85-93). New York: National League for Nursing Press.

Miller, J. B. (1986). Toward A New Psychology of Women. Boston: Beacon Press. 
Miller, K. L. (1988). Feminist ideology in nursing: A foundational inquiry.

Dissertation Abstracts International, 49(08), 3107B. (University Microfilms No. AAG8819531).

Miller, K. L. (1991). A study of nursing's feminist ideology. In R. M. Neil \& R. Watts, (Eds.), Caring and Nursing: Explorations in Feminist Perspectives (NLN Publication No. 14-2369, pp. 43-56). New York: National League for Nursing. Miller, N. (1995). An interview with Ann Marie Brooks. Nursing Economics, $13(5), 265-271$.

Mish, F. C. et al. (Eds.). (1984). Webster's Ninth New Collegiate Dictionary. Springfield, Massachusetts: Merriam-Webster Inc.

Morgan, B. (1986). Images of Organization. Beverly Hills, CA: Sage Publications.

Moss, M. T. (1996). Principles, values, and ethics set the stage for managed care nursing. Nursing Economics, 13(5), 276-284.

Mulqueen, M. (1992). On Our Own Terms: Redefining Competence and Femininity. Albany, New York: State University of New York Press.

Nelson, J. A. (1993). The study of choice or the study of provisioning? Gender and the definition of economics. In M. A. Ferber \& J. A. Nelson (Eds.), Beyond Economic Man. Feminist Theory and Economics (pp. 23-36). Chicago: The University of Chicago Press.

Nursing Economics data bank. (1996). Nursing Economics, 14(2), 85.

Nyberg, J. (1993). Teaching caring to the nurse administrator. Journal of Nursing Administration, 23(1), 11-17. 
ONE-California. (1996-1997). 1996-1997 Resource Directory. Sacramento, CA: Author.

Padgett, D. L. (1993). Women and management: A conceptual framework. Administration in Social Work, 17(4), 57-75.

Parmet, W. E. (1993). Regulation and federalism: Legal impediments to state health care reform. American Journal of Law \& Medicine, XIX(1\&2), 121-144.

Perry, W. G. (1970). Forms of Intellectual and Ethical Development in the College Years. New York: Holt, Rinehart \& Winston.

Peterson, J. (1994). Introduction. In J. Peterson \& D. Brown (Eds.), The Economic Status of Women Under Capitalism. Institutional Economics and Feminist Theory (pp. x-xvii). Aldershot, Hants, England: Edward Elgar Publishing Limited.

Rakich, J. S., Longest, B. B. Jr., \& Darr, K. (1992). Managing Health Services Organizations (3rd ed.). Baltimore, MD: Health Professions Press.

Ray, M. A., Didominic, V. A., Dittman, P. W., Hurst, P. A., Seaver, J. B., Sorbello, B. C., \& Stankes Ross, M. A. (1995). The edge of chaos. Caring and the bottom line. Nursing Management, 26(9), 48-50.

Redmond, G. M. (1995). "We don't make widgets here": Voices of chief nurse executives. Journal of Nursing Administration, 25(2), 63-69.

Reinhardt, U. E. (1993). Reforming the health care system: The universal dilemma. American Journal of Law \& Medicine, XIX (1\&2), 21-36.

Reinharz, S. (1992). Feminist Methods in Social Research. New York, NY: Oxford University Press. 
Reverby, S. M. (1987). Ordered to Care: The Dilemma of American Nursing. 1850-1945. New York, New York: Cambridge University Press.

Roberts, S. J. (1983). Oppressed group behavior: Implications for nursing. Advances in Nursing Science, 5(4), 21-30.

Schatzman, L. (1991). Dimensional analysis: Notes on an alternative approach to the grounding of theory in qualitative research. In D. R. Maines (Ed.), Social Organization and Social Process (pp. 303-314). New York: Aldine De Gruyter.

Schatzman, L., \& Strauss, A. L. (1973). Field Research: Strategies for a Natural Sociology. Englewood Cliffs, New Jersey: Prentice-Hall, Inc.

Skousen, M. (1991). Economics On Trial. Lies, Myths, and Realities. Homewood, II. Dow Jones-Irwin.

Steinem, G. (1994). Moving Beyond Words. New York: Touchstone.

Stivers, C. (1993). Gender Images in Public Administration: Legitimacy and the Administrative State. Newbury Park, California: Sage Publications, Inc.

Stivers, C. (1991). Why can't a woman be less like a man? Women's leadership dilemma. Journal of Nursing Administration, 21(5), 47-51.

Strauss, A. (1987). Qualitative Analysis For Social Scientists. Cambridge, Great Britain: Cambridge University Press.

Strauss, A, \& Corbin, J. (1990). Basics of Qualitative Research: Grounded Theory Procedures and Techniques. Newbury Park, CA: Sage Publications. 
Strauss, A., \& Corbin, J. (1994). Grounded theory methodology. An overview. In N. K. Denzin, \& Y. S. Lincoln (Eds.), Handbook of Qualitative Research (pp. 273-285). Thousand Oaks, CA: Sage Publications.

Strassmann, D. (1993). Not a free market: The rhetoric of disciplinary authority in economics. In M. A. Ferber \& J. A. Nelson (Eds.), Beyond Economic Man. Feminist Theory and Economics (pp. 54-68). Chicago: The University of Chicago Press.

Vezeau, T. M., \& Schroeder, C. (1991). Caring approaches: A critical examination of origin, balance of power, embodiment, time and space, and intended outcome. In P. L. Chinn (Ed.), Anthology on Caring ( NLN Pub. No. 15-2392, pp. 1-16). New York: National League for Nursing Press.

Waller, W. (1994). Technology and gender in institutional economics. In J. Peterson \& D. Brown (Eds.), The Economic Status of Women Under Capitalism. Institutional Economics and Feminist Theory (pp. 55-76). Aldershot, Hants, England: Edward Elgar Publishing Limited.

Webb, C. (1993). Feminist research: Definitions, methodology, methods and evaluation. Journal of Advanced Nursing, 18, 416-423.

Wells, K. (1993). State health reform initiatives: They're calling it managed competition. Caring Magazine, XII(6), 34-38.

Williams, C. L. (1995). Hidden advantages for men in nursing. Nursing Administration Quarterly, 19(2), 63-70. 
Wuest, J. (1995). Feminist grounded theory: An exploration of the congruency and tensions between two traditions in knowledge discovery. Qualitative Health Research, $\underline{5}(1), 125-137$.

Young, L. C., \& Hayne, A. N. (1988). Nursing Administration: From Concepts to

Practice. Philadelphia: W. B. Saunders Company. 


\section{APPENDICES}


APPENDIX B

INITIAL RECRUITMENT LETTER

Reproduced with permission of the copyright owner. Further reproduction prohibited without permission. 


\section{CHERYL L. BRANDI, DNSc(c), RNC, CNA 3916 Crown Point Drive \\ San Diego, CA 92109 \\ (619) 274-9816}

June 22, 1996

Director of Nursing

Dear Ms. ,

I am a doctoral candidate in the University of San Diego Doctor of Nursing Science program, and am in the data collection phase of my dissertation research. I am writing to ask if you would consider volunteering to participate in my study.

The focus of my qualitative study is women who are Chief Nurse Executives in the context of the managed care environment of Southern California. I firmly believe that research on this topic is essential to the future of the nurse executive community and to the entire nursing profession.

The term, Chief Nurse Executive (CNE), for this study means a female senior-level nurse manager at the top of the nursing hierarchy in a Health Services Organization (HSO), who reports to an administrative supervisor outside of the nursing arena (such as CEO). Although her role may have been expanded to include other aspects of HSO operations, the CNE for this study must still maintain responsibility for the nursing department or for nursing services.

Participation in the study involves several contacts with myself. The first contact involves a tape-recorded interview. You will then have opportunities to review and critique your interview transcript as well as a written draft of the final study results. I may need to contact you during the study for clarification of information discussed. I have enclosed a copy of my informed consent for your review. I guarantee you complete confidentiality regarding any aspect of this study, and if you decide to participate, I will do everything I can to make this process convenient for you. 
I will be contacting you soon by telephone to see if you are interested in volunteering for this study and to answer any questions or concerns you might have. However, in the interim, please feel free to contact me at any time at the telephone number listed above.

Thank you for taking the time to consider this important project, and I look forward to talking with you.

Sincerely yours,

Cheryl L. Brandi 
APPENDIX C

UNIVERSITY OF SAN DIEGO CONSENT

TO ACT AS A RESEARCH PARTICIPANT 


\section{UNIVERSITY OF SAN DIEGO \\ CONSENT TO ACT AS A RESEARCH PARTICIPANT}

Cheryl L. Brandi, MS, MSN, RNC, CNA is conducting a research study to explore the influence of a highly managed care environment on the woman/nurse/executive. The study is being conducted as partial fulfillment of the requirement for Cheryl Brandi's Doctorate in Nursing Science.

Participation in this study involves several contacts which include: participating in a taped interview with Cheryl Brandi; a review of my transcribed interview and a follow-up interview at approximately four to six weeks after the first interview; a possible additional interview; and a review and critique of the first draft of the report and a final brief interview. The interview(s) involve sharing information about myself regarding the topic being researched. The first interview is anticipated to take about one-and-a-half to two hours, and other contacts should require one hour or less of my time. Interviews will be conducted at times and places convenient for me. I understand that Cheryl Brandi may need to contact me throughout her study in order to clarify information discussed during the interviews. Participation in this study involves no foreseeable risks, and no direct benefits to me, but the benefits of this study are expected to extend to future nurse executives.

My participation in this study is entirely voluntary and I may withdraw at any time without any explanation or jeopardy to my reputation or position.

I understand that my research records will be kept completely confidential and coded in such a way that tracing my responses back to me will not be possible. My identity will not be disclosed without consent required by law. I further understand that my anonymity will be protected in any publication of the results of the study.

Cheryl Brandi has explained this study to me and answered my questions. If I have other questions or research-related concerns, I can reach Cheryl Brandi at (619) 274-9816 at any time during the study. I understand that there are no expenses incurred to me for my participation in this study other than perhaps my transportation to the interview site and the donation of my personal time.

There are no other agreements, written or verbal, related to this study beyond that expressed on this consent form. I understand that the researcher will provide me with a copy of this document.

I, the undersigned, understand the above explanations, and on that basis, I give consent to my voluntary participation in this research.

Signature of Participant

Signature of Researcher

\section{Date}

$\overline{\text { Date }}$ 
APPENDLX D

REVISED RECRUITMENT LETTER

Reproduced with permission of the copyright owner. Further reproduction prohibited without permission. 
CHERYL L. BRANDI, DNSc(c), RNC, CNA

3916 Crown Point Drive

San Diego, CA 92109

(619) 274-9816

E-Mail Address: cbrandi@pwa.acusd.edu

October 3, 1996

To:

Dear Ms. ，

I am a full-time doctoral candidate in the University of San Diego Doctor of Nursing Science program, and am in the data collection phase of my dissertation research. I am writing to ask if you would consider volunteering to participate in my study.

The focus of my qualitative study is women who are Nurse Executives in the context of the managed care environment of Southern California. I firmly believe that research on this topic is essential to the future of the nurse executive community and to the entire nursing profession.

The term, Nurse Executive (NE), for this study means a female senior-level nurse manager at the top of the nursing hierarchy in a Health Services Organization (HSO), who reports to an administrative supervisor outside of the nursing arena (such as CEO). Although her role may have been expanded to include other aspects of HSO operations, the NE for this study should still maintain some responsibility for the nursing department or for nursing services.

Participation in the study involves several contacts with myself. The first contact involves a tape-recorded interview. You will then have opportunities to review and critique your interview transcript as well as a written draft of the final study results. I may need to contact you during the study for clarification of information discussed. I have enclosed a copy of my informed consent for your review. I guarantee you complete confidentiality regarding any aspect of this study, and if you decide to participate, I will do everything I can to make this process convenient for you. 
There are two other important points regarding this study. First, the interview for the study is to be conducted at a time and place of your choice. It does not have to be in your work setting, but if that is a most convenient place for you, I am more than happy to set up an appointment and come to your office at a time which is least disruptive to your work schedule. I am not seeking formal institutional research review approval from any of the participants' agencies. Second, I expect the data collection phase of this study to continue through November, 1996.

Because I know how busy you are, I have enclosed a response form and a self-addressed envelope to facilitate communication and arrangements regarding the study. If you have questions or concerns, please feel free to contact me directly at any time.

Thank you for taking the time to consider this important project, and I look forward to talking with you.

Sincerely yours,

Cheryl L. Brandi 
From:

Instructions: Please check all applicable responses, and return to Cheryl Brandi in the pre-addressed, enclosed envelope.

Study decision:

_ I would like to participate in this study.

_ I I would like more information about this study.

Study Arrangements:

Please contact my secretary to set up an appointment.

Please contact me directly to make arrangements.

Other:

Any comments or additional information: 


\section{APPENDIX E}

INTERVIEW GUIDE

Reproduced with permission of the copyright owner. Further reproduction prohibited without permission. 


\section{NTERVIEW GUIDE}

1. Describe the health care organization in which you work. What changes has your organization recently experienced? What impact have these changes had upon you?

2. How do you influence change within your organization?

3. Describe a typical day for me. (Probe: what are your responsibilities?)

4. What helps you to do your job to the best of your ability?

5. What do you consider to be the barriers which prevent you from doing your job to the best of your ability?

6. What are some of the conflicts you experience in doing your job? How do you handle them?

7. Describe your relationships with your: (a) immediate supervisor

(b) the nursing staff of your organization.

8. Who do you consider as part of your support network within your organization?

9. What advice would you give to new nurse executives?

10. Tell me about yourself. (Probe: How did you come to serve in your position?)

11. Who can you recommend to include in this study?

12. Is there anything else important to this study topic you would like to share with me? 


\section{APPENDIX F \\ RESEARCHER REFLECTION NOTE GUIDE}




\section{RESEARCHER REFLECTION NOTE GUIDE}

\section{The researcher-participant relationship}

1. How are this woman and I alike? How are we different?

2. How are these similarities and differences reflected in our interactions? How are these interactions affecting the research? What are they doing to the research problem?

3. What are my feelings toward our interactions?

4. How are my values influencing this process?

5. Am I expressing myself in a way which conveys honesty and authenticity? Are my communications nonhierarchical, non-controlling, and dialogical?

6. Am I allowing the interview to flow where it leads, but keeping to the topic?

7. What is the participant telling me about this process, either verbally, or non-verbally? How open is she to sharing information and recommending other participants?

\section{Researcher relationship with the participant data}

1. Am I using the literature in a way which does not impose masculine norms and standards on women?

2. Am I making any biased assumptions? Am I directing blame at this participant for any of the findings or interpretations?

3. How does this concern all nurse executives? How does it concern female nurses?

\section{Participant relationship with the data}

1. How is this participant responding to the data?

2. Does my interpretation of the data make sense to her?

3. Does the data encourage questions from her?

Other concerns, reflections, impressions:

Adapted from Christman, 1988; Duffy \& Hedin, 1988; Strauss \& Corbin, 1990 